FRESH WATER ALGA AND THE

\title{
DESMIDIEAE
}

of the United States

\author{
BY \\ DR. ALFRED C. STOKES
}

9.3 
FROM THE

Cibrary of Rboda Я. Esten

A teacher and supervisor in the schools of the City of Providence from January, 1878 , to May, 1901 .

Donated to tbis Iibrary under tbe provisions of ber will. 


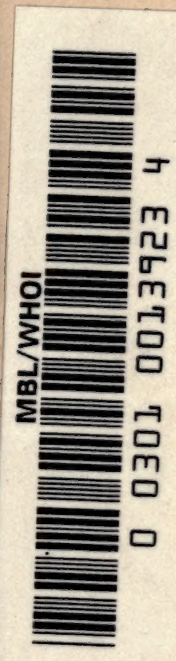

LIBRAIRY

RHODA A. EUT 






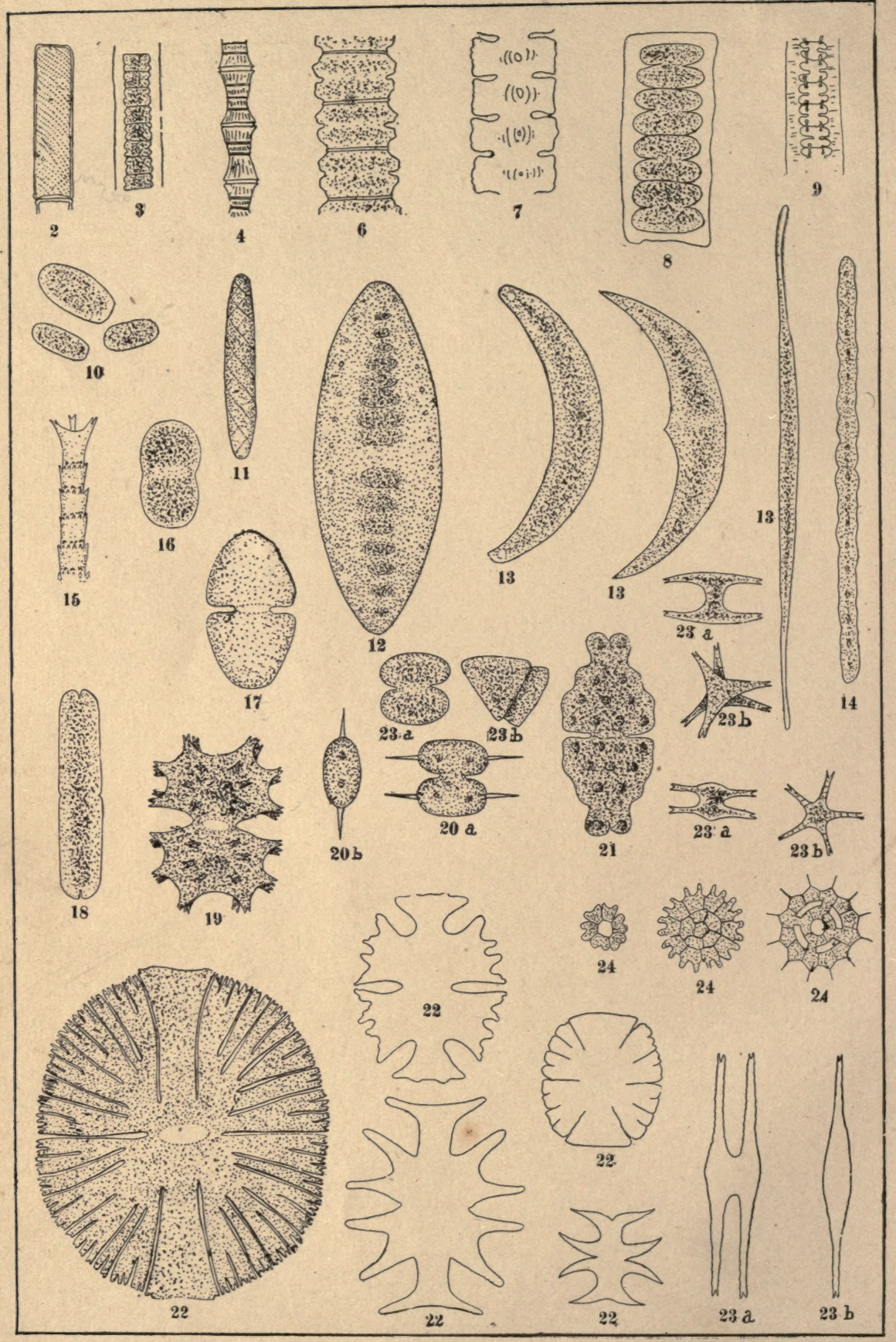




\section{ANALYTICAL KEYS}

TO THE

\section{GENERA AND SPECIES}

OF THE

\section{FRESH WATER ALGE}

AND

The Desmidieæ of the United States,

FOUNDED ON THE CLASSIFICATION OF

THE REV. FRANCIS WOLLE'S MONOGRAPHS,

BY

DR. ALFRED C. STOKES,

Author of "Microscopy for Beginners;" "A Contribution toward a Natural History of the Fresh Water Infusoria of the United States," etc.

PORTLAND, CONN.:

Edward F. Bigelow, Publisher.

1893. 
Entered according to act of Congress, in the year 1893, by

E. F. BIGELOW, Publisher,

in the office of the Librarian of Congress, at Washington.

5137 


\section{CONTENTSS.}

PAGE.

Explanation of Plate,

Value of of Mikrons in parts of an inch, _ _ $\quad$ - 9

Introduction,

Key to the Classes of the Fresh-water Algx,

Key to the Genera of the Fresh-water Algæ,

Key to the Species of the Fresh-water Algæ,

Key to the Genera of the Desmidieæ,

Key to the Species of the Desmidieæ,

Glossary, 



\section{Value of Microns $(\mu)$ in fractions of an inch.}

$\mu$ Inches. $\mu$ Inches. $\mu$ Inches. $\mu$ Inches. $\mu$ Inches.

\begin{tabular}{|c|c|c|c|c|}
\hline & & & & \\
\hline $1.0=I-25000$ & $\mathbf{I} 8.0=\mathrm{I}-\mathrm{I} 3^{8} 3$ & $45.0=\mathrm{I}-533$ & $79 \cdot 0=I-3 I 6$ & I I $3.0=I-22 I$ \\
\hline $\mathrm{I} \cdot 5=\mathrm{I}-\mathrm{I} 6666$ & $\mathrm{I} 8.5=\mathrm{I}-\mathrm{I} 35_{\mathrm{I}}$ & $46.0=I-543$ & & I I $4.0=I-219$ \\
\hline $2.0=\mathrm{I}-\mathrm{I} 2500$ & $9.0=\mathrm{I}-\mathrm{I} 3 \mathrm{I} 5$ & $0=\mathrm{I}$ & $81.0=\mathrm{I}-308$ & I $15.0=\mathrm{I}-2 \mathrm{I} 7$ \\
\hline $.5=\mathrm{I}-\mathrm{I} 0000$ & $9 \cdot 5=\mathrm{I}-3333$ & $8.0=x-52 x$ & & \\
\hline $3.0=x-8333$ & $20.0=I-1250$ & $9.0=\mathrm{I}-5 \mathrm{I0}$ & & I I $7.0=1-213$ \\
\hline $3.5=x-7222$ & $20.5=\mathrm{I}-\mathrm{I} 2 \mathrm{I} 4$ & $0.0=\mathrm{I}-500$ & $4.0=\mathrm{I}-297$ & \\
\hline $4.0=\mathrm{r}-6250$ & 2 I.O $=$ I - I I 43 & $\mathrm{r} .0=\mathrm{I}-490$ & $85.0=I-295$ & I I $9.0=I-209$ \\
\hline $4 \cdot 5=x-5555$ & $2 \mathrm{I} .5=\mathrm{I}-\mathrm{I} \mathrm{I} 62$ & $2.0=I-480$ & $86.0=I-29 I$ & $120.0=\mathrm{I}-208$ \\
\hline $5.0=I-5000$ & $22.0=I-I I 3 I$ & $0=I-4$ & $7.0=x-287$ & I 2 I.O $=\mathrm{I}-206$ \\
\hline $5 \cdot 5=\mathrm{I}-4545$ & $22.5=I-I$ & & & $122.0=1-205$ \\
\hline & 87 & $0-1$ & & \\
\hline & $23.5=\mathrm{I}-\mathrm{I} 064$ & $6.0=I-446$ & $0.0=1-277$ & $24.0=I-20 I$ \\
\hline $7.0=1-3285$ & $24.0=\mathrm{I}-\mathrm{IO} 42$ & $7 \cdot 0=I-43^{8}$ & $1.0=1-274$ & $\mathrm{I} 25.0=\mathrm{I}-200$ \\
\hline $7 \cdot 5=x-3$ & $24.5=\mathrm{I}-\mathrm{IO} 20$ & $3.0=I-43 I$ & $2.0=I-27 I$ & $\mathrm{I} 26.0=\mathrm{I}-\mathrm{I} 98$ \\
\hline & $25.0=1-1000$ & - T & & I $27.0=x-196$ \\
\hline & & & & \\
\hline $9.0=1$ & & & & \\
\hline$=I-263 I$ & & & & 192 \\
\hline $0=\mathrm{I}-2500$ & $29.0=I-862$ & $3.0=1-396$ & $7.0=I-259$ & I3I.O $=$ I-I9I \\
\hline $0.5=I-238 I$ & $30.0=1-833$ & $4.0=1-390$ & $8-\pi$ & I $32.0=\mathrm{I}-\mathrm{I} 89$ \\
\hline & $31.0=x-806$ & $5.0=1-384$ & & I $33.0=1-$ \\
\hline $\mathrm{I} \cdot 5=\mathrm{I}-2 \mathrm{I} 73$ & & $66.0=1-378$ & $00.0=\mathrm{I}-250$ & I $34.0=\mathrm{I}-\mathrm{I} 86$ \\
\hline $2.0=1-2166$ & $33.0=x-787$ & $67.0=13$ & $1.0=1-247$ & \\
\hline $2.5=1-2000$ & & $0.0-1-$ & $2.0=I-245$ & I $36.0=\mathbf{I}-\mathbf{I} 83$ \\
\hline $3.0=1-19^{2} 3$ & 4 & $69.0=\mathrm{I}-$ & - & 82 \\
\hline & $o=\mathrm{I}-694$ & $70.0=1-3$ & $4.0=I-240$ & I $38.0=I-I 8 I$ \\
\hline $0=1-1785$ & & $71.0=1-35^{2}$ & $05.0=1-238$ & I $39.0=I-179$ \\
\hline $4.5=I-I 724$ & & $72.0=I-345$ & $06.0=I-235$ & $140.0=1-178$ \\
\hline & $39.0=I-64 I$ & $73.0=1-34^{2}$ & $07.0=I-233$ & $\mathrm{I} 50.0=\mathrm{I}-\mathrm{I} 66$ \\
\hline & $40.0=x-625$ & $74.0=x-337$ & $108.0=I-23 I$ & $\mathrm{I} 75.0=\mathrm{I}-\mathrm{I} 4^{2}$ \\
\hline & $41.0=I-609$ & $75.0=I-333$ & $109.0=I-228$ & $200.0=\mathrm{I}-\mathrm{I} 25$ \\
\hline $6.5=\mathrm{I}-\mathrm{I} 5 \mathrm{I} 5$ & $42.0=I-593$ & $76.0=1-328$ & I I $0.0=$ I - 227 & \\
\hline $7.0=1-1470$ & $43.0=1-5^{8} 3$ & $77.0=1-324$ & I I I.O = I-225 & \\
\hline $7 \cdot 5=\mathrm{I}-\mathrm{I} 42 \mathrm{I}$ & $44.0=1-567$ & $78.0=\mathrm{I}-320$ & I I $2.0=I-223$ & \\
\hline
\end{tabular}





\section{Explanation of Plate.}

[FRONTISPIECE.]

GENERA OF DESMIDS.

Each Figure is numbered to correspond with the number of the genus.

FIG.

1. Gonatozygon. Omitted; the cell needs no figure.

2. Genicularia.

3. Hyalotheca.

4. Bambusina.

5. Leptozosma. Omitted; the cell needs no figure.

6. Desmidium.

7. Phymatodocis.

8. Sphærozosma:.

9. Onychonema.

г. Mesotænium.

I I. Spirotænia.

I2. Penium.

I3. Closterium; three figures, showing central inflation and ends produced into beaks.

14. Docidium.

15. Triploceras; end and part of cell.

I6. Calocylindrus.

I 7. Cosmarium.

18. Tetmemorus.

I9. Xanthidium.

20. Arthrodesmus; $20 a$, front view, $b$, end view.

2I. Euastrum.

22. Micrasterias; five forms.

23. Staurastrum; four forms; $23 a$, front view, $b$, end.

24. Pediastrum; three forms. 



\section{INTRODUCTION.}

To know the origin of any object, event or act, is always of interest. To know what lead up to a certain acceptable innovation or aid is pleasing to everyone, and often important to the historian of any department of the world's work. What was the form of the first analytical key, who made it and what induced him to make it, are interesting questions that the writer at least cannot answer. Such tables have become very popular in the various departments of botany and of zoology, but who originated them is not known; nor when the first was published, nor where. Like many other good things, these keys may have been the result of simultaneous thought and experiment on the part of several workers that felt the need of some outside aid to the inside treasures of the ever increasing mass of scientific knowledge. But to whomsoever belongs the credit of originating these devices, to him belong much praise and many hearty thanks.

That analytical keys were needed is proved by their popularity. They are welcomed by the student in all the sections into which $\mathrm{Na}$ ture is for convenience divided. It is true that there are some observers who scoff and laugh in derision when "keys" are mentioned, but these few belong to that rlass, fortunately limited, whose members are unable to use them. There are persons that seem to be deficient in those mental qualities that make the use of such tables a pleasure and a delight, as there are others unable to arrange even the simplest of keys. If in a scheme of the kind there are three groups, a blue, a black and a green, these unfortunate opponents of keys seem unable to decide what to do next, when the specimen happens to be green while the first description in the list calls for a blue 
object. That they should glance down the list to see if by any chance a green specimen may have been provided for, does not occur to them; they toss the paper aside, and laugh at the utter folly of the statement that any intelligent person should be able to use a key. The truth is that inability to use these valuable aids is an evidence of a defect in the mental organization. Such critics are forced to page through the monographs they attempt to study, with great loss of time and with much labor, to find the information that may be wanted; whereas with the object and a key to its class in hand the labor becomes a delight, and the result a valuable acquisition, because no key to any department can be used even to a limited extent without teaching the student many facts that he might otherwise have overlooked.

A table of the kind will draw attention to the morphology of the object in a way that will lead not only to its proper classification, but to something much more important, the enlarging of the student's powers of observation. Some of those that oppose the use of artificial keys are themselves compelled not only to page through an unfamiliar monograph, but in many instances to scan the pictures for the light they are groping after; and failing pictures they guess as to the character of the object from its resemblance to something remotely similar, and in the end, at great expense of time, and perhaps of temper, may get a clue that may lead them to the goal they have been so laboriously seeking. With the intelligent use of an artificial key the place, the character, and even so unimportant a matter as the name, can be rapidly obtained, and the student be led on to further study and investigation.

It is always encouraging to feel that by one's efforts a way has been opened to further conquests, or even that a path has been cut to some previously unknown view. This the use of artificial keys always accomplishes. When the beginner feels that he can do something unaided he is inspired to do more. When he feels that he has travelled alone through some pathway in some department of natural science, he is anxious to go further. One step taken with the aid of an artificial key is sure to be an encouragement toward another. The powers of observation are increased. The ability to balance one thing against another is cultivated. In a word, an artificial key can be made one of the most important aids in the mental development of the beginner that can be imagined. The observer that scoffs at these aids, the observer that refuses to take advantage of them, is doing a foolish thing and losing a good one. 
There are two distinct varieties of these valuable aids, the natural and the artificial. The former is founded only on the characters that the advanced scientist uses in his classification. These are often so exceedingly natural that to learn the proper position of the object it must be destroyed. To learn something of an animal through them the animal must be dissected, and the anatomy of its nervous system, and the morphology of its osseous system, and the structure of its heart be accurately observed before it can be classed. These arrangements may be, they often are exceedingly valuable to the advanced scientist; to the amateur and the beginner they are terrible. They haunt his dreams like horrid night-mares, provided he is incautious enough, or ignorant enough to attempt to use them. I have not a word to say against such analytical tables. I cammend them for use in their proper places. They are important for their purpose, but that purpose cannot be the beginner's or the amateur's. It is the learned man that can delight his soul with such a scientific key. To him it is instructive and helpful. To any one else it is a bugbear and a horror. The beginner is not prepared to begin with the nervous system of his "find," or even with the structure of its heart. He must have something nearer the surface and more easily seen than are these parts. His key must deal with the external and the evident characters. It is for him that the artificial key is intended, and to him it is inspiring and helpful.

This second kind of key, this artificial kind, is as its name indicates, founded not on what the advanced investigator would use in his classification of the animal or the plant, but on some obvious, preferably external, points that may be of no use in the art of classification, but that can be used as crutches to help the student over the miry and the stony ground to the hills of science where he will be able to look back and smile at his former helplessness. These artiñcial keys have this for their object, and only this. They aim to help over the hard places; to encourage the user to go further, and to do more, so that finally he may become an expert, when he will no longer need any but the natural aids, or may even get along without any other assistance than skilled eyes and a "learned touch."

The beginner, however, must have a guide, especially if he be trying to work alone. This is true in every department of natural science. It is especially true in microscopy. The field is so immense, the outlook so vast, the work so apparently endless, that without an aid the beginner at once begins to flounder in his sea of troubles, and before long he sinks discouraged to rise no more. $\mathrm{He}$ 
becomes so disheartened since everything is so new and strange, and there seems to be no one within call to lead him out of the difficulties, or out of the embarrassment of scientific riches, that he is entirely discouraged, his enthusiasm is lost, and with this loss is abandoned a study that would have lessened his cares, increased his joy in living and lengthened his life. The beginner working alone wastes much time. To be sure, he may before long learn that a green object that stands still is a plant, or may be; and also before long he hears that all green microscopic objects that stand still are not always plants. If he have a teacher his condition is a more favorable one; but if he be alone he must have an artificial guide, or fail. For such students the artificial keys are providential.

Once introduced to them he is ready to go on to new conquests. The use of such tables in the popular treatises on botany has done more to popularize that beautiful study than a score of learned monographs on the subject. As soon as the pupil learns that he can by his own efforts obtain even the botanical name of his plant, a feeling of enthusiasm fills his heart, and he is eager for another specimen to analyse. And in the analysis he is learning the principles of classification, the structure of the specimen and the function of the various organs. By means of the key he goes with little trouble and waste of time to the order, there he finds another key that leads him pleasantly to the genus, and perhaps a third that takes him to the species. There he finds the plant exactly described. He has had the prominent characters brought to his notice in a pleasing way, and the final result is that he not only learns to love the science of botany, but that he soon learns to know at a glance, without the use of the artificial key, to what order a strange specimen may belong. He has become scientific without knowing how he became so. He has travelled by the royal road. It is so, or should be so, in the science of microscopy, to call for convenience a science that which is really a combination of all the sciences.

If every department of microscopy could have an artificial key to open the doors of its treasure-houses, the amateur would have a happier time, science would be benefitted and the maker of the key, the scientific artisan, would himself be blessed both in this world and in the next. Such a pleasing state of affairs can not be attained. The doors are too numerous to be opened by a single key. To make the proper number is not possible for one worker, however willing he may be to try. Each specialist could forge a key to the doors or to the dark passage-ways of his special scientific castle, and offer it to those that would follow after him if they could. But the specialists are not 
disposed to become scientific blacksmiths, and to forge keys to the treasures they have locked up in their formidable monographs. Indeed, it is not possible that they should. They have no time to make the entrance ways easy and agreeable. They are after the facts of the science; they are seeking the internal secrets of the creatures they have studied and written about; they are content to leave the enlarging of the building to other specialists that may come after. It is no fault of the writers of learned monographs that they put forth their treatises without a single loop-hole of entrance for those that would, if they could, enter in to see some of the treasures of which rumor has told. When a man has spent his days and his nights and his earthly and bodily substance on the production of a treatise that shall make his name known to the world, he is naturally disinclined to labor longer and harder to make easy grades and smooth paths and shady retreats along the way to his treasure house; and when the learner has arrived at the gates, the learned man is not disposed to stop his further investigations to throw a pretty key out of the window and ask the uninvited guest to come in and sup with him. $\mathrm{He}$ is too busily engaged in the new investigation that his completed investigations have made necessary. There is no end to the questions to be studied and decided. He cannot, much as he may be willing, condescend to make keys for the beginners. If he makes any at all, they will be of the severest kind and intended for his scientific equals only, not for the humble followers in his foot-steps. We should never blame the writers of learned monographs for not offering these gilded keys. They cannot. They have gone up too high to stop, for the higher they go the more there is to be done. And they that have climbed that high are the ones best adapted to climb higher, for they find it easier to go up than to come down.

But if such books are to be used by any others than the rather limited class of experts that have the knowledge needed to find their way unaided through the pages, then a guide of some kind must be furnished. An index will not answer the purpose, as to use it demands just that information not at the disposal of the novice or of the amateur. All of these scientific treatises may be as useful to the modest student as to the learned investigator, provided, as I have so often said and repeated, some means can be devised by which he may be helped to make an intelligent entrance into its various departments.

Mr. Wolle's monographs on the Algæ and the Desmids are no exception to the rule. They are not adapted to the use of the ama- 
teur microscopist in the state in which the author has left them. It is not possible for the youthful microscopist to read the description of one hundred and twenty genera of Algæ in order to locate a single specimen that he may find in the wayside ditch. To ascertain with any degree of comfort the probable resting place of the specimen he must have some help. It is that help that this little compilation hopes to supply. By its intelligent use the student may ascertain the specific name of any fresh water Alga or Desmid in the ponds and the ditches of the United States. This he can do with the expenditure of the least time and labor, leaving them to be spent in the subsequent study of the plant, after he has had the satisfaction to learn what it is, and where in the classification it belongs. If the worker has the name of the specimen, he then feels that he has a support on which he may hang his subsequent information, and a starting point for further investigations. Not to know the name of the object and yet to try to study it, is like an attempted conversation with a stranger whose antecedents and local habitation are unknown. The effort is not an agreeable one. The conversation languishes, and interest is lacking. The name and the habitat of the person add much to the pleasure of the meeting, and many suggestions to the interview. So the name of the microscopical or other specimen is almost essential to the well being of the young student.

The name is, too, about the first thing the advanced scientist tries to learn. It is impossible to do otherwisè. The object can not be referred to by speech or in writing until its name is known; what other workers in other parts of the world may have said about it or done with it, can not be known until its name is learned, as without the name all indexes are closed in all the books of all the libraries. The name is the clue to further knowledge, its starting point, even the hook upon which further information is to be hung. Whatever advanced scientists may say to the contrary, their first effort, perhaps it is an unconscious one, but their first real effort is to ascertain the name of their new specimen. If it has none, they at once proceed to give it one. All the wild talk about the undesirability of learning the name is wrong in principle. The name is, as every one will cheerfully admit, only of secondary importance when compared with a study of habits or of morphology, but it is as essential, since it is and must ever be the starting point for further investigations, at least on the part of the amateur. If he chooses to stop at the name, that is his misfortune; but even then he has gained something. If those whom I may be able to help by these keys shall do nothing more than identify their 
"finds," I shall feel that I have done some little thing to help them and their friends. I shall feel pretty sure that the mere finding of the name will not be the end; but if it should be, where will be the harm? Is it a crime to know the scientific name of the plant or of the animal ? Knowing that is knowing something, I think. Would you have the pupil dissect the nervous system before he has learned to recognize a nerve, or before he knows the muscles to which the nerves are distributed? Of course he might say "This is a nerve," and "That is a nerve and it goes to that muscle," but would you have him carry the dead body about with him in order to dissect it and point out the nerves and the muscles that receive them whenever he wished to communicate with you or with any of his friends in reference to the nerves and the muscles of that special creature? This is exactly the result which those that cry out against learning names would accomplish if their desires prevailed. No, no! Get the name the very first thing, if you wish. It will make a good starting point. It is not the end and the aim of any study; it is only the bridge that takes us over the swamp. After awhile we will be big enough and strong enough to pass the swamp without the bridge, as after awhile we will be able to get along without an artificial key. But do not condemn the bridge that has carried you safely over.

The keys in this little book are as artificial as they could be made. In some instances they are perforce somewhat natural; that is, the fruiting plant has been used to the exclusion of the more frequent sterile condition. This, however, has been avoided as much as possible, and in several instances two keys have been prepared to the same genus of plants, one for the fertile, the other for the sterile filaments. They are all, as the title page indicates, founded on the classification contained in the admirable monographs by the Reverend Francis Wolle on the fresh water Algæ and the Desmids of this country. Until Mr. Wolle took up the subject our American microscopic plants had scarcely been touched, except by a few observers in a desultory way. He has brought order out of chaos, and has prepared two monographs that are monuments to his learning, skill, care and patience. These keys are made not alone with the object of leading the beginner to the study of the fresh water Algæ and the Desmids, but to introduce him to these fine works of Mr. Wolle's. While the beginning mcroscopist in his study of microscopical botany may, to a certain extent, succeed in identifying his "finds" with these keys alone, to do so with entire satisfaction he should have access to the monographs on the Algæ and on the Desmids. The references at the end of the 
classes and of the genera are to the numbers preceeding those classes and genera in this list; those following the species are in every case for reference to the pages on which will be found the extended descriptions in the monographs already so often referred to, where references will also be found to the illustrations.

The measurements of the Algæ are given in parts of a mikron $(\mu)$; in the Desmids, by both fractions of an inch and of mikrons. The former will necessitate a little calculation, if the reader is not entirely familiar with the minute space called a mikron and represented by the Greek letter $\mu$. It measures the $\frac{1}{25000}$ of an inch in length, and the calculation needed to bring it to the fractions of an inch as given in the measurements of the Algæ, are slight. Twenty-five mikrons, for instance, being $\frac{25}{25000}$ inch, or $\frac{1}{1000}$ inch. It is only necessary therefore to use the number of mikrons as given with the Algæ for the numerator of a fraction of which the 25000 forms the denominator, and reducing the whole to the lowest terms. In the Desmids the calculations have been made, and the measurements given in both forms. The student will therefore need an eye-piece micrometer, but it may be ruled to parts of an inch. The use of the mikron, like the use of the metric system, has not and probably never will come into popular favor.

Does the reader know how to use a key of this kind? To some this appears to be a mysterious thing, although a little inspection of the key itself should make it plain. It is simply a matter of examination, comparison and rejection. With the specimen in hand, which in this instance means under the microscope, begin at the beginning of the key and compare the description in the first sentence with the object under the instrument. Do the two agree in every particular? If not, leave that reference and go to the next having the same letter or other symbol at its frunt. If that should describe the specimen, notice the letter in the parenthesis at the end of the line, and seek that same letter at the beginning of a line in some other part of the key. You will probably find several lines beginning with that letter. Starting at the first, compare the description there given in a word or two with the actual specimen, and if it does not agree pass to the line next below. If at the end of this line there is another reference letter in parenthesis, turn to that, and so continue until at the end of some line you find the generic or the specific name of the plant. Mistakes are easily made, here as elsewhere. If you should happen to make one at the start every step forward will lead you further and further astray. With care and intelligent observation, errors may be 
avoided and the specimen readily run down to its proper place. After a little practice, the use of such artificial keys becomes a great pleasure. The benefit has already been referred to. The only secret of their successful use is to be certain that each progressive step is right before it is abandoned for the next. And after a little practice, too, the student will become so familiar with the Algæ or with the Desmids that he will not need to apply to the generic keys for aid, but will be able to turn at once to the proper genus, and there use the keys to the species; and with a little further experience he will be enabled to recognize at a glance the species, and then will be prepared to proceed with his investigations, or to refer intelligently to the object so as to communicate with his friends and fellow workers in regard to it. It is as impossible to speak or to write of an Alga or of a Desmid without using its proper name, as it is to speak or to write of your most intimate friend without using his.

Algæ and Desmids are singly invisible to the naked eye. It is only when they occur in large masses that the eye can take cognizance of them. It rarely occurs, however, that the Desmids are so abundantly congregated that they thus obtrude themselves on the observer. When a large quantity has been collected and the vessel placed near a window, they will collect in a green film at the surface of the water on the lighted side, and there become visible in mass. In the ponds and shallows such an occurrence is not common. At times they are found so abundantly that by holding a glass vessel of the water up to the light they may be seen floating about as minute green objects, which the trained eye will recognize and the pocket lens make distinct. But these varieties are among the largest of the forms; according to my experience they are always exclusively confined to the Closteriums. Other large forms, like Micrasterias, at least in the writer's locality, rarely occur in such profusion. To collect the Desmids, therefore, it is necessary to collect by faith. The microscopist can know exactly what he has only when he gets home and examines the water drop by drop under the microscope.

With the Algæ it is different. These are usually visible to the naked eye, as they are almost invariably collected in large masses floating on the surface, submerged just beneath the surface, or attached in waving tufts or fringes to sticks and stones and other plants in the ponds. The eye of faith is not needed to recognize them. They usually force themselves on the wondering attention of the observing pedestrian in the wayside lanes, beside the ditches and slow brooks. As soft emerald clouds, or graceful streamers floating 
in the sluggish current, or resting like a green skum on the surface, they are readily seen and as easily gathered. No collecting tools are demanded for either Algæ or Desmids, except a dipper of some kind, a common tin dipper is as good as anything, and a few bottles or other vessels to carry the treasures home, and to keep them concealed from inquisitive people; the collecting naturalist must always be prepared for a meeting with such persons.

Many media have been recommended for the preservation of these beautiful plants. The trouble with the majority of these preparations is that they will in time, some usually in a very short time, allow the cell contents to contract and to become so distorted that the object is worthless for any serious study, and worthless, too, as the object of beauty that it was when first mounted. Some of the commended media act well on some kinds of Algæ and Desmids, but fail on others. The following are among the best, yet even these are not all adapted to all the different kinds. They are mentioned in the order of their excellence.

CAMPHOR WATER.-This is made by placing a lump of camphor in distilled water and leaving it there for several days. Mr. W. H. Walmsley, an expert preparer of microscopical slides, says that he has had a specimen of Draparnaldia in camphor water for twenty years, and that it is now as beautifully green as when first mounted, and that the chlorophyll, its green coloring matter, seems to be unchanged. When he desires to mount an Alga or a Desmid, he places it in a small quantity of camphor water to which a few drops of glycerine have been added. At first the plant will become lemon color, but after a few hours the original green returns in all its vividness, and then he at once mounts the plant in some of the fluid.

CARBOLIC ACID WATER, made by adding a few drops of the acid to a phial of water, is recommended by the Rev. Mr. Wolle, but he says that although this will preserve them for months or even years without deterioration, it may allow the coloring matter, the chlorophyll, to fade; this however in the case of the Desmids is of little importance.

A SOLUTION OF CHLORAL HYDRATE, in the proportion of five grains of the salt to one ounce of water, answers well for some specimens. Like camphor water it has the merit of being easily made and easily used.

A SOLUTION OF COPPER made after the following receipt is admirable for some of the Algæ, preserving the color and the form entirely unchanged, while on others it will not act so favorably. 
Camphor water, - - _ _ _ _ _ - 50 grammes; Distilled water, - - _ - _ _ - - 50 grammes;

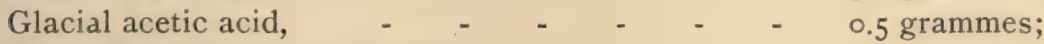
Crystallized chloride of copper, _. - _ _ _ $\quad 2$ grammes; Crystallized nitrate of copper, - $\quad$ - $\quad$ - $\quad$ - $\quad 2$ grammes.

Dissolve and filter.

When mounting with this copper solution the cell should be made and the cover cemented down with shellac. With almost any other cement failure is pretty certain, as the cement will surely run under and ruin the preparation. After the shellac is hard, it is a good plan to add some of Brown's rubber cement around the cover. This is entirely transparent and will make the mount more secure, and at the same time add something to the beauty of the finish.

TRENTON, N. J., I892. 



\section{PART I.}

Key to the Classes and the Genera of the Fresh-Water Algæ. 

KEY TO THE CLASSES AND THE GENERA OF THE FRESH WATER ALGA.

CLASSES OF THE ALGA.

$\S$ Rosy red, blood-red, reddish-brown, purple or blackish; many celled

CLASS I.

$\S$ Chlorophyll-green, sometimes becoming crimson, purplish, fleshcolor or yellow-brown; I, 2 or many celled; often nucleated,

CLASS II.

$\S$ Never chlorophyll-green; colorless or variously colored; I or many celled; in jelly when out of the water . . . . . CLASS III.

KEY TO THE GENERA OF THE ALG E.

\section{CLASS I.}

- Olive, brown or grey, black with age; filamentous, often hollow, bristle-like, rigid (A).

- Violet, violet-purple or bluish-green; filaments articulate, branched or not (E).

- Purple; tufts loose; filaments I in. long, not branched (D).

- Purplish, smooth, forming a firmly attached coating to stones,

Hildebrantia, 7

- Brownish red, vermillion, or greenish with red centre; cells 4-8, free or in a short lived cluster . . . . Chlamydococcus, 38

T Blood red, cells large, tegument thick, lamellose, stem ringed,

Urococcus, 66

A. Filaments nodose, tufted; fertile filaments hollow, with internal axillary thread; in rapid water (B).

A. Filaments transversely banded or annularly constricted; with internal central axis $(\mathrm{C})$. 
B. Axillary thread a single series of cells with transverse threads at regular intervals

C. Axillary thread of cohering filaments, with many whorls of moniliform branchlets . . . . . . . . . . Tuomeya, 2

D. Simple or branched, slippery; cells in a single layer, membrane thick, colorless . . . . . . . . . . . Bangia, 3

E. Branched; main stem often with an external, parallel series of cells; branches moniliform, clustered . . Batrachospermum, 4 E. Branched; main stem without external parallel series of cells; branches not moniliform (F).

F. Filaments articulate, villose, branchlets dichotomous . Thorea, 5

F. Filaments articulate; branches not whorled; plant steel blue or purplish . . . . . . . . . . Chantransia, 6

F. Filaments articulate; branches erect-spreading; plant olive-green, Compsopogon, 8

\section{CLASS II.}

$\S$ Multicellular or apparently so (A).

$\S$ Unicellular, the cells often clustered or forming a colony $(\mathrm{F})$.

A. Chlorophyll diffused, not in patterns (B).

A. Chlorophyll in spiral bands, axillary laminæ, or twin, stellate nuclei $(p)$.

B. Filamentous (C).

B. Not filamentous; articulate, prostrate, or net-like, often membranous, sometimes parasitic (M).

C. Basal cell lobately divided, or with a terminal disk attaching the young plant (D).

C. Basal cell not lobate nor disciform (E).

D. Not branched; terminal cell sometimes setiform, CEdogonium, Io

D. Not branched; no setæ; strongly contracted at intervals,

Schizomeris, 24 a

D. Branched; with long terminal setæ bulbous at base, Bulbochete, II

D. Branched; no setæ; cells long, cylindrical . . . Sciadium, 46

E. With branches (G).

E. Without branches, but sometimes with lateral processes (L).

F. Plants filamentous $(\mathrm{N})$.

F. Plants not filamentous, sometimes curved or spiral, without rootlets $(\mathrm{T})$.

F. Plants globose, small, on moist earth, with colorless rootlets $(\mathrm{O})$.

G. Filaments erect $(\mathrm{H})$.

G. Filaments prostrate or creeping, branched or not (*). 
* Without dorsal spine; cell walls thick .

Gongrosira, 2 I

With dorsal spine

H. Immersed in firm jelly Aphanochete, 20

H. Not in a firm jelly (I).

Chatophora, 18

I. Filaments dichotomously or trichotomously branched,

I. Filaments not dichotomously branched (J).

Microthamnion, 19

J. Branches in lateral clusters; cells of main stem with a transverse, central chlorophyll band . . . . . . Draparnaldia, 16

J. Branches not in lateral clusters (K).

K. Cell membrane usually thick, cells longer than broad; ultimate branches, much thinner than the primary,

Cladophora, 23, or Pithophora, 24

K. Cell membrane very thin and hyaline; stem and branches barely separably in size and appearance

Stigeoclonium, I7

$\mathrm{K}$. Cell membrane thin; branches radiating, umbel-like, one-celled,

Sciadium, 46

L. Distinctly many celled $(\mathrm{P})$.

L. Articulate (apparently multicellular) (Q).

M. Articulate, branched, forming a little mass or a subdisciform layer

M. Articulate, prostrate or creeping, a spine on the back,

Aphanochate, 20

M. Expanded, leaf-like, smooth, formed of angular cells; always adherent

Prasiola, I4

M. Membranaceous, tubular or utricular, fixed only when young,

Enteromorpha, I5

M. Forming a green net, visible to the naked eye, Hydrodictyon, 4I

M. Forming a colony, plane; discoid or stellate, often perforated; cells polygonal . . . . . . . . . . . . Pediastrum, 40

N. Filaments tufted, long, sometimes branched, . . Vaucheria, 30

O. Rootlets much divided, descending from the cell base into the earth

Botrydium, $3^{\mathrm{I}}$

P. Cells long; chlorophyll enclosing large, regularly placed vacuoles,

Spharoplea, $\mathbf{1} 2$

P. Cells long, filaments somewhat geniculate, without vacuoles $(t)$.

P. Cells short, cylindrical or oblong; without vacuoles; filaments not contracted; attached when young . . . . Cylindrocapsa, I3

P. Cells short, broader than long, filaments contracted irregularly,

Schizomeris, 24 a

Q. Filaments simple, not laterally united, (R). 
Q. Fi'aments 2 or more laterally united, or in flat narrow bands,

R. With one row of cells, (S).

Schizogonium, 26

S. Without lateral processes (except Ulothrix rivularis), strictly unbranched . . . . . . . . Ulothrix, 25; Conferva, 27

S. With short, irregular, lateral processes, I-3 or more celled,

Rhizoclonium, 29

T. Parasitic, i.e. penetrating the membrane of the host $(g)$.

T. Not parasitic $\left({ }^{*}\right)$.

* Cells united or clustered in families (U).

* Cells scattered, independent or irregularly clustered (Z).

U. Colonies motile, each cell with 2 cilia $\left(V^{\top}\right)$.

$\mathrm{U}$. Colonies often free but not spontaneously motile, without cilia $(c)$.

V. Colony (cœnobium) spherical or circular (W).

V. Colony flat, cells $4-16$, angles rounded, in a colorless sheath,

Gonium, $3^{6}$

W. No gelatinous coating; cells many on a hollow globe Volvox, 32

W. With gelatinous coating $(\mathrm{X})$.

$\mathrm{X}$. Colony ovate or spherical (Y).

$\mathrm{X}$. Colony of 8 cells at equal distances around a circle,

Stephanosphara, 37

Y. Cells I6-32, globose, at regular intervals on a colorless sphere,

Eudorina, 33

Y. Cells 8-16-32-64, globose, crowded, often angular from pressure, Pandorina, 34

Z. Cells free-swimming $(a)$.

Z. Cells attached to aerial or to submerged objects $(b)$.

a. Ovate, granular, in a hyaline, obtuse sheath; contractile vesicle present . . . . . . . . . . . Chlamydomonas, 39

a. Cylindrical, straight or curved, ends sometimes spinous,

Ophiocytium, 47

a. Spherical, $3^{-15} \mu$ in diameter

Protococcus, 49

a. Spherical, $100-\mathrm{I} 50 \mu$ in diameter

Eremosphara, 65

a. Compressed, 3-4-8 angled, angles often produced or bifid,

b. Aquatic; form variable, cells not spinous, usually stipitate,

Polyedrium, 50

Characium, 48

b. Aquatic; form variable, cells often with a dorsal spine,

Aphanochate, 20

b. Aerial; cells circular, flat, numerous, becoming red by exposure, 
b. Aerial, on moist objects; gelatinous, cells globose or angular, becoming red

Porphyridium, 57

c. Family in jelly mass, thallus pyriform, irregular, tubular, clustered, branched, etc. $(i)$.

c. Family globose $(d)$.

c. Family plane, discoid or stellate, often perforated; cells polygonal,

c. Family cubical, cells 4-8-I6, rhomboidal

Pediastrum, 40

c. Family of laterally united, often spinous or crescentic cells $(e)$.

c. Family of cylindrical cells $(f)$.

d. Cells in a single stratum; cœnobium hollow

Coelastrum, 42

d. Cells 4-8-16-32, wedge-shaped, apices sinuate or bifid; cœnobium solid

d. Cells 2-4-8, globose or oblong

Sorastrum, 43

e. Cells cylindrical to ovate, ends often spinous

Glococystis, 60

$e$. Cells not spinous, fusiform, cylindrical, straight or variously curved, single or united

Rhaphidium, 62

$f$. Upper cells spreading, contracted at base .

Sciadium, 46

$g$. Cells globose or pear-shaped $(h)$.

$h$. Neck not cylindrical, aperture with a lid

Chytridium, 68

h. Neck cylindrical, elongated .

$i$. Cells connected by fine filaments $(*)$.

$i$. Cells not connected by filaments $(j)$.

* Filament attached to the convex side of the cells,

* Filament attached to the concave side of the cells,

Dimorphococcus, $6_{3}$

Dictyospharium, 5 I

j. Families free-swimming (not attached), $(k)$.

$j$. Families not free-swimming (attached), $(l)$.

k. Cells oblong, reniform, 2-4-8-16; tegument oval or reniform; variable

Nephrocytium, 6I

$k$. Cells oval, small, in grape-like clusters; tegument thin, diffluent,

Botrycoccus, 59

$k$. Cells globose, large, cell walls firm, border hyaline; chlorophyll sometimes radiate . . . . . . . . . . Eremosphara, 65

l. Cells fusiform, crescentic or straight, cylindrical, ends cuspidate or acuminate, tegument thin

Rhaphidium, 62

l. Cells globose, elliptical or elongate $(m)$.

$m$. Cells red, large; tegument thick, concentrically lamellate, stem ringed

Urococcus, 66

m. Cells green; tegument not lamellate $(n)$. 
$n$. Thallus soon diffluent into shapeless mucus,

Tetraspora, 54, or Palmella, $5^{6}$

n. Thallus with a definite form (o).

o. Cylindrical or cumpressed, branched, 2-12 inches long; one pole of cells colorless . . . . . . . . . . Hydrurus, 52

o. Cylindrical, sometimes septate, attached at one end and spreading, Palmodactylon, 53

o. Pear-shaped, fixed by the stem-like base Apiocystis, 76

$p$. Chlorophyll in spiral bands $(q)$.

$p$. Chlorophyll in two, many-rayed bodies in each cell $(r)$.

$p$. Chlorophyll in axile plates $(t)$.

q. Conjugation geniculate. Gulf States . . . Sirogonium, 7 I

q. Conjugation ladder-like . . . . . . . Spirogyra, 70

$r$. Conjugation ladder-like or lateral $(s)$.

s. Spore in one of the cells . . . . . . . . . Zygnema, 72

s. Spore in the connective between the cells . . . Zygogonium, 73

t. Conjugation ladder-like $(u)$.

t. Conjugation lateral $(v)$.

t. Conjugation geniculate $(w)$.

t. Conjugation absent, spore formed spontaneously in the cell,

Gonatonema, 78

$u$. Spore in the connective between the cells,

Mougeotia,74, or Mesocarpus, 75

u. Spores in one of the cells . . . . . . Plagiospermum, 77

v. Spore lateral, at the point of two cells . . Pleurocarpus, 76

w. Spore formed at point of conjugation . . . Craterospermum, 80

$w$. Spore between the cells, quadrangular in front view,

Staurospermum, 79

\section{CLASS III.}

$\S$ Multicellular or apparently so, filamentous (A).

$\S$ Unicellular, the cells sometimes clustered or in families (V).

A. With hair-like points (B).
A. Without "
" (C).

B. Branched (but spuriously so); in small tufts

Calothrix, $8 \mathbf{I}$

B. Not branched; not in jelly mass; heterocysts yellow, at the base of the filaments; free or in small mats . . . Mastigonema, 82

B. Not branched; in more or less firm mucilage or jelly $(h)$.

C. Branched; in a sheath or jelly mass (E).

C. Branched; not in jelly.

C. Not branched (D). 
D. In a sheath or a jelly mass $(\mathrm{K})$.

D. Not sheathed nor in jelly $(\mathrm{P})$.

E. Branched at almost right angles to the stem; cells in a single series

E. Branched irregularly or with twin branches (F).

Hapalosiphon, $9^{2}$

F. Cells in single series in young plants, several series when older,

F. Cells in a single series only (G).

Sirosiphon, 91

G. Sheath broad, striate, hyaline, wing-like

Petalonema, 90

G. Sheath not wing-like (H).

H. Sheaths distinct, not agglutinated to one another (I).

H. Sheaths agglutinated in erect, wick-like bundles,

I. Heterocysts present $(\mathrm{J})$.

Symphyosiphon, 87

I. " not present; sheath with a single bluish filament,

Plectonema, 89

J. Heterocysts disconnected from the twin branches, Scytonema, 86

J. Heterocysts near the usually single branches . . Tolypothrix, 88

K. In a sheath; filaments moniliform, curved . . . . Nostoc, 93

$\mathrm{K}$. In a sheath; filaments not moniliform (Q).

$\mathrm{K}$. In mucilage or jelly mass (L).

L. Jelly mass spherical; filaments transversely plicate, radiate,

L. Jelly mass hemispherical, filaments radiate

Glootrichia 84

L. Jelly mass a stratum or indefinite (M).

M. Filaments erect, attached at base, jelly stratum flat, often incrusted . . . . . . . . . . . . Isactis, 83

M. Filaments not attached at base, not moniliform, heterocysts terminal, single . . . . . . . . Cylindrospermum, 98

M. Filaments not attached, not moniliform, colorless, heterocysts none

Crenothrix, 99

M. Filaments moniliform, cells globose or elliptical (N).

M. " " cells compressed disciform (O).

N. Heterocysts intercalated in the filaments,

Anabana, 94, or Spharozyga, 95

O. Heterocysts intercalated at regular intervals, yellow,

P. Bluish, bluish-green, blackish (T).

Nodularia, 97

P. Whitish or silvery; in sulphur waters .

Beggiatoa, 105

Q. Two or more filaments in each sheath Microcoleus, 103

Q. One filament only in each sheath (R). 
R. Parasitic; sheaths thin; cells short, tubular . Chamasiphon, Ioo

R. Not parasitic (S).

S. Agglutinated in erect, wick-like clusters, articulate, base prostrate, Symploca, ro2

S. Not agglutinated; exceptionally appearing branched; often forming a stratum . . . . . . . . . . . . . Lyngbya, Iо I

T. Filaments parallel in dense clusters; free-swimming,

Aphanizomenon, 96

T. Filaments short, heterocysts at their base; not free-swimming,

T. Filaments slowly motile Mastigonema, 82

T. Filaments not motile (U).

U. Filaments very slender, articulations more or less indistinct,

Leptothrix, 106

U. Filaments cruciformly branched Asterothrix, го6а

V. Free-swimming, (i.e. not adherent), (W).

V. Not free-smimming (X).

W. Cells globose, or oblong when dividing, in a single, quadrate layer, bluish-green . . . . . . . . Merismopedia, I I 2

W. Cells globose, sometimes in a small colony, brownish or red, sometimes greenish

W. Cells wedge-shaped, in radiating families . Gomphospharia I I 5

W. Cells filamentous or ring-like, spirally twisted, usually motile,

W. Cells filiform, very minute, spirally twisted

Spirillum, 107

$\mathrm{X}$. Sheath present, gelatinous or jelly-like, often colorless (Y).

$\mathrm{X}$. Sheath none; cells spherical or angular by pressure, solitary or in small families

Chroococcus, I2 I

Y. Aquatic $(a)$.

Y. On moist timbers and earth; cells small, in globose bodies in a thin membrane . . . . . . . . . Microcystis, I16

a. Sheaths thin, not confluent; cells tubular, short, parasitic,

Chamasiphon, roo

$a$. Sheaths confluent, in a mucous stratum, or elongation or membranous $(b)$.

$a$. Sheaths bladder-like, colorless; cells cylindric, ends rounded,

Gloothece, 109

b. Sheaths confluent $(c)$.

b. Sheaths membranous $(f)$.

c. Cells spherical or nearly so $(d)$.

c. Cells not spherical (e). 
d. Tegument mucous, cells spherical or elongated, one pole colorless, not in families . . . . . . . . . . . Hydrurus, 52

d. Tegument mucous, with small indistinct families of innumerable cells

Anacystis, II 7

d. Tegument soft, thick . . . . . . Aphanocapsa, I 20

d. Tegument a mucous stratum, containing groups of two cells, these surrounded by another tegument . . . . Glococapsa, i 19

d. Tegument a mucous stratum; thallus spherical, hollow, cells many, small, on the surface . . . . . . . Colospharium, II3

$e$. Tegument confluent, firm; cells longer than broad,

e. Tegument inconspicuous; cells elongate, cylindrical,

Aphanothece, 1 1о

Synechococcus, I I I

e. Tegument soon perforate, breaking into lobed forms; cells very small, embedded . . . . . . . . . Clathrocystis, I1 8

$f$. Cells globose, united in families, clustered grape-like,

Polycystis, in 8

$g$. Irregularly branched, often closely interwoven; stems and primary branches of the same thickness; often aerial, Chroolepus, 22

g. Cruciformly branched, ends acute; filaments articulate or not,

Asterothrix, го6а

$g$. Somewhat dichotomously branched, apices rounded; floating and yellow, gr not yellow and coating wet rocks . Calothrix, 8I

h. Filaments erect, laterally adherent, basally attached, forming layers on flat surfaces

Isactis, 83

$h$. Filaments distinctly sheathed at base, sheaths broad, often saccate, transversely plicate; heterocysts basal . . Glootrichia, 84

$h$. Filaments agglutinated by mucilage, and forming hemispherical or bladdery forms

Rivularia, 85 



\section{PART II.}

Key to the Species of the Fresh-Water

Algæ. 



\section{KEY TO THE SPECIES OF THE FRESH WATER ALGA.}

I. LEMANEA.

A. Filaments straight, $4-5$ in. long, . . . . . . fluviatilis, 52 A. " arcuately curved $(a)$.

a. $\mathrm{I}-2$ in. long, olive green, black with age. . . . . torulosa $5^{\mathrm{x}}$

a. 5 in. long, violet in mass; regularly constricted . . catenata, $5^{2}$

2. TUOMEYA.

A. Much and irregularly branched; tufts $\mathrm{I}-2$ in. long . fluviatilis, 53 A. Not branched, . . . . . . . . . . . grande, 53

3. BANGIA.

Filaments about $\mathrm{I}$ in. long; in lax purple tufts . atro-purpurea, 55 4. BATRACHOSPERMUM.

A. Branches sometimes setigerous, internodes naked or nearly so; gelatinous. Variable . . . . . . . moniliforme, 56

A. Branches not setigerous, whorls imperfectly developed, the branchlets often impacted; color bluish green . . . . vagum, 57

5. THOREA.

Much branched, ramuli horizontal, long and short alternating, ramosissima, 58

6. CHANTRANSIA.

A. Tufts I in. long; filaments with many straight branches; fertile branches very short

A. Tufts I-6 mm. long $(a)$.

$a$. Parasitic on other plants $(b)$.

a. Not parasitic $(c)$.

b. Fresh water; bright violet, $2 \mathrm{~mm}$. long; branches erect, ends obtuse, violacea, 59 
b. Marine; $\mathrm{I}-4 \mathrm{~mm}$. long in close fringe; branches rarely opposite, often hairy . . . . . . . . . . . virgatula, 61

c. Terminal cells cuspidate or piliferous . . . Hermannii, 60

c. " " rounded . . . . . . . . pygmaa, 6r

7. HILDEBRANTIA.

a. Fresh water; cells red; on river stones . . . . . rivularis, 6r

a. Marine; cells spherical . . . . . . . . rosea, 62

8. COMPSOPOGON.

One species

caruleus, 62

9. COLEOCHÆTE.

A. Filaments irregularly disposed, variable in form . irregularis, 65 A. " radiating $(a)$.

a. Filaments not laterally adhering, forming small disks . soluta, 64 a. " adhering side to side, forming a disk (b).

b. Disk irregularly orbicular; cells subquadrangular . . scutata, $\boldsymbol{\sigma}_{4}$ b. " exactly orbicular, thin, flat, . . . . . . orbicularis, 64 b. “ orbicular, upper surface rounded, about $2 \mathrm{~mm}$. high,

pulvinata, 64

\section{io. Eedogonium.}

It is only possible to identify the sixty-three species of this genus when the plants are in fruit, the forms being arranged in groups according to some characteristic or peculiarity of the oöspore (the seed or spore), and of the oögonium (the sac containing the oöspore). It is therefore scarcely possible to devise an artificial key.

$\S$ Male and female organs on the same plant (A).

$\S$ Male and female organs on different plants (B).

$\S$ Male organs of fructification not known (C),

A. Oöspores globose or nearly so (D).

A. " elliptical or ovate $(i)$.

B. Males short (dwarf), I-celled ( $k$ ).

B. Males short (dwarf), 2-many-celled $(p)$.

B. Males filamentous, many-celled plants $(g g)$.

C. Oöspores globose or nearly so $(p p)$.

C. " elliptical or ovoid (ss).

D. Oögonia globose or nearly so $(a)$.

D. " elliptical or ovoid $(h)$.

a. Oögonia opening by a pore (b).

a. " " " "lid $(f)$.

b. Pore median; veg. cells 4-6 times as long as wide cryptoporum, 70 
b. Pore above the middle $(c)$.

c. Oöspore not quite filling the oögonium $(d)$.

c. Oöspore entirely filling the oögonium $(e)$.

d. Veg. cells 3-5 times as long as wide . obsoletum, 7 I d. " $2 \cdot 5-3 \cdot 5$ "

d. " 4-10

$e$. Veg. cells 4-5 times as long as wide plusiospermum, 72 polymorphum, 73

e. " $2-4$ - fragile, $7 \mathbf{1}$

$f$. Oöspores subglobose, filling the oögonia - zig-zag, $7 \mathbf{1}$

$f$. Oöspores obovate, not entirely filling the oögonia $(g)$.

$g$. Veg. cells 4-6 times as long as wide autumnale, 73

g. Veg. cells $2-4$

$h$. Oögonia single, opening by a superior pore; oöspore globose not filling the oögonium urbicum, 73

$i$. Oögonia opening by a pore above the middle $(j)$.

i. Oögonia " " " lid . . . . . . . . gracillimum, 74

$j$. Veg. cells 3-7 times as long as wide paludosum, 74 $j$. " " $2-5$

$k$. Oögonia with 7-1 2 vertical constrictions - crassum, 74

$k$. Oögonia without vertical constrictions $(l)$.

l. Oöspore globose or nearly so $(m)$.

l. " subellipsoid $(o)$.

$m$. Diameter veg. cells $1_{5-17}^{-1} \mu, 4$ times constricted . undulatum, 76 $m$. " " " $28-38 \mu$, not constricted . . cataractum, 77 $m$. " " " " from $9-\mathrm{I} 5 \mu(n)$.

$n$. Oöspore depressed-globose platygynum, 75

$n$. " . exactly globose

o. Dwarf males adhering to all parts of the female o. “ " " on or near the oögonia

$p$. Oöspore membrane smooth $(q)$.

p. " " beset with bristles $(c c)$.

$q$. Oöspores globose or nearly so $(r)$.

q. " ellipsoid or ovate $(w)$.

$r$. Ögonia opening by a lid $(s)$.

$r$. " " a pore $(t)$

s. Terminal cell rounded Lundense, 79

s. " " apiculate macrandrium, 80

t. Pore in the middle or a little above $(u)$.

$t$. " above the middle $(v)$.

$u$. Veg. cells $4 \cdot 5^{-6}$ times as long as broad

flavescens, 78

$u$. " " $2-4$

Braunii, 79 
v. Diameter of veg. cells $13-14 \mu$ pyriforme, 95

v.

" " " " $16-20 \mu$

$v$. " " "

$27-30 \mu$

$w$. Ö̈gonia opening by a pore $(x)$.

w. " " " "lid $(a a)$.

$x$. Pore above the middle $(y)$.

$x$. "below " " oöspore with 4 spiral ridges . Huntii, 85

y. Oöspore longitudinally costate . . . . . . . Wolleanum, 82

z. Diameter of oögonia $45-50 \mu$ by $60-75 \mu$. . . Boriseanum, $8 \mathrm{r}$ z. " " " $70-83 \mu$ by $90-105 \mu$. . . concatenatum, $8 \mathrm{I}$ z. " " " $" 29-32 \mu$ by $33-38 \mu$. . . . sexangulare, 82 $a a$. Oöspore longitudinally costate, filling the oögonium,

aa. " not " " $(b b)$.

acrosporum, 83

bb. Terminal cell setiform

bb. " " not setiform . . . . . . . obtruncatum, 84

cc. Oöspores ellipsoid oögonia opening by a pore in the middle, Hystrix, 87

cc. " globose $(d d)$.

$d d$. Oögonia opening by a pore at the middle . echinospermum, 86 dd. " " " " " above the middle $(e e)$.

ee. Spines of oöspores conical $(f f)$.

$f f$. Diameter of veg. cells $2.5-5$ times as long as wide . stellatum, 85 ff. " " " " " $1-2$ times as long as wide . Donnellii, 85 ff. " " " " " " " " " " " " " " cchinatum, 86

$g g$. Ö̈gonia not or scarcely swollen $(h h)$.

gg. “ " manifestly swollen (ii).

$h$. Diameter of oöspore $22-52 \mu$ by $38-62 \mu$. . . . capillare, 87 hh. " " " $47-49 \mu$ by $50-66 \mu$.. . . stagnale, 87 ii. Oöspores globose or subglobose $(j j)$.

ii. " " ellipsoid or oval $(o o)$.

jj. Oögonia opening by a pore $(k k)$.

jj. " " " " " lid; oöspore globose . . Pringsheimii, 90 $k k$. Pore in the middle; membrane of veg. cells and of oögonia spirally punctate . . . . . . . . . . . puncto-striatum, 90 $k k$. Pore in the middle; membrane not punctate . . rufescens, 89 $k k$. Pore above the middle $(l l)$.

ll. Oöspore filling or barely filling the oögonia $(\mathrm{mm})$.

Il. Oöspores not filling the oögonia $(n n)$.

$\mathrm{mm}$. Oöspore globose, filling the oögonium, diameter $25-29 \mu$ by $24-30 \mu$ 
$m m$. Oöspore sub-globose, barely filling the oögonia, diameter $42-50 \mu$ by $46-56 \mu$

carbonicum, 90 $n n$. Diameter of oöspore $37-45 \mu$ by $40-50 \mu$. . . capilliforme, 88 $n n$. " " " $5 \mathrm{I}-54 \mu$ by $73-85 \mu$. . pachyandrum, 89 $n n$. Diameter of oöspore $42-60 \mu$ by $42-60 \mu$. . . . cardiacum, 90 oo. Diameter of oögonia $40-45 \mu$ by $80-100 \mu$ Boscii, 91

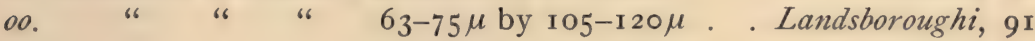
o. " " " " " $70-85 \mu$ by $130-160 \mu$. . . rivulare, 92 oo. " " " " $90-100 \mu$ by $130-150$. . . var. major, 92 $p p$. Diameter of veg. cells less than $\mathrm{I} 6 \mu(q q)$. $p p$. " " " " " $6 \mu$ or more $(r r)$.

qq. Diameter of oögonia $17-18 \mu$ by $20 \mu$ delicatulum, 93 q9. " " " $24-28 \mu$ by $28-35 \mu$ qq. " " " " $33-35 \mu$ by $33-43 \mu$ qq. " " " " $24-25 \mu$ by $26-28 \mu$ $r$. Diameter of oögonia $36-40 \mu$ by $44-45 \mu$. $r r$. " " " $6 \mathrm{I}-75 \mu$ by $68-80 \mu$. ss. Diameter of veg. cells less than $25 \mu(t t)$. ss. " " " " $25 \mu$ or more $(u u)$.

tt. Diameter of oöspore $35-36 \mu$ by $45-48 \mu$ pyriforme, 95 tt. " " " $15-16 \mu$ by $17-19 \mu$ longatum, 95 uи. Diameter of oöspore $54-65 \mu$ by $75-103 \mu$ uи. " " " $45-5 \circ \mu$ by $68-72 \mu$ gigateum, 94 grande, 95

\section{BULBOCHÆTE.}

In reference to the sixteen species forming this genus, the remarks made in connection with Edogonium might be repeated. The species can be identified only when in fruit; to make an artificial key is therefore almost an impossibility.

Replying to a personal inquiry in regard to the division of the species into monœcious and diœcious groups, with the presence of dwarf males on or near the oögonia of all the so-called diœcious forms, Mr. Wolle writes: "These male forms are not developed when they appear; they are supposed to have been formed in distinct cells known as androsporangia, and when they have developed and escaped, they float about and then attach themselves on, at or near the oögonium, but they are not necessarily a part of the plant on which they may be seated." 
$\S$ Oögonia globose or nearly so (A).

$\S$ “ ellipsoid or nearly so; oöspores longitudinally crenulatecostate $(\mathrm{F})$.

A. Dwarf males I celled, on or near the oögonia, elachistandra, 97 A. " " 2 celled (B).

B. Basal part (stem) of dwarf males, shorter than the spermogonia (C). B. " " " " " longer than the spermogonia; oöspore warty . . . . . . . . . . . . . gigantea, 99

C. Diameter of veg. cells $20 \mu$ or less (D).

C. " " " " more than $20 \mu$; oöspore granulate, setigera, 98

D. Oögonia without terminal seta . . . . . . intermedia, 97

D. “ with terminal seta, or beneath a male cell (E).

E. Dissepiment supporting oögonia in the middle of cell or slightly below

E. Dissepiment above the middle of the cell . . . polyandra, 98

E. " below the middle . . . . . . . Brebisonii, 99

F. Monœcious (G).

F. Diœcious $(\mathrm{H})$.

G. Diameter of oögonia $27-35 \mu$ by $46-56 \mu$. . . mirabilis, 100 G. " " " $20-25 \mu$ by $33-36 \mu$. . . . . nana, 100

H. Dissepiment of cells supporting oögonia obsolete (I).

H. " " " " "

I. Diameter veg. cells $12-5 \mu$, length less than diameter, pygmaa, roI

J. Diameter veg. cells $16 \mu$ or less $(\mathrm{K})$.

J. " " " more than $16 \mu(\mathrm{L})$.

$\mathrm{K}$. Veg. cells I-I.5 times as long as wide . . . subsimplex, IоI

$\mathrm{K}$. " " $2-3.5$ " " " " " . . . . . repanda, 102

$\mathrm{K}$. " " $1.5-2$ " " " " " . . . rhadinospora, 103

L. Veg. cells $2.5-4.5$ times as long as wide . . . . insignis, IOI

L. " " $1.5-3$ " " " " " . . . . . minor, IOI

L. " " $1.25-3$ " " " " " . . . rectangularis, 102

I 2. SPHAROPLEA.

Cells 8-10-20 times as long as broad, chlorophyllose rings $20-30$ in each annulina, 104

I3. CYLINDROCAPSA.

Ends of cells clear and pearly

amona, 105

Ends of cells not clear geminella, 104 
I4. PRASIOLA.

Tufts 2-6 mm. high and broad, cells $4-6 \mu$ in diameter, crispa, Io6 “ $\mathrm{I}-3$ inches long and broad, cells $6-8 \mu$ " " Mexicana, Io7

\section{I5. ENTEROMORPHA.}

$\S$ In brackish water $(a)$.

a. Fronds simple, elongate; cells $3-5-6$ angled . . intestinalis, 107 a. " compressed, tubular . compressa, 107

I6. DRAPARNALDIA.

A. Every mature joint with 2-4 clusters of branches, Ravenellii, Iro A. Branches less abundant, not at every joint $(a)$.

a. Branches opposite, their stems thick, short, tapering to a point or seta . . . . . . . . . . . . . spinosa, 109 a. Branches opposite or alternate . . glomerata, 108, plumosa, Iо9

I7. STIGEOCLONIUM.

$\S$ In warm or hot water; I-2 in. long, much branched, apex a bristle, thermale, II I

$\S$ Not in water of high temperature $(a)$.

$a$. Branches ending in a hair or bristle (b).

$a$. Branches not ending in a hair or bristle $(k)$.

b. Bristle a colorless, apparently hollow prolongation (c).

b. Bristle a delicate, filamentous, hair-like extension $(d)$.

$c$. Cells nearly cylindrical, equal or twice as long as broad,

d. Parasitic, dwarf, $2 \mathrm{~mm}$. long; in mucus

protensum, $1 \mathrm{I} 2$

d. Not parasitic $(e)$.

e. Diameter of largest cells $20 \mu$ or less $(f)$.

e. " " " " $25-40 \mu$.. . . . nudiusculum, II3

$f$. Diameter of filaments I $1-20 \mu$; basal cells 6-8 times longer than wide . subsecundum, II 2

$f$. Diameter of filaments 10-16 $6(\mathrm{~g})$.

$g$. Branches opposite on cells smaller and more oval than the others,

g. Branch-bearing cells not smaller $(h)$.

$h$. Upper branches clustered, moniliform . flagelliferum, I 12

h. " " not moniliform $(\jmath)$.

$j$. Two or more inches long, branches mostly opposite,

fasciculare, II 4

j. Two to ro $\mathrm{mm}$. long, simple to near the end, there branches clustered

longipilus, I 5 
$k$. Length 4-50 mm.; somewhat branched, branches simple, tenue, 110

k. " 2-3 mm.; branches alternate, ends obtuse, . nanum, I I 2 $k$. " $\quad 12 \mathrm{~mm}$.; branches mostly opposite, ends acute,

amonum, II 3

18. СHÆTOPHORA.

$\S$ Jelly mass globose or nearly so $(a)$.

$\$$ Jelly mass elongated to 3 inches, margins tattered, forming ragged branches . . . . . . . . . . endiviafolia, II7

$\S$ Jelly mass orbicular, small; filaments hair-pointed . longipila, ir8 a. Branches more or less moniliform; jelly mass $2 \mathrm{~mm}$. diameter,

a. Branches not moniliform, radiating $(b)$.

monilifera, I 18

b. Jelly mass smooth $(c)$.

b. " " tuberculose, ends of branches rarely hair-like,

tuberculosa, I 16

c. Diameter of branchlets $6 \mu$; 1.5-3 times longer . pisiformis, I 6

c. " " branches $7-10 \mu ; \mathrm{r}-\mathrm{r} .5$ " ". . . elegans, II6

I9. MICROTHAMNION.

But one species

Kuetzingianum, I 18

20. APHANOCHÆTE.

$\S$ Parasitic $(a)$.

$\S$ Not parasitic $(b)$.

a. Cells globose, a bristle on the back . . . . . . repens, II9

a. Cells various, elongate, curved, worm-like, sub-globose, vermiculoides, II 9

b. Cells globose, or subpyritorm, a seta on the back or apex; in mucus . . . . . . . . . . . . . globosa, II9

2I. GONGROSIRA.

One species Sclerococcus, 120

20. CHROOLEPUS.

a. Cells globose, broadly elliptic or ovate $(b)$.

a. Cells more or less elongate $(c)$.

b. Dull or bright red; diameter $14-22 \mu$

umbrinum, I 23

b. Ash color when dry; diameter 20-25 . . . . moniliforme, 123

c. Diameter of cells more than $25-40 \mu$; branches rather dichotomous,

Iolithus, 122

c. " " " less than $25 \mu(d)$. 
d. Stratum tawny red, drying greenish; diameter of nilaments 9-14 $\mu$, odoratus, 122

d. Stratum orange-red, drying yellow; diameter of filaments $7-9 \mu$, lichenicolus, 122

d. Stratum red or orange, soft, silky; much branched; diameter of cells $10-12 \mu$

aureus, $12 \mathrm{I}$

\section{CLADOPHORA.}

$\S$ Chlorophyll diffused, not in spirals $(a)$.

$\S \quad$ " disposed to be net-like or in lax spirals $(d)$.

a. Cell membrane smooth (b).

a. " " plicate-striate; contents of young slightly spiral, crispata, 126

b. Cells more or less swollen; irregularly branched; variable,

b. Cells not noticeably swollen (c).

fracta, $\mathbf{1} 24$

c. Diameter of branches $28-40 \mu$

c. " " " about $15 \mu$... . . Flotowiana, 126

d. Branches united (connate) at base; cells $5^{-8}$ times as long as broad,

d. Branches not connate at base $(e)$.

canilicularis, II 7

$e$. Filaments not radiating from common centre, cells smooth $(f)$.

e. " " " cell membrane plicate . Alavescens, 128

$e$. " radiating from a common centre, much branched, agagropila, $\mathbf{2} 4$

f. Diameter of stems $60-100 \mu$. . . . . . . glomerata, I 27

f. " " " $\mathrm{I} 20-\mathrm{r} 35 \mu$. . . . . . Aluitans, 128

24. PITHOPHORA.

A. Fertile stem $65 \mu$ thick

A. " " $175 \mu$ thick

A. " " $59 \mu$ thick

Edogonia, $\mathbf{1 3 0}$ aqualis, I3 I

Kewensis, I3 I

24a. SCHIZOMERIS.

One species

Leibleinii, Pl. CXXV.

25. ULOTHRIX.

$\S$ Length of cells equal to width $(a)$.

$\S$ " " " greater than width $(e)$.

$\S$ " " " less than width $(h)$.

$a$. Color dark, light or bright green $(b)$.

a. Color yellowish green $(d)$. 
b. Filaments dividing longitudinally; mucous; 4 in. long, floating, Lenormandi, ${ }^{3}{ }^{8}$

b. " not dividing longitudinally $(c)$.

c. Joints often constricted; diameter of cells 9-1о $\mu$. rivularis, 136

c. Joints not constricted; aquatic; variable; diameter of cells $5-50 \mu$, subtilis, $\mathbf{1} 35$

“

6

filaments tortuous, very long, muralis, $\mathbf{I} 37$

c. " " " On damp walls, pavements, exposed rocks, etc., (*) *. Cells $6-7 \mu$ in diameter; on walls, pavements, etc. . mitens, I 37

*. " $7-9.5 \mu$ " cell contents usually at one side; on exposed rocks, etc. . . . . . . . . . . . flaccida, 137

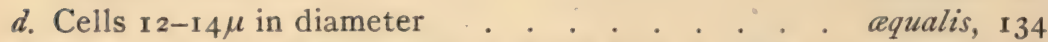

d. Cells about $7 \mu$ in diameter; on moist clay or sand . varia, 138

e. Green, cell contents usually on one side, hemispherical, flaccida, I 37

e. Green, dark, bright or pale; contents diffused $(f)$.

$f$. Joints often constricted; cells $9-10 \mu$ in diameter . rivularis, I 36

$f$. " not constricted; filaments attached, $17-25 \mu$ in diameter,

tenuis, $\mathbf{3} 4$

$f$. " " " filaments not attached $(g)$.

$g$. In brackish water, filaments $\mathrm{I}-3$ in. long, $10-30 \mu$ dia.,

Younganum, $\mathbf{I} 35$

g. In fresh water subtilis, $\mathbf{1} 35$

$h$. Filaments dividing longitudinally, 4 in. long, floating,

Lenormandi, 138

h. " not dividing $(i)$.

$i$. Joints often constricted, cells $9-10 \mu$ in dia.. . . rivularis, 136

$i$. " not constricted in sterile filaments $(j)$.

$j$. Filaments го $\mu$ or more in diameter $(k)$.

$j$. " less than $10 \mu$ in diameter $(m)$.

$k$. In brackish water; filaments $20-30 \mu$ in dia. . Younganum, I 35

$k$. In brackish and in fresh water; filaments $38-50 \mu$ in dia.,

$k$. In fresh water only or on the ground $(l)$.

speciosa, I 35

l. On shaded ground; flexuous, interwoven.

-parietina, $\mathrm{I} 38$

l. Aquatic; filaments $10-12 \mu$ in dia.

oscillarina, 137

l. " " $14-40 \mu$ " . . . . . . . Zonata, I33

$m$. Bright, grass green; filaments tortuous, very long, interwoven,

$m$. Yellowish green, mucous; cells shorter than wide . compacta, I 36 
26. SCHIZOGONIUM.

One species; found on moist cliffs, Colorado

murale, 139

27 CONFERVA.

$\S$ In brackish water; diameter $\mathbf{1} 2-14 \mu$ fugacissima, var. salina, I4 r $\S$ In fresh water (A).

A. Diameter of filament from $3-5 \mu(a)$.

A. " " " " from $6-12 \mu(b)$.

A. " " " from $14-25 \mu(g)$.

a. Very pale; cells $1 / 2-2-3$ times as long as wide . tenerrima, I43 a. " " " $" 4-9$ " " " " " "

a. Green; célls 3-4 " " " " " . . rhypophila, 143

b. Cells before division 7 times as long as wide . . . affinis $\mathrm{r}_{4 \mathrm{I}}$ b. " " " " $4-5$ " " " " " (c).

b. " " " less than 4 times as long as wide $(e)$.

c. Not constricted at the joints . . . . . . . . fugacissima, 14 I

c. Slightly " " " " (d).

d. Cells before division about 4 times as long as wide . Funkii, 142 d. " " " " " " " " 5 " filaments of irregular thickness . . . . . . . . . . bombycina, I42

e. Cells more or less swollen $(*)$

e. Cells not swollen, joints not constricted $(f)$.

* Diameter of filaments $10-12 \mu$. . . . . . . . vulgaris, 142

* " " " $7-9 \mu$. . . . . . var. Farlowii, 142

f. Attached; chlorophyll evenly diffused . . . abbreviata, 143

f. Not attached; contents granular . . . . . . punctalis, $\mathbf{I}_{42}^{2}$

g. Diameter of filaments $20-25 \mu$. . . . . . amona, 140

g. " " " less than $20 \mu(h)$.

$h$. Cells more or less swollen, about twice as long as wide, floccosa, I40 $h$. " " " " constricted at the joints,

utriculosa I40; fontinalis, I4I

28 CHÆTOMORPHA.

Marine, therefore omitted.

29 RHIZOCLONIUM.

$\S$ On moist ground; cells I.5-3 times as long as wide,

$\S$ In brackish water $(a)$.

hieroglyphicum, $\mathbf{1} 44$

$\S$ In sweet waters $(b)$.

a. Filaments irregularly curved and angled. California, Casparyi, 145

a. Filaments not specially curved; diameter $20-30 \mu$. . salinum, 145

a.

666

"6

$33-48 \mu$. . major, 146 
b. Permanently attached, in rapid streams

b. Not permanently attached $(c)$.

c. Diameter of filaments $13-15.5 \mu$

fluitans, 145

c.

"

" "6

$25-33 \mu$

fontinali, I 44

$c$.

"

66

36-40 $\mu$

stagnale, 145

Horsfordii, 145

\section{VAUCHERIA.}

I. KEY TO THE STERILE PLANTS.

$\S$ In salt or brackish water; mats velvety, feet in extent,

Thuretii, 149

\& In sweet water or somewhat terrestrial $(a)$.

$\S$ Apparently terrestrial only $(h)$.

$a$. Filaments dichotomous, branches constricted at the base of the divisions, often intermediately, tuberosa, 154

a. Filaments not constricted at the branching points (b).

b. Stratum dense, pellucid below, creeping; terminal branches erect, clustered, often crooked . . . . . . . . velutina, I53

b. Stratum not pellucid below (c).

c. Branches not clustered, vague. Thus far found only in California, hamata, $\mathbf{1 5 3}$

c. Branches dichotomous or sparingly formed $(d)$.

d. Diameter of filaments roo $\mu$ or more $(e)$.

d. " " " less than $\operatorname{roo} \mu(g)$.

e. Diameter 100 to $200 \mu(f)$.

f. Diameter 1 $25 \mu$; tufts dense, dark green . . . geminata, I5I

$f$. " $\quad$ го $\mu$; tufts loose, expanding in all directions, aversa, $\mathbf{1} 49$

f. " $100-200 \mu$; dirty green or brownish; about limestone springs . . . . . . . . . . . . . dichotoma, 149

f. Diameter $180-200 \mu$, often hyaline; drying ash gray . pilus, 153

g. In turfy mats; filaments densely intricate; $50-75 \mu$ in diameter,

sericea, I 50

g. In dense, intricate tufts; filaments dichotomous, $50 \mu$ in diameter,

$g$. In loosely intricate clusters; filaments about $50 \mu$ in diameter, geminata, $\mathbf{1} 5 \mathbf{I}$

$h$. Stratum thin, expanded, filaments about $50 \mu$ in diameter, sessilis, ${ }^{5} \mathrm{I}$ Dilluynii, 150

h. " " densely interwoven, dark green terrestris, I53 
II. KEY TO THE FRUITING PLANTS OF VAUCHERIA.

$\S$ Antheridia slightly bent; the opening at top $(a)$.

$\S \quad$ " bent like a horn or hook $(d)$.

$\S \quad$ " not known $(g)$.

a. Oögonia nearly round $(b)$.

a. " not round; oval, of ten rather oblique (c).

b. Oögonla about $100 \mu$ in diameter . . . . . . dichotoma, 149

b. " $125-120 \mu$ " " . . . . . . Thuretii, 149

c. Oögonia $\mathbf{I}-6$, on one side, mouths lateral, produred beak-like,

c. “ erect, mouths not lateral, not produced beak-like, sericea, 150 aversa, $\mathbf{1} 49$

d. Antheridia beside or between the subsessile oögonia $(e)$.

d. Antheridia terminal, with the oögonia on each side or lower down $(f)$.

e. Terrestrial, broadly expanded; antheridia bag-shape or clavate,

Dillwynii, $\mathbf{5}^{\circ}$

e. Aquatic; antheridia short and straight, or elongate and variously curved . . . . . . . . . . . . . . sessilis, $15 \mathrm{I}$

f. Terrestrial only; antheridium long, curved, oögonia on its back, terrestris, 153

$f$. Not strictly terrestrial; fruit on short lateral branchlets,

geminata, $\mathbf{1 5}$

$f$. " " " fruit on short segments on the divided ends of branchlets . . . . . . . . . hamata, $\mathbf{1}_{52}$

g. Branches regularly constricted at base and often elsewhere,

g. Branches not constricted; filaments $180-200 \mu$ in diameter,

tuberosa, 154 pilus, 153

\section{I. BOTRYDIUM.}

One species - granulatum, 155

32. VOLVOX.

One species globator, ${ }^{5}{ }^{8}$

33. EUDORINA.

One species stagnale, I6o

34. PANDORINA.

One species morum, I6 I 


\section{EUGLENA.}

The question as to the animal or vegetal character of Euglena has been debated. The present tendency is to consider it an alga, although the evidence is rather negative than positive. For the present purpose however, it seems best to leave it among the Infusoria, where the older investigators classed it.

36. GONIUM.

One species pectorale, 163

\section{STEPHANOSPHÆRA.}

No forms yet found in this country.

38. CHLAMYDococcus.

a. Cells subglobose, brownish-red, sometimes green; variable, pluvialis, 164

a. Cells globose, red; at first with a hyaline border; on the snow of high peaks, etc. . . . . . . . . . nivalis, 166

39. CHLAMYDOMONAS.

$\S$ With a red pigment spot $(a)$.

$\S$ Without " " " (b).

$a$. Ovate; length twice the width; pigment spot lateral,

b. Pale, whitish green; oblong-elliptical

pluviusculus, $\mathbf{1} 68$

b. Bright light-green $(c)$.

c. Ovate or oval

c. Spherical or nearly so hyalina, 168 tingens, 167 pluviale, 167

40. PEDIASTRUM.

For full descriptions and figures of the species, see Wolle's "Desmids of the United States," from which the following classification is compiled.

$\S$ Apices cuspidate, each cell with one cusp or bristle $(a)$.

$\S$ " " " " two " " " (c).

$\S$ Apices or angles, bidentate; small; cells often 4 . cuspidatum, I54 $\S$ Apices truncate; cells 4 in form of cross, 4-sided; small, tetras, I54 $\S$ Apices concave, undulate $(d)$.

$\S$ Apices bilobed $(e)$.

a. Cells six, ovate or subfusiform, radiately connected; centre closed, simplex, $\mathbf{I}^{52}$

a. Cells six, 5 angled; centre open Sturmii, 153

a. Cells more than six (b). 
b. Outer circle $\mathbf{I}_{4}$, inner 7 , centre closed by I; outer spaces 7 , inner 4 ,

b. Outer circle I 2 , inner 4 , centre open; outer spaces 4 , simplex var., 153

duodenarius, 153

b. Outer circle 14 , inner 7 , centre closed by 4 ; outer spaces 7 , inner 4 , simplex var., I53

c. Marginal cells 2-lobed, each cuspidate; cells 8-I6- I28; centre closed, Boryanum, I 53

d. Perforated by small openings brachylobum, 154

d. No openings; centre closed; muticum, angulosum, 153

e. Perforate by small openings, or centre open $(f)$.

e. Not perforate, centre closed $(g)$.

$f$. Cells r 6-32-64

$f$. Cells 6, centre open

g. Apices converging, space between oval

g. Apices not converging $(h)$.

h. Each apex 2-lobed, sometimes diverging . Ehrenbergii, I54

4I. HYDRODICTYON.

One species utriculatum, 169

42. CEELASTRUM.

a. Cells globose, with interstitial openings microporum, $\mathbf{1} 70$

a. Cells angular, each with a tubercular process cambricum, I 70

43. SORASTRUM.

One species spinulosum, $\mathbf{1} 7 \mathbf{I}$

44. STAUROGENIA.

One species - cruciatum, I $7 \mathbf{I}$

45. SCENEDESMUS.

$\S$ Cells armed with spines $(\bar{a})$.

$\S$ Cells not armed with spines $(e)$.

a. Aquatic (b).

a. On moist sand, Florida; cells 2-4, fusiform,

antennatus, var. rectus, I72

b. Cells oblong, cylindrical, ovate or globose (c).

$b$. Cells, some at least, spindle-shaped $(d)$.

c. Spines recurved on outer cells caudatus, $\mathrm{I}_{72}$

c. Spines straight, single or sometimes two . . . polymorphus, I73

c. Spines straight, three to five . . . . . . . . rotundatus, I74

d. Inner cells fusiform, armed, outer lunate, . . . dimorphus, I73

d. Fusiform, oval or globose; spines straight . . polymorphus, 173 
e. Cells, some at least, fusiform $(f)$,

e. Cells oblong or ovate, obtuse; 3-5 times as long as wide, obtusus, 173

$f$. Cells in a single even row; outer cells lunate . . dimorphus, 173

$f$. Cells usually all alike, acute, 3-6 times as long as wide, acutus, 173

46. SCIADIUM.

a. Attached, umbellate; cells usually straight; base contracted into a short stem . . . . . . . . . . . arbuscula, 174

a. Floating; a collection of umbels connected by a usually straight cell . . . . . . . . . . . . gracilipes, 175

47. OPHIOCYTIUM.

$\$$ One or both ends spinous $(a)$.

$\S$ Without spines $(c)$.

$a$. Both ends spinous $(b)$.

$a$. One end spinous, one end rounded; cells curved or coiled, cochleare, $\mathbf{1 7 5}$

b. Cells arched or nearly straight, ends more or less enlarged, capitatum, 176

b. Cells crescentic, Closterium-like, large . . . . cuspidatum, 176

c. Cells small, curved, often in masses, ends rounded, parvulum, 176

c. Cells long, narrow, repeatedly coiled, ends rounded, circinatum, I 76

48. CHARACIUM.

$\S$ Sessile, no stipe; cells pyriform, apex somewhat produced,

$\S$ Not sessile, stipe present but often short $(a)$.

sessile, $\mathrm{I} 77$

a. Apex rounded or truncate $(b)$.

a. Apex acute $(d)$.

b. Stipe short, scarcely noticeable, end dilated; cells producing a short neck

b. Stipe longer, noticeable $(c)$.

c. Apex produced as a thick neck; stipe brownish yellow,

Pringsheimii, 177

c. Apex always rounded, cells obovate, stipe base not dilated,

c. Apex rounded, truncate when open; stipe hyaline, Nagelii, I $78^{2}$

heteromorphum, 178

d. Producing a short neck; cells ovate acutum, 177

d. No distinct neck; lanceolate or sword-shaped, ends tapering, ambiguum, 177 
$\S$ Aerial forms $(a)$.

49. PROTOCOCCUS.

$\S$ Aquatic $(c)$.

$a$. Cells without gelatinous envelope $(b)$.

$a$. Cells with gelatinous envelope in which they divide; angular from pressure . . . . . . . . . . . angulosa, I8I

b. Common everywhere on trees, fences, etc.; cells yellowish green, viridis, 181

b. On moist old wood; cells dark green; decussately dividing, dissectus, $\mathbf{1} 8 \mathrm{I}$

b. On pots, etc., in green-houses; orange, reddish-brown, yellowish green

c. Beset with small spines or hairs

miniatus, 182

c. Smooth, in gelatinous tegument, vestitus, 183

c. " not in tegument $(d)$.

d. Cells clustered somewhat grape-like

botryoides, 182

d. Cells single, membrane thick, often lamellate Wimmeri, 183

d. Cells varying in size, membrane not lamellate . infusionum, 182

50. POLYEDRIUM.

$\S$ Angles rounded, not spinous $(a)$

$\S$ “ “ $\quad$ bifid or trifid $(b)$.

a. Cells 4 or 5 angled, diameter $35-70 \mu$. . . . . gigas, 184 a. " 4 angled, diameter $8-10 \mu$. . . . . . minimum, I85 a. " 3 angled, diameter $12-15 \mu$. . . . . . . muticum, 185 b. Angles bifurcate, sharply tipped . . . . . bifurcatum, 184 b. " often repeatedly bilobed, hyaline, acute . . enorme, 184 c. Centre scarcely body-like, radii thin, much prolonged,

longispinum, 185

c. Centre distinctly a body; angles spinous . tetragonum, minus, 184

5 I. DICTYOSPHÆRIUM.

a. Cells ovate or subglobose

Ehrenbergianum, 186

a. Cells reniform, about twice as long as wide reniforme, 186

a. Cells oval, often centrally constricted Hitchcockii, 186

52. HYDRURUS.

One very variable species fotidus, $\mathbf{1} 87$

53. PALMODACTYLON.

a. Family of cylindrical, bladder-like radiating cases; cells in $\mathbf{I}$ or more rows . . . . . . . . . . . . . varium, 189

a. Family simple, not branched, more filamentous . . simplex, r89 


\section{TETRASPORA.}

$\S$ Thallus tubular, splitting $(a)$.

$\S$ Thallus irregularly expanded $(b)$.

$\S$ Thallus membranous, saccate, obovate, sinuate, bullose (c).

a. Cells about $16 \mu$ in diam.; ends tapering to a fine point,

a. Cells 8-1o $\mu$ in diam.; yellowish-green

cylindrica, 190

b. Colorless, or green edged

lubrica, $19 \mathrm{I}$

b. Green, rather soft and slippery . . . . . explanata, I9I

c. Dark green, smooth or somewhat warty; cells crowed in $2 \mathrm{~s}$ or $4 \mathrm{~s}$, bullosa, $\mathbf{9} 90$

\section{SCHIZOCHLAMYS.}

Supposed to be a form of Tetraspora.

$\S$ Aquatic $(a)$.

$$
\text { 56. Palmella. }
$$

$\S$ On wet ground or dripping rocks $(b)$.

$\S$ On wet wood . . . . . uvaformis, 193, botryoides, 194

$a$. Irregularly expanded; cells minute $\left(0.75^{-1.00 \mu}\right)$, crowded,

a. Somewhat globose, tuberculate; cells elliptical, 5 by $8 \mu$, hyalina, 193

Mooreana, I 93

b. Thallus expanded or indefinite . . . mucosa, 192, miniata, I93

57. PORPHRYDIUM.

One species; terrestrial

58. BOTRYDINA.

One species; terrestrial . . . . . . . . . . . vulgaris, 195

59. BOTRYCOCCUS

One species; aquatic . . . . . . . . . Braunii, 195

6o. GLœOCYSTIS.

$\S$ Aquatic $(a)$.

$\S$ On wet rocks and walls; cells $3-5 \mu$ in diameter . . rmpestris, 196 a. Dirty or bright green; families $45-90 \mu$ in diameter . ampla, 196 a. " " " " families about $35 \mu$ in diameter, vesiculosa, 196 a. Brownish-yellow or reddish . . . . . . rufescens, 196

61. NEPHROCYTIUM.

Families oblong or elliptical, cells reniform . . Agardhianum, 197 Families subspherical, cells oblong or elliptical . . Nagelii, 197 
62. RHAPHIDIUM.

a. Cells straight or nearly so, length ${ }_{15}^{-20}$ times the diameter,

aciculare, 197

a. " " " " " " $" 20-30$ or more times the diameter, contortum, 198

a. Cells decidedly curved; often crescentic or sigmoid (b).

b. Cells sigmoid, single or $2-4$ connected . . . . sigmoideum, 198

b. Cells more or less crescentic (c).

c. Cells connected back to back, crescentic, sometimes single,

convolutum, 198

c. Cells not connected, long, slender, . . . . . falcatum, I98

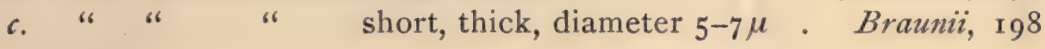

63. DIMORPHOCOCCUS.

One species

cordatus, 199

64. міsснососcus.

One species

confervicola, 200

65. EREMOSPHERA.

One species

viridis, 200

66. UROCOCCus.

a. Stem densely ringed, often divided

Hookerianus, 201

a. Stem short, remotely annulated

insignis, 201

67. ApIOCYsTis.

One species

Brauniana, 202

68. CHYTRIDIUM.

a. On the oögonia of various $Q$ Edogonia; cells somewhat urn-shaped, with a lid

a. On various filamentous Algæ (b).

b. With a low lid; pale yellow

acuminatum, 202

b. Without a lid; cells spherical

minus, 203 globosum, 203

69. OLPIDIUM.

$\S$ On the exterior of the host; cells globose; mouth cylindrical, nearly as long as the cell . . . . . . ampullaceum, 203

$\S$ In the interior of the host; perforating neck tubular, middle globosely dilated . . . . . . . . . intestinum, 203

$\S$ In the interior; perforating neck straight, not inflated, 
70. SPIROGYRA.

I. KEY TO THE STERILE PLANTS.

As it is often difficult to determine the number of spiral bands within a cell of Spirogyra, the following method, originally suggested by "The Botanical Gazette," will be found exceedingly convenient. Select a band near the middle of a cell, count those that cross it, add one to the number, and the result will be the whole number of bands in the cell.

$\S$ Membrane of ce'ls folded in at the ends $(a)$.

$\S$ " " " not folded in at the ends $(j)$.

a. Chlorophyll bands one only (b).

a. " " two or more $(g)$.

b. Membrane of spore smooth $(c)$.

b. " " " punctate $(f)$.

c. Filaments $28-33 \mu$ in diameter; cells 3 to ro times as long as wide,

Grevilleana, 209

c. " $\quad 24-30 \mu$ " " cells $3-9$ times as long as wide,

c. " $\quad 18-28 \mu$ " $\quad$ " $(d)$.

c. " $9-18 \mu$ " "

d. Cells ro-25 times as long as wide; spiral of $1 / 2$ to 4 turns, quadrata, 208

d. Cells $6-\mathrm{r}_{5}$ " " " " " spiral of $3^{\mathrm{T} / 2}$ to 6 turns,

Weberi, 208

e. Cells $4^{-1} 5^{-1 i m e s}$ as long as wide; spiral of $3^{-6}$ turns,

tenuissima, 207

e. " $3-8$ " " " " " spiral of 3-8 turns, inflata, 207

$f$. Diameter of filaments $36-40 \mu$; cells $6-12$ times the diameter, calospora, 209

g. Spirals two $(h)$.

g. Spirals three; cells $30-33 \mu$ wide, $4-8$ times as long as wide, Hassallii, 210

$h$. Cells $16-22 \mu$ in dia., 4-8 times as long as wide, . Hilseana, 209 h. Cells $30-33 \mu$ " " $4-8$ " " " ". . Hassallii, 210

$h$. Cells $3^{6-45} \mu$ in diameter $(i)$.

i. Cells 4-1 2 times as long as wide . . . . . . . insignis, 2 Iо $i$ " $3-5$ " " " " " . . . . . . . Hantzschii, $2 \mathbf{1} \mathbf{I}$

$j$. One spiral in each cell $(k)$.

$j$. Two or more spirals in each cell $(t)$. 
$k$. Membrane of spore smooth $(l)$.

$k$. " " " punctate $(s)$.

l. Cells less than twice as long as wide $(m)$.

l. Cells twice or more " " " " $(n)$.

$m$. Diameter $22-25 \mu$; $1-1 / 2$ times as long as wide, . subsalsa, 212 $m$. " $25-33 \mu ; \mathrm{I}-2 \mathrm{I} / 2$ " " " " " . varians, $2 \mathrm{I} 2$ $m$. " $\quad 33-40 \mu ; \mathrm{I}-2$ rarely 6 " " " " " " " quinina, $2 \mathrm{I} 3$ $m$. " " $48-75 \mu ; \mathrm{I}-\mathrm{I} 1 / 2$ times " " " " . condensata, 2 I 5 .

$n$. Diameter $33 \mu$ or more $(o)$.

$n$. " less than $33 \mu(q)$.

o. Diameter $33-40 \mu$; I-2 rarely 6 times as long as wide, quinina, 2 I 3 o. " $\quad 30-55 \mu(p)$.

$p$. Cells $3^{-7}$ times longer than wide; spiral dentate. Lutetiana, 2 I 4 p. " $2-4$ " " " " fusco-atra, 2 I 5.

$q$. Cells $3-5$ times as long as wide $(r)$.

$q$. Cells $2-12$ times as long as wide $(g g)$.

$r$. Diameter $22 \mu$ or less . . flavescens, gracilis, $21 \mathrm{I} ;$ communis, 213 $r$. " $24 \mu$ or more . . ... varians, 2 1 2 ; Jurgensii, 213 s. Diameter of cells $24-27 \mu, 6-\mathbf{I} 2$ times longer than wide, punctata, 2 I 5

t. Spirals $2(u)$.

t. " $3(x)$.

t. " $4(a a)$.

t. " $5(e e)$.

t. " 6 or more $(f f)$.

$u$. Diameter of cells $40 \mu$ or less $(v)$.

u. " " " more than $4 \circ \mu(w)$.

v. Cells 2-4 times as long as wide decimina, 2 I 6 v. " 4-I4 " " " " " " ". elongata, $22 \mathrm{I}$ w. Cells $1-2$ times as long as wide subaqua, 2 I 7 w. " $1.5^{-2.5}$ " " " " " . . . . . . . . . dubia, 220 $x$. Cells $90-100 \mu$ in diameter, joints somewhat constricted,

$x$. Cells $5 \circ \mu$ or less in diameter $(y)$.

jugalis, 219

$x$. Cells more than $50 \mu$ in diameter $(z)$.

y. Cells 7-I I times as long as wide rivularis, 220

$y$. " less than 7 times as long as wide dubia, adnata, 2 I 7

z. Cells $\mathrm{I}-2$ times as long as wide

z. " $2-3$

z. " $2-5$

2. 66

$2.5-10$ "

66
66
66

66

$\begin{array}{ll}6 & 6 \\ 6 & 66 \\ 6 & 66\end{array}$

subaqua, 2 I 7 orthospira, 218 neglecta, 226 majuscula, $22 \mathrm{x}$ 
$a a$. Cells more than $100 \mu$ in diameter $(b b)$.

aa. " from 72 to $100 \mu$ " " $(c c)$.

aa. " less than $70 \mu$ " " $(d d)$.

bb. Cells ${ }_{5} 5^{0-1} 5^{6} \mu$ in diameter (the largest species) . . crassa, 219 bb. " $102-110 \mu$ " " . . . . . . . setiformis, 219 cc. Cells $90-100 \mu$ in diameter . . . . . . . . . jugalis, 219 cc. " $72-78 \mu$ " " $" \mathrm{I}-3$ times as long as wide nitida; $2 \mathrm{I} 7$ cc. " $75 \mu$ " " $2-4$ " " " " parvispora, $22 \mathrm{I}$ $d d$. Cells $58-65 \mu$ " " . . . . . . . . orthospira, 218 dd. " $33-38 \mu$ " " . . . . . . . . fuviatilis, 216 ee. Cells $65-78 \mu$ in diameter . . . . . . . . . bellis, $2 \mathrm{I} 7$ ee. " $58-65 \mu$ " " . . . . . . . orthospira, 218 $f f$. Filaments of two diameters, one i $25 \mu$, the other $80 \mu$,

incqualis; 218

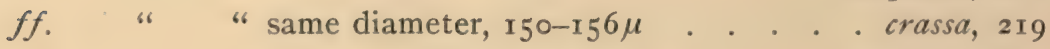

ff. " " " " " "

$f f$. " " " " "

$f f$. " " " " $\quad 54-62 \mu$. . . . . majuscula, $22 \mathrm{I}$

gg. Cells 4-10 times as long as broad, $24-27 \mu$ diam. . mirabile, 2 II gg. " 2-I " " " " " $25-30 \mu$ diam. . longata, 2 I 4

II.-KEY TO FERTILE FILAMENTS OF SPIROGYRA.

For method of determining the number of bands in the cell, see the Key to the sterile filaments of Spirogyra, p. $5^{6}$

$\S$ Cell membrane folded in at the ends $(a)$.

$\S$ " " not folded in at the ends $(j)$.

a. Chlorophyll band single, rarely double $(b)$.

a. " " " two or more $(h)$.

b. Membrane of spore smooth $(c)$.

b. " " "

c. Spores elliptical or fusiform $(d)$.

c. " " ovate or oval $(e)$.

d. Spore $24-30 \mu$ by $50-58 \mu$. . . . . . . . tenuissima, 207

d. " $30-36 \mu$ in dia., twice as long . . . . . . inflata, 207

d. " $27-32 \mu$ in dia., $2-4$ times as long . . . quadrata, 2 c8

e. Spore-bearing cells inflated $(f)$.

e. " " " slightly dilated; spore $26-30 \mu$ in dia.,

Weberi, 208

f. Spores $36 \mu$ in diam., 2-3 times as long as wide . Spreeiana, 208 f. " $30-36 \mu$ in diam., 2-2 $1 / 2$ " " " . Grevilleana, 209 
g. Mature spores yellow or orange, $40-42 \mu$ in dia. $2-3$ times longer, calospora, 209

$h$. Spore-bearing cells not swollen, spores twice as long as wide, Hantzschii, 2 I I

$h$. Spore-bearing cells swollen $(i)$.

i. Mature spore yellow, $42-48 \mu$ long . . . . . . Hassallii, 2 ro

$i$. " " brown, elliptic, $28 \mu$ in diameter . . . insignis, 2 Iо

$j$. One chlorophyll band in each cell $(k)$.

$j$. Two or more " " " " " $(v)$.

$k$. Membrane of spore smooth (l).

k. " " " punctate $(u)$.

l. Mature spore yellow $(m)$.

l. " " not yellow $(p)$.

$m$. Spore cell slightly swollen on one side, spore oval, twice as long as wide

$m$. Spore cell not swollen $(n)$.

$m$. Spore cell swollen $(o)$.

$n$. Filaments $20-22 \mu$ in diameter

communis, $2 \mathrm{I} 3$

$n$. "25-30 " " .

longata, $2 \mathrm{r} 4$

๑. Filaments $24-26 \mu$ in diameter Jurgensii, 2 I 3

o. " $40-43 \mu$ " " . . . . . . . . Lutetiana, 214

$p$. Spore-bearing cell decidedly swollen $(q)$.

$p$. " " " not or slightly swollen $(r)$.

p. " " " " swollen on one side only . . . varians, $2 \mathrm{I} 2$

$q$. Filaments $24-27 \mu$ in diameter . . . . . . mirabile, $2 \mathrm{II}$

q. " $13-20 \mu$ " " . . . . . . flavescens, $2 \mathrm{II}$

$r$. Filaments more than $30 \mu$ in diameter $(s)$.

$r$. " $3 \circ \mu$ or less in diameter $(t)$.

s. Diameter of filaments $33-40 \mu$; spores polymorphous, quinina, 2 I 3

s. " " " $40-55 \mu$; spores polymorphous,

fusco-atra, 215

s. " " " $\quad 48-75 \mu$; spores broadly elliptic,

condensata, 2 I 5

$t$. Diameter of filaments $25-30 \mu$; spore twice as long as wide,

longata, 2 I4

t. " " " $22-25 \mu$; spore slightly longer than wide,

subsalsa, 2 I 2

u. Mature spore yellow, spore cell much inflated, . punctata, 2 I 5

v. Spirals $2(w)$.

ข. “ $3(y)$.

v. " $4(e e)$. 
ข. “. $5(i i)$.

v. “ 6 or more $(j j)$.

$w$. Spore-bearing cells inflated, spore elliptic or ovate, elongata, 22 I $w$. " " " not or only slightly swollen $(x)$.

$x$. Filaments $32-40 \mu$ in diam. . . . . . . decimina, 2 I6 $x$. " $43-50 \mu$ " ". . . . . . . . . . dubia, 2 I 7 $x$. " $55-60 \mu$ " ". . . . . . . . . subcequa, 220 $y$. Mature spores yellow, oval, $1 / 2$ longer than wide . neglecta, 2 I 6 $y$. " " not yellow (z).

z. Diameter of filaments $90-100 \mu$; spore oval jugalis, 2 I 9 z. " " " $40-65 \mu(a a)$. z. " " " " $32-36 \mu(d d)$.

$a a$. Spore orbicular, flattened orthospira 2 I 8

$a a$. Spore not flattened $(b b)$.

bb. Spore spherical or broadly ovate subaqua, $2 \mathrm{I} 7$

$b b$. Spore not elliptical or ovate $(c c)$.

cc. Spore oval-elliptical or subcylindrical . . . dubia, adnata, 220 cc. Spore oval or subglobose, spore cells $2-4$ times longer than wide, majuscula, 221

$d d$. Sterile cells $7-\mathbf{I}$, fertile cells about 4 , times as long as wide, rivularis, 220

ee. Spore-bearing cells much inflated, spore oval, $80 \mu$ long,

ee. " " " slightly or not inflated $(f f)$.

$f f$. Spore flattend, orbicular

fluviatilis, 216

$f f$. Spore not flattened $(\mathrm{gg})$.

$g g$. Diameter of filaments $150-156 \mu$

orthospira, 218

gg. " " " " $102-110 \mu$

crassa, $2 \mathbf{I} 9$

gg. " " " " " $90-100 \mu$. .

gg. " " " " $\quad 72-78 \mu(h h)$.

hh. Chlorophyll bands making $\mathrm{I}-4$ turns in each cell setiformis, 219 $h h$. " " $11 / 2$ " spore $50 \mu$ wide,

nitida, 2 I 7 parvispora, $22 \mathrm{I}$ ii. Spores flattened, orbicular, membrane smooth . . orthospira, 218 ii. Spores " " " punctate or porose, bellis, 217

jj. Filaments of two widths, one $\mathbf{2} 25 \mu$, the other $80 \mu$, inaqualis, 218 jj. " of equal width $(k k)$.

$k k$. Diameter $150-156 \mu$. crassa, 2 I9 $k k$. " $\quad \mathrm{II8-125 \mu .}$ $k k$. " " $102-110 \mu$ $k k$. " " 54-62 maxima, 2 I 8 setiformis, 219 majuscula, $22 \mathrm{I}$ 


\section{I. SIROGONIUM.}

One species

sticticum, $222 z$

72. ZYGNEMA.

§. Color soon becoming dark purple; filaments $20-25 \mu$ in diam.,

$\S$ Color green, or when in fruit yellowish or brownish $(a)$.

purpureum, 224

a. Filaments with gielatinous sheath; cells $25 \mu$ wide, anomalum, 224 a. " " " " " cells $40-44 \mu$ wide, crassum, 224

a. " without sheath $(b)$.

b. Spore membrane smooth $(c)$.

b. " " " punctate or granulate $(d)$.

c. Diameter of filaments $20-22 \mu$. . . . . . leiospermum, 222

c. * * " $626-30 \mu$. . . . . . . insigne, 223

d. Diameter of filaments $10-36 \mu$, very variable . . stellium, 223

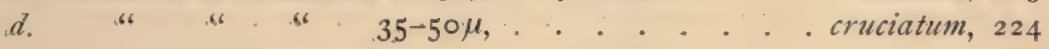

73. ZYGOGONIUM.

$\S$ Diameter of filaments $20 \mu$ or less $(a)$.

$\$$ " " " more than $20 \mu(c)$.

a. Diameter of filaments $\mathrm{I}_{5}-\mathbf{I} 8 \mu$.

Agardhii, 226

a. " " " " $18-20 \mu(b)$.

b. Spore spherical . . . . . . . . . . decussatum, 262

b. " compressed ellipsoid, twice as long as wide . Ralfsii 227

c. Cells slightly constricted at the joints; spore punctate,

c. " not constricted $(d)$.

d. Filaments $30-33 \mu$ in diameter . . . . . . aquale, 226

d. " $\quad 22-24 \mu$ " * . . . . . parvulum, 227

\section{MOUGEOTIA.}

\$ Filaments $20-25 \mu$ in diameter $(a)$.

$\S \quad$ " less than $20 \mu$ in diameter $(b)$.

a. Spore spherical, diameter about $40 \mu$. . . . spharocarpa, 227

a. " " " . . . divarecata, 228

b. Filaments I $^{-1} 8 \mu$ in diameter . . . . . Minnesotensis, 228

b. " $10-14 \mu$ " " 4 (c).

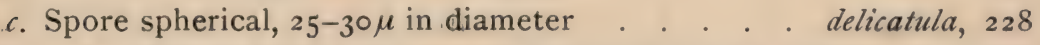

c. " oval, radiately corrugated, yellowish-brown glyptosperma, 229

๔. " " coarsely granular, dark brown . . . verrucosus, 229 


\section{MESOCARPUS.}

$\S$ Diameter of filament $50 \mu$; spore smooth

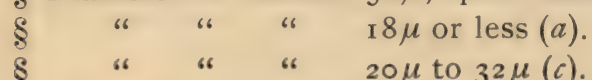

a. Spore membrane punctate; filaments 9-15 4 diam. nummuloides, 23 I a. " " smooth $(b)$.

b. Filaments $8-10 \mu$ in diameter . . . . . . . parvulus, 230 b. " $10-18 \mu$ " 8 . . . . . . . recurvus, $23 \mathrm{I}$ c. Spore membrane punctate; filaments $25-32 \mu$ in diam. robustus, 23 I e. " " smooth $(d)$.

d. With short branchlets from the middle of a cell . radicans, $23 \mathrm{I}$ d. Without branchlets $(e)$.

e. Diameter of spores and filaments about equal . . scalaris, 230 e. " " " twice that of the filaments . macrospora, 230 76. PLEUROCARPUS.

$\S$ Diameter of filaments $25-30 \mu$. . . . . . mirabilis, 232 $\S$ " " " $37-40 \mu$. . . . . . Columbianus, 232

77. PLAGIOSPERMUM.

One species tenue, 233

78. GONATONEMA.

One species ventricosum, 233

79. STAUROSPERMUM.

$\S$ Diameter of filaments $14-20 \mu$, becoming bluish, spore smooth,

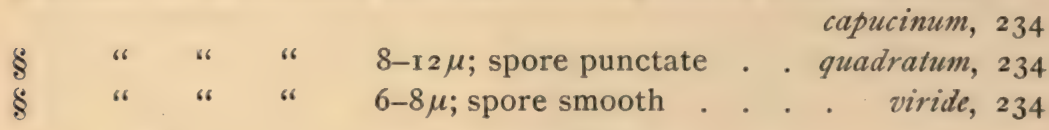

80. CRATEROSPERMUM.

One species - lativerens, 235

8I. CALOTHRIX.

$\S$ Diameter including sheath $6-8 \mu$ at base
$\S$
"
“
" $10-14 \mu(a)$.
“ $\quad 15-30 \mu(b)$.

$a$. Sheath lamellose, ends colorless, torn into fibres; cells $6-8 \mu$ in diam. Meneghiniana, 238

a. " not fibrous at ends; brown or black in mass, gypsophila, 237 a. " " " " " bluish, rarely brownish, Dillwynii, 237 
b. Floating, dichotomously branched, apices slightly bent; diameter $15-20 \mu$

lacucola, 239

b. Attached $(c)$.

c. Ends rounded, obtuse, fibrous with age, bluish . crustaceum, 239

$c$. Ends tapering, or hair-pointed $(d)$.

d. Forming a stratum $(f)$.

d. Forming tufts $(g)$.

f. Branches tapering to a fine hair-point . . . Horsfordii, 239

$f$. " cuspidate at apex or obtuse . . . . Orsiniana, ${ }_{2} 3^{6}$

g. Tufts small, wavering; filaments somewhat curved, clustered, radiating; sheath up to $30 \mu$, wide . . . . . radiosa, 239

g. Tufts bright bluish, sometimes brown; sheath widens with age, Brebissonii, 238

82. MASTIGONEMA.

\$ Filaments rounded or truncate at apex $(a)$.

$\S \quad$ " tapering to a hair-point $(b)$.

a. Sheath thick, apex truncate, open; diam. $8 \mu$. . . fertile, 244

a. " in young plants ending in a seta, becoming open and truncate; diam $\mathbf{2} 2 \mu$. . . . . . . . . . . . Halos, 243

b. Mature sheath becoming fibrillose at the ends $(c)$.

b. Mature sheath not fibrillose or rarely so $(d)$.

c. Filaments $4 \mu$ in diam,; yellowish or greenish; parasitic,

sejunctum, 243

c. Filaments Io-I I $\mu$ in diam.; bluish green; on wet rocks, fiorosa, 244

d. Thallus subglobose or fusiform, blackish, firm; filaments bluish, diam. $6-7 \mu$. . . . . . . . . . . . elongatum, 243

d. Not subglobose; filaments straight, bent or curved, arugineum, 24 I

83. ISACTIS.

a. Filaments closely compacted, suddenly acuminate . fuviatilis, 244

a. Filaments erect, awl-shaped . . . . . . caspitosa, 245

84. GLEOTRICHIA.

$\S$ Sheath irregularly constricted; variable in size and form, natans, 246 $\S$ " close, simple, not inflated nor constracted, subspherical, pisum, 247

85. RIVULARIA.

a. Sheaths inconspicuous; filaments clustered, base about $7 \mu$ diam., echinulata, 249

a. Sheaths distinct; filaments some apparently withered, others more swollen, base $8-9 \mu$ diam.

- dura, 249 


\section{SCYTONEMA.}

$\S$ On warm sandy soil; blackish; diam. with sheath $10-14 \mu$,

thermale, 259

$\S$ On bark of trees, in small, olive green or brown tufts $(a)$.

$\S$ On old wet wood $(b)$.

$\$$ On moist rocks, wall, earth, etc. $(c)$.

$\S$ Submerged in sweet water. $(g)$.

$\S$ Floating in sweet water; diam. of filaments $\mathrm{I} 2-20 \mu$. natans, $25 \mathrm{I}$ \& " " " " " " " $\quad 14-18 \mu$ cincinnatum, 254

$\S$ Brackish or salt; filaments curved and interwoven, chrysochlorum, 253

a. Filaments bluish; branches forming long loops, ends continuous, mirabilis, 255

a. Filaments creeping; branches not looped, ends not continuous,

cortex, 256

b. Diameter of filaments with sheath about $20 \mu$. . intertextum, 258 b. " " " " " " " $" 10-15 \mu$. . simplice, 259 b. " " " " " " " $" 20-25 \mu$. . Heppii, 260

6. Mare or less cushion-like, may become confluent $(d)$.

c. Forming a stratum $(e)$.

६. Tufted or turflike $(f)$.

d. On pots etc. in conservatory; filaments bluish, sheath close, colorless

d. On maist rocks, etc; sheath thick, often with a lime deposit,

cinereum, 258

e. Diameter of sheath $25-33 \mu$, lamellate myochrous, 252

e. Filaments flexuous, long, apices rounded; diam. I 2-I6-25 $\mu$,

cataracta, $25^{2}$

e. « entangled, branches mostly single; cell ends somewhat contracted . . . . . . . . . . . . gracile, 253

e. Filaments interwoven, cells about as long as wide .turfosum, 253 $e$. " " sheath dissolving into fibrils,

Notarissii, 255

f. Branches thi iner, often $1 / 2$ or less than the stem, tolypotrichoides, 250

$f$. Branches thinner at base only, quickly enlarging . Negelii 252

g. Filaments somewhat curved, branches thinner, bluish, calotrichoides, $25 \mathrm{I}$

1

87 SYMPHYOSIPHON.

§. Diameter of filament without sheath $7 \mu$ or less $(a)$.

§. " " " " $"$ " more than $7 \mu(b)$. 
a. Diameter of filaments $2-3 \mu$, of sheath at the base $6-7 \mu$, apex $3-4 \mu$ crustaceus, $26_{3}$ a. " " " $5-7 \mu$. . . . . . . . ambiguum, 262

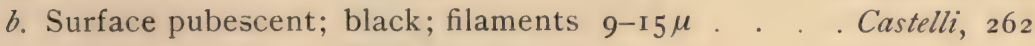
b. " " filaments $15-20 \mu$. ... . Austinii, 262

b. Surface not pubescent $(c)$.

c. Diameter of filaments $15 \mu$ or less $(d)$.

d. Filaments brown, $12-15 \mu$, cells $1 / 2$ as long as wide,

Bornetianum, 26I

d. " bluish, 8-10 $\mu$, cells about as long as wide hirtulus, 26I d. " bluish, 8-12 2 , sheath wider at base . Hofmanni, 262

\section{TOLYPOTHRIX.}

$\S$ On tree trunks, surface velvety, blackish; diam. I I-I $4 \mu$,

truncicola, 266

$\S$ On wet exposed rocks $(a)$.

$\S$ Aquatic $(b)$.

$a$. Reddish brown; filaments with dark transverse bands,

Ravenellii, 265

a. Red, purple and black; filaments much branched . rupestris, 265

b. Spherical, pea-like masses, filaments bluish . Agagrophila, 264

b. Not spherical masses $(c)$.

c. Diameter of filaments $3-4 \mu$. . . . . . . . . tenuis, 265

c. Diameter ro-r $7 \mu(d)$.

c. " 9-II $\mu$, of ten interrupted by inclined disc-like cells, muscicola, 264 d. Impossible to separate here, distorta, 263; pulchra, 264; Alaccida, 265

89. Plectonema.

One species

mirabile, 266

90. PETALONEMA.

One species

alatum, 267

91. SIROSIPHON.

$\S$ Aquatic; brown; cells of stems 2-rowed, in branches I-rowed, ocellatus, 272

$\S$ On old wood and tree trunks; in black spots; often aggregated,

$\S$ In soda springs, west; not fully described Brandegeei, 274

$\S$ On damp soil or wet rocks $(a)$. 
a. Branches polymorphous $(b)$.

a. Branches not polymorphous $(d)$.

b. Apices obtusely rounded $(c)$.

b. " attenuate, or filaments with scattered spines, Alpinus, 269

$c$. Plants attached only by the mucus surrounding them,

c. Plants firmly attached to rocks and stones

pulvinatus, 268

d. Diameter of filaments about $50 \mu$. Alpine coralloides, 270

d. " ". " less thàn $50 \mu(e)$.

e. Cells broadly ovate, moniliform; on wet rocks. compactus, $27 \mathrm{I}$

e. Cells small, not moniliform $(f)$.

$f$. Filaments flexuous, curved, not rigid, branched, $16-17 \mu$,

scytonematoides, $27 \mathbf{I}$

f. " short, intricate; branches many, irregular $(g)$.

g. Mature sheath deep reddish brown, of branches yellowish, apices colorless

argillaceus, 274

g. Mature sheath colorless, hyaline, rarely light yellow crustaceus 274

92. HAPALOSIPHON.

$\S$ Aquatic, often parasitic $(a)$.

$\S$ On tree trunks $(c)$.

$\$$ On wet rocks $(d)$.

a. Diameter of filaments about $15 \mu$; much branched, bluish; sheath often yellowish brown . . . . . Brebissonii, 276

a. Diameter of filaments less than $\mathrm{I}_{5} \mu(b)$.

b. Cells about as long as wide; filaments 10-12 $2 \mu$. Braunii, 275

b. Cells about as long as wide; filaments $7-8 \mu$, branches $3-4 \mu$, tcnuissimus, 277

b. Cells equal to twice as long as wide; filaments $8-1$ I $\mu$ fuscescens, 277

c. Filaments $20-25 \mu$, branches rather thinner . . byssoideus, 276

d. Filaments apt to be solitary, cells moniliform, bluish,

torulosus, 276

93. NOSTOC.

$\$$ Fronds soft, often without definite form $(A)$.

$\S$ Fronds globose or nearly so, or discoid or linear, often irregular with age $(B)$.

$A$. Aquatic $(a)$.

$B$. Aquatic (c).

$B$. Terrestrial (b). 
a. Without 'mucilage; filaments in irregular masses, coiled,

tenuissimum, 282

a. With mucilage; joints equal, rather distant . . comminutum, 282

b. Soft, becoming gelatinous cushions $(e)$.

b. " " tongue-shaped, plane, irregularly expanded $(d)$.

b. With a firm coating $(f)$.

c. Fronds with a firm coating $(g)$.

d. Mature frond suborbicular, often perforated and expanded,

d. " " linear, straight, long; filaments parallel,

commune, 283

flagelliforme, 285

e. Globose thalli within a subspherical gelatinous mass, muscorum, 282

e. Globose, firm; filaments olive . . . . . . humifusum, 282

e. Suborbicular, soft; filaments bluish green . . . . calcicola, 283

f. Globose, firm, coating brownish; joints subspherical,

spharicum, 283

$f$. " soft, sheath often colored and general mucus colorless, rupestre, 283

f. " not $\mathrm{I} \mathrm{mm}$ in diam.; cells cylindrical, slightly constricted, macrosporum, 284

$g$. Cells of two kinds, unequal $(h)$.

$g$. Cells uniform, regular $(i)$.

$h$. One kind elongated, the other spherical; bluish . cœruleum, 284

$i$. Fronds globose, from $2 \mathrm{~mm}$ to size of a cherry . pruniforme, 284 $i$. " rounded or discoid, becoming hollow $(j)$,

$j$. Fronds subglobose, warty, brownish green . . verrucosum, 284

$j$ Fronds suborbicular, erect, smooth, tenacious . . Alpinum, 285

\section{ANABENA.}

$\S$ On tree trunks, near the water's edge, bluish . cupressaphila, 288 $\S$ In brackish ditches; stratum bluish . . . . oscillarioides, 288

$\S$ In sweet waters $(a)$.

a. Cells $3-4 \mu$ in diameter (b).

a. Cells $4-$ I r $\mu$ in diameter $(c)$.

b. Deep blue green; filaments curved, almost parallel,

variabilis, 287

b. Pale bluish, sometimes yellowish; filaments curved, usually in clusters . . . . . . . . . . . . stagnalis, 288

c. Filaments curved, often coiled . . . . . flos-aqua, 286

c. Filaments straight, often coiled when young . . gigantea, 287 


\section{SPHEROZYGA.}

$\S$ Filaments in $2-4$ in. long, vertical, closed tubes, $1 / 4$ in. thick, more or less attached . . . . . . . . . . . saccata, 290

$\S$ Filaments straight, in a definite gelatinous sheath; joints subspherical, spores cylindrical . . . . . . . Smithii, 290

$\S$ Filaments equal, curved or coiled in thin bluish stratum,

Hassallii, 289

$\S$ Filaments subsolitary or associated, bluish, variously curved, polysperma, 289

96. APHANIZOMENON.

One species

flos-aqua, $29 \mathrm{I}$

97. NODULARIA.

One species paludosa, 29

98. CYLINDROSPERMUM.

$\S$ Spores about I $4 \mu$ in diam.; cells $3-4 \mu$.

macrospermum, 292

$\S$ " “ $10 \mu(a)$.

a. Diameter of cells about $4 \mu$. . . . . . . Alexuosum, 292

a. " " " $3 \mu$; terminal cells with flexible, hair-like filaments

comatum, 293

\section{CRENOTHRIX.}

One species polyspora, 294

IOO. CHAMÆSIPHON.

\&ength $16-17 \mu$

$\S$ " $25-35 \mu$

incrustans, 295 confervicola, 295

IOI. LYNGBYA.

$\S$ In brackish water; filaments rigid, curved; cells 3-4 times wider than long, diam. $20-28 \mu$. . . . . . estuarii, 296

$\S$ On moist ground or wet rocks $(a)$.

$\S$ Aquatic $(g)$.

§. Marine . . . . . majuscula, 297; vermicularis. Omitted.

a. Stratum bright green; filaments 8-10 $\mu$ in diam. . arenarium, 299

$a$. Not pure green $(b)$.

b. Stratum blue green $(c)$.

$b$. Stratum blackish green (e).

b. Stratum blue, red, purplish, olive, brown or becoming yellow $(f)$. 
c. Filaments $4 \mu$ in diameter, curved; substratum whitish,

c. Filaments $3-3.5$ in diam., slightly curved inundata, $3 \circ 3$

c. Filaments $7-8$ in diam. $(d)$.

d. Cells finely punctate; on rocks . . . . . .. . ruprestre, 300 d. Cells not punctate, joints somewhat contracted; moist ground, Fla.

subtorulosa, 300

e. More or less radiating; apices obtuse . Juliana, 301; Retzii, 302 f. Filaments straight, sheathed, $5-9 \mu$ diam. . . . . vulgaris, 300 $f$. " slightly curved or flexuose; with sheath $40-80 \mu$ diam., pallida, 298

f. " $\quad$ forming a purple stratum, long, waving, 8-9 $\mu$ diam., tinctoria, 3 ОI

$g$. In alpine lakes or marshes cincinnata, 296

$g$. Not alpine $(h)$.

$h$. Tufted on stones; filaments $40-45$ to 50-60 $\mu$ diam. . Wollei, 297 $h$. In a stratum or floating singly $(i)$.

$i$. Filaments $\mathrm{I} 2-\mathrm{I} 8 \mu$ diam. obscura, 298 $i$. " 7-9.5 diam., matted; wet marsh bottoms,

$i$. $\quad$ 5-7 diam. $(j)$.

phormidium, 299

$j$. Stratum thin, paper-like, substratum, pallid, of empty sheaths, papyrina, 302 $j$. " membranous, mucous, filaments yellowish,

interrupta, 302

IO2. SYMPLOCA.

$\S$ Stratum dull green or blackish; filaments $4-6 \mu$ diam.

Friesiana, 304 $\S$ Stratum bluish green; filaments $3-4 \mu$, lucifuga, 303; fuscescens, 304

IO3. MICROCOLEUS.

$\S$ On rocks or moist earth $(a)$.

$\S$ Aquatic $(b)$.

a. Diameter of filaments $3 \pi / 2$ to $4 \frac{1}{2} \mu$. . . . . anguiformis, 306 a. " " " $5-6 \mu$. . . . . . . terrestris, 305 a. " " " $12 \mu$. . . . . . . Ravenellii, $3 \circ 7$ a. " " " " b. Stratum cushion-like, large, $6-8$ in. or more in diam., 
b. " " thin, skin-like, expanded .

b. " dense gelatinous, on partly submerged stones, heterotrichum, 307

\section{OSCILLARIA.}

$\S$ Articulations indistinct $(a)$.

$\begin{array}{lll}\S & \text { about as long as wide }(c) . \\ \S & \text { " } & \text { one-half " " " " } \\ \S & \text { " less than half as long as wide }(j) .\end{array}$

$a$. In hot water from waste steam pipes; diam. г.8-2.8 $\mu$,

a. Not in hot water $(b)$.

b. Filaments $\mathbf{I}-\mathbf{I} .5 \mu$ in diam.

amphibia, 310

b. " $\quad 1.8-2.5 \mu$ in diam.

subtilissima, $3 \circ 9$

b. " $2 \mu$ in diam.

tenerrima, $3 \circ 9$

c. Diameter $2.8-3 \mu$, rarely $3.5 \mu$

detersa, 3 10

c. "

$2.7-3.2 \mu$

elegans, 3 ro

c. " "

$3 \mu$

gracillima, 3 I I

c. " $4.5-5.5 \mu$; on moist ground chlorina, leptotricha, 3 I I

d. Floating on hot water; diam. 6-7 $\mu$

antliaria, 310

d. On wet ground (e).

d. Aquatic $(f)$.

e. Diameter $4.5-5 \mu$; on shaded mud

brevis, 3 I 2

e. " 4 4-4.7 $\mu$; in greenhouses violacea, 3 I I

e. " $6-7.75 \mu$; in swampy places

limosa, 3 I 3

e. " $\quad 7-8 \mu$; wet grounds, Fla. chalybea, 3 I 4

$f$. In large jelly masses; diam. $4-5-6 \mu$ cruenta, 3 I 2

$f$. Not in distinct jelly masses $(g)$.

$g$. Stratum black $(h)$.

g. " bluish or not black $(i)$.

$h$. Filaments with two short cilia at the end; diam. 4.6-6.6 $\mu$,

h. Filaments without cilia; diam. 9-10 subfusca, $3^{\mathbf{I} 2}$

$i$. Diameter 9-I I $\mu$; stratum thin

i. " " $\quad 5.5-8.2 \mu$

i. " $\quad 4-5 \mu$

nigra, 3 I 5

$j$. In brackish or submarine waters $(k)$.

$j$. In sweet waters $(l)$.

k. Diameter $38-20 \mu$

Grateloupii, $3 \mathbf{1 6}$

k. $\quad$ I $2-15 \mu$

littoralis, 3I 7 
l. Diameter $30 \mu$ or more $(m)$.

" less than $3 \circ \mu(n)$.

$m$. Cells $\frac{1}{4}$ to $\frac{1}{5}$ as long as wide; diam. $30-45 \mu$. . . princeps, $3 \mathrm{I} 7$

$m$. Cells about $\frac{1}{9}$ as long as wide . . . . . . . imperator, $3 \mathrm{I} 7$

$n$. Diameter less than $19 \mu(o)$.

$n$. " $\quad$ r $9 \mu$ or more $(p)$.

o. Diameter $15 \mu$; cells $1 / 3-1 / 4$ as long as wide . . percursa, $3 \mathrm{I} 5$

o. " г $10-\mathrm{r} 8 \mu$; variable . . . . . . . Fralichii, 3 I5

p. Diameter $19-22 \mu$; cells $1 / 3-1 / 4$ as long as wide . . major, 3 I 6

p. " $23-28 \mu$; cells $\frac{1}{4-\frac{1}{5}}$ " " " ". Bonnemasonii, 3 I6

105. BEGGIATOA.

a. Diameter of filaments $\mathrm{I}-\mathrm{r} .5 \mu$. . . . . . . niveum, $3 \mathrm{I} 8$

a. " " " $1.8-2.5 \mu$. . . . leptomitiformis, 319

IO6. LEPTOTHRIX.

$\S$ In hot waste water, waving, $6 \mathrm{~mm}$ thick . . . hinnulia, 320

$\S$ On old wet walls; filaments strongly curved . . calcicola, 319

$\S$ On wet wood, herbaceous green; diam. $1.8-2.25 \mu$. herbacea, 320

$\S$ Aquatic, sometimes on wet rocks $(a)$.

a. Forming spherical masses, light yellowish, tough, hollow, 4-8 mm diam. . . . . . . . . . . . bullosa, 321

$a$. Forming cloud-like, floating fragile masses, yellowish; filaments about $2 \mu$ diam. . . . . . . . . . . . ochracea, 322

a. Forming a stratum $(b)$.

a. Forming a tuft $(e)$.

b. Filaments $3 \mu$ or more in diam. . . . . . . . . tenax, 3 I9

b. " less than $3 \mu$ in diam. $(c)$.

c. Stratum composed of clusters, light bluish . . . rigidula, $32 \mathrm{I}$

c. " more or less expanded $(d)$.

d. Bluish or greenish above, yellowish or colorless below,

d. Bright bluish, thin, membranaceous

laminosa, $32 \mathrm{I}$

e. Bluish, becoming ye

e. Purple green or amethyst . . . . . . . . tinctoria, $32 \mathrm{I}$

IO6a. ASTEROTHRIX.

One species

Creginii, 322 
I07. SPIRULINA.

$\S$ A continuous, twisted, ring-like band duplex, 323

$\S$ Not continuous but flamentous $(a)$.

$a$. In stagnant water; diameter $7-8 \mu$

Jenneri, 323

a. In sulphur springs; diameter $4-5 \mu$

I08. SPIRILLUM.

One species

undula, 324

IO9. GLEOTHECE.

One species

confluens, 325

I IO. APHANOTHECE.

a. More or less globose, size of a cherry, usually floating,

a. Gelatinous, 4-6 mm thick, in small masses; wet ground,

prasina, 325

pallida, 325

II I. SYNECHOCOCCUS.

One species; on wet rocks

aruginosus, 326

I I2. MERISMOPEDIA.

a. Rarely more than 4-64 cells, $3-5 \mu$ diam. . . . . . glauca, 326

a. Often of 256 geminate cells, $4-4.5 \mu$ diam. . . . convoluta, 326

I I3. CELOSPHÆRIUM.

One species

Keutzingianum, 327

I I . CLATHROCYSTIS.

One species

aruginosa, 327

I I5. GOMPHOSPHÆRIA.

One species

aponia, 328

II6. MICROCYSTIS.

One species; on moist timbers, ground, tree trunks, protogenita, 328

II 7. ANACYSTIS.

a. Cells г $\mu$ in diam; thallus light brown . . . . brunnea, 329

a. Cells $2-3 \mu$ diam. " glaucous or pale bluish . pulvereus, 329

a. Cells $3-4 \mu$ " " globular, margins colorless,

marginata, 329

I 8. POLYCYSTIS.

One species

icthyoblabe, 330 
I I 9. GLœOCAPSA.

These forms have been divided into as many species as there are different colors to the cells or to the integument; they are green, red, black, brown, coppery, orange, yellow, olive, purple or colorless. They have no value as distinct plants, being phases or stages of development of higher Algæ. Mr. Wolle considers them to be spores or macrogonidia, of Sirosiphon . . . . . . . . . . . . 33 r

\section{. I20. APHANOCAPSA.}

\$ Submerged; thallus globose . . . . . . . . Grevillei, 333

$\S$ On wet rocks; thallus expanded . . . . . . . virescens, 333

I 2 I. CHROOCOCCUS.

a. Cell contents bright bluish, becoming brownish; $13^{-25} \mu$ diam. turgidus, 334

a. " " reddish or yellowish brown; $12-16 \mu$ diam.

rufescens, 335

a. " " blue green; $3-6 \mu$ diam. cohorens, 335 



\section{PART III.}

Key to the Genera and Species of the Desmidieæ. 



\section{A KEY TO THE GENERA AND THE SPECIES OF THE DESMIDIE Æ.*}

Plants composed of symmetrical cells, usually constricted in the middle, often of beautiful, ornamental forms, single or conjoined into filiform series, and sometimes involved in a maternal jelly. Asexual multiplication takes place by transverse division, or by separation of the semi-cells, and by development of new parts similar to the mother semi-cells.**

*The greater part of the following key was originally published in "The American Monthly Microscopical Journal," and is here reproduced by permission of the editor.

**Wolle: Desmids of the United States. 


\section{KEY TO THE GENERA OF THE DESMIDS.}

\section{$\S$ Cells united into filaments $(a)$.}

$\S$ Cells not united into filaments $(g)$.

$a$. In a transparent, jelly-like sheath $(b)$.

$a$. Not in a jelly-like sheath $(d)$.

b. Cells with 2 teeth on each narrow end . . . . . Desmidium, 6

b. Cells deeply constricted, almost into two parts $(c)$.

b. Cells not deeply constricted, and without teeth . . Hyalotheca, 3

c. With 'claspers' across the sutures . . . . . . Onychonema, 9

c. Without 'claspers;' cells united by a narrow isthmus, Spharozosma, 8

$d$. Band not twisted; cells with 'claspers' across the sutures,

Onychonema, 9

d. " " cells without 'claspers' $(e)$. .

d. Band twisted; cells triangular or quadrangular . Desmidium, 6

e. Cells barrel or hub-shaped, with I or 2 median bands, Bambusina, 4

e. " " " without bands, the sutures projecting,

Leptozosma, 5

e. Cells cylindrical, sometimes swollen at base $(f)$.

$e$. Cells quadrangular, deeply constricted, often slightly twisted,

Phymatodocis, 7

$f$. Ten to 30 times longer than broad

Gonatozygon, I

$f$. Three to 6 times longer than broad . . . . Genicularia, 2

g. Cell more or less crescentic . . . . . . . . Closterium, I3

$g$. Cell cylindrical, fusiform, dumb-bell or hour-glass shaped (i).

$g$. Cell flattened; orbicular, oblong, or elliptical $(h)$.

$h$. Mostly orbicular or broadly elliptical; centre deeply constricted, the semi-cells 3-5 lobed, the lobes entire or variously incised, Micrasterias, 22

h. Mostly oblong or elliptical; margins wavy, the depressions rounded; ends usually notched or incised Euastrum, $2 \mathbf{I}$ 
$i$. Cell constricted in the middle; no arms nor spines $(j)$.

$i$ " " " with arms or spines $(l)$.

$i$. Cell not constricted; no arms nor spines $(m)$.

j. Cell cylindrical, ends simply notched . . . Tetmemorus, 18

$j$. " . ends rounded, truncate or divided $(k)$.

$j$. Cell more or less dumb-bell, or hour-glass shaped $(p)$.

$k$. Cell 6 to 30 times longer than broad . . . . Docidium, I4

$k$. Cell 2-5 times longer than broad; ends rounded, Calocylindrus, 16

l. Arms 2, 3 or more, radiating . . . . . . Staurastrum, 23

l. Arms none; semi-cells with a central, rounded, truncate or denticulate tubercle; spines usually numerous and marginal,

Xanthidium, 19

l. Arms none; no central tubercle; spines 4 to 8 , two on each end,

$l$. " " " spines 16 , four on each end,

Arthrodesmns, 20

$m$. Chlorophyll in one or more spiral bands . . . Spirotania, I I

$m$. " not in spiral bands $(n)$.

$n$. Surface rough with tooth-like or rounded elevations, Triploceras, I5

$n$. Surface without tooth-like elevations; ends rounded $(o)$.

o. Cells in mucus, short, cylindrical or oval . . Mesotonium, ro

o. Cells not or rarely in mucus . . . . . . . Penium, 12

$p$. End view $3^{-6}$ or more angular $(r)$.

$p$. End view not angular $(s)$.

$r$. Angles obtuse, acute, or with horn-like prolongations,

Staurastrum, 23

s. Margins smooth, dentate or crenate; no spines . Cosmarium, I7 


\section{KEY TO THE SPECIES OF THE DESMIDS.}

I. Gonatozygon.

I. Cells swollen at base, with 6 longitudinal lines of short setæ,

2. Cells not swollen at base $(a)$.

sex-spiniferum.**

a. With hair-like spines clothing the surface . . . . pilosum, 22

a. Without hair-like spines; surface minutely roughened, asperum, 22

2. Genicularia.* Fig, 2.

I. Cells $3^{1} \frac{1}{2}$ to 6 times longer than broad; granules in spirals,

Americana.*

I. Cells Io-I 2 times longer than broad; granules scattered, spirotamia.*

3. Hyalotheca. Fig. 3 .

I. Cells slightly constricted, length $1 / 2$ the width, sides not notched, dissiliens, 22

I. " " " " " sides arched, centrally notched . . . . . . . . . . . hians.**

2. Cells slightly concave, length twice the width . Iundulata, 23

3. Cells not co:istricted, margins straight; sheath wide, mucosa, 23

3. " " " " sheath absent, dubia, 24

4. Bambusina. Fig. 4.

r. Cells hub-shaped, somewhat longer than broad . Brebissonii, 24

2. Cells hub-shaped, nearly twice as long as broad . gracilescens.**

3. Cells subcylindrical, 4 times longer than broad . delicatissima, 25

*Journ. R. Micr. Soc., Dec, $188_{5}$.

**F. W. Algæ, p. 2 I. 
5. Lep'tozosma.

An immature form of Desmidium, 6.

6. Desmidium. Fig. 6.

I. Mucous sheath present

I. Mucous sheath absent $(a)$.

cylindricum, 25

$a$. Cells united by their entire end margins (b).

$a$. Cells united by the outer portions of the ends $(d)$.

b. Cells nearly twice as long as broad . . . . . . longatum, 26

b. Cells less than twice as long as broad $(c)$.

c. Cells in side view quadrate . quadratum, 26; quadrangulatum, 27

c. Cells in side view triangular . . . . . . . . Swartzii, 26

d. Borders crenate or undulate . . aptogonium, 27; diagonum, 159

d. Borders straight, filament twisted . . . . . . Baileyi, 27

7. Рhymatodocis. Fig. 7 .

One species

Nordstedtianum, 28

8. Spherozosma, Fig. 8.

1. Cells twice broader than long, lobes not constricted $(a)$.

I. " " " $"$ lobes constricted near the end,

2. Cells twice longer than broad, in sheath or not . excavatum, 29

2. Cells less than twice longer than broad (b).

a. Cells closely approximate, ends rounded . . . . pulchrum, 29

a. " " " ends truncate, concave, rectangulare, 3 I

a. Cells more or less remote, ends rounded . . vertebratum, 30

b. Ends pointed; semi-cells remote; sinus deep, wide, moniliforme. ${ }^{* *}$

b. Ends rounded, spinous; cells slightly constricted, spinulosum, 3 I

b. Ends rounded, not spinous; cells deeply constricted, filiforme, 29

b. End truncate, concave . . . . . . . . . . Wallachii, 30

b. Ends truncate, not concave . . . . . . . pulchellum.**

9. ONYCHONEMA.* FIG. 9.

I. Cells with spine-like projecting ends

2. Cells without spine-like ends

serratum, 30 Nordstedtianum.†

IO. MESOT ÆNIUM. FIG. IO.

I. Cells cylindrical $(a)$.

I. Cells oval or elliptical, about twice longer than wide, in mucus on wet wood ... . . . . . . . micrococcum, 32

*Mr. Wolle joins this to Spharozosma. † Journ. R. Micr. Sec., Dec., I885.

*F. -w. Algæ, .pp 23 et seq. 
a. Mucous masses floating; cells $2-2 \frac{1}{2}$ times longer than wide, Braunii, 3I

a. Mucous masses mingled with filamentous algæ; cells $3^{-4}$ times longer than wide . . . . . . . . Endlicherianum, 32 a. Mucous masses on wet rocks and mosses; cells 2-3 times longer than wide clepsydra, 32

II. SPIROTÆNIA. FIG. II

I. Spiral band single $(a)$.

I. Spiral bands more than one - obscura, 33

a. Cell 8 to ro times longer than broad

a. Cell 4 times longer than broad condensata, 33 bryophila, 33

I2. PENIUM. FIG. I2.

1. Chlorophyll interrupted by I central transverse band $(a)$.

I.

I.

" "

striate
"6

66

" 3 transverse bands; cytioderm smooth,

interruptum, 35
cytioderm spirally
spirostriolatum.**
in mucus, crassa, 37

6

interruptum, 35
cytioderm spirally
spirostriolatum.**
in mucus, crassa, 37

interruptum, 35
cytioderm spirally
spirostriolatum.**
in mucus, crassa, 37

2. Chlorophyll concentrated into 2 or more nuclei; in mucus, crassa, 37

3 . " diffused $(b)$.

a. Ends truncate, square

6 4 6

truncatum, 35

a. Ends not truncate; cells slightly constricted, sides straight,

a. " " " " " " " cruciferum.**

a. " " " cell not constricted, 3-5 times longer than wide digitus, 34

a. Ends not truncate; cell not constricted, 5-6 times longer than wide . . . . . . . . . . closterioides, 35

b. Cytioderm smooth $(c)$.

b. " with pearly granules in longitudinal rows,

margaritaceum, 34

c. Cells in mucus, diameter $\frac{1}{300}$ to $\frac{1}{400}$ in. $(63-83 \mu) 3$ to 4 times as, long as wide . . . . . . . . . . . oblongum, 34

c. " " " " about twice as long as wide . . . rupestre, 37

c. " " " more than 3 times as long as wide . Brebissonii, 36

c. Cells not in mucus; each semi-cell a truncated cone . tumidum.**

d. Cells oblong, often slightly constricted . . . . lamellosum, 34

d. Cells subcylindrical, in families of various sizes intermingled,

d. Cells subcylindrical, not in families polymorphum, $3^{6}$

d. Cells broadly fusiform, 4-5 times longer than wide, navicula, 36 **J. R. M. S., Feb. '8g. 
13. ClOSTERIUM. FIG. I3, $a, b, c$.

$\S$ Ends not or but slightly produced (r).

$\S$ Ends produced into long, often setiform, beaks (2).

I. Cells straight or slightly curved; ends slightly tapering $(a)$.

I. " " " " " " dorsum convex, ventrum nearly straight $(g)$.

I. Cells conspicuously curved; ventrum concave, with a central inflation (i).

I. Cells conspicuously curved; ventrum without an inflation $(j)$.

2. Body margins equally convex; beaks longer than body, cetaceum, 47 2. " " " " beaks $1 / 2$ as long as the body,

2. Body margins not equally convex $(m)$.

pronum.**

$a$. Length $5^{-12}$ times the width $(b)$.

a. Length more than 12 , less than 20 times the width $(e)$.

a. Length 20 times or more than the width $(f)$.

b. Ends suddenly contracted; cell fusiform, 5 times longer than wide, smooth

- nasutum, 4I

b. Ends not contracted, but tapering, acute; chlorophyll bands severaI, granules in $\mathbf{r}$ row

lanceolatum. 39

b. Ends not contracted, rounded (c).

b. " " "

c. Cell slightly curved. small, 6-12 times longer than wide, smooth, acutum, 44 c. " " " 5-10 longer than wide, smooth, obtusum, 38 c. Cell nearly straight, decussately striate . . . . decussatum, 39 c. " " " smooth, apices obtusely rounded, didymotocum.* d. Cell slightly curved, 6-I 2 times longer than wide, striate; vacuole distinct . . . . . . . . . . didymotocum, 39

e. Cytioderm with 4-5 longitudinal striæ, often with 2 or 3 transverse bands and decussating striæ

angustatum, 40

e. Cytioderm striate; ends slightly incurved; globules about 20 in each, semi-cell, axillary . . . . . . . . . lineatum, 43

e. Cytioderm striate; ends truncate, corners rounded; with three transverse sutures . . . . . . . . . subdirectum.**

f. Diameter $2 \mu$ or less; smooth . . . . gracillima-lavissima.*

$f$. Diameter $3-4 \mu$; slightly curved, smooth, or with $\mathbf{I}-4$ trans. striæ, subtile, $\mathrm{I}_{5} 8$

$\begin{array}{lll}f & \text { " } & 5-6 \mu ; \text { smooth } \\ f . & \text { " } & \text { 10-16 } 6 \mu(\uparrow) .\end{array}$ gracile, 39

*F.-w. Algæ. p. 23 et seq. ** J. R. M. S., Feb. 89. 
$f$. Diameter $18 \mu$; about 30 times as long as wide, smooth, ends rounded

Brebissonii**

f. " " $20-21 \mu$; striated, ends rounded . . prelongum.*

$f$. " $\quad 36 \mu$; about 20 times as long as wide, smooth, ends not curved

Surface smooth; slightly tapering from the middle . strigosum, 42 " longitudinally striate only; diam. II-I $2 \mu$, juncidum, 38 " " " with $\mathbf{I}-4$ trans. striæ; diam. $12-13 \mu$, macilentum, $3^{8}$

$g$. Ends inclined upward at a dorsal depression; ventrum slightly concave; striæ fine, numerous . . . . . . . . turgidum, 4I

g. Ends suddenly contracted to a narrow point; cell slightly curved,

g. Ends not suddenly contracted $(h)$. attenuatum, 4I

$h$. Cytioderm deeply striate; distinctly granulate or areolate, areolatum, 43 h. " more or less distinctly striate; cell linear-fusiform, I5-24 times longer than wide . . . . acerosum, 4I h. Cytioderm 9-1 2 longitudinally costate; cell fusiform, 4-5 times longer than wide . . . . . . . . . subcostatum.*

h. Cytioderm more or less distinctly striate; cell semi-lunar, 5-6 times longer than wide, . . . . . . . . . . Lunula, 40

i. Diameter $\frac{1}{200}$ to $\frac{1}{300}$ in. $\left(75^{-1} 10 \mu\right)$; cytioderm smooth,

Ehrenbergii, 45

l. Diameter $\frac{1}{400}$ to $\frac{1}{625}$ in. $(40-60 \mu)$; globules a single row, moniliferum, 45; Leibleinii, 46 $i$ " " " $\quad$ " c cell curved, rapidly tapering into narrow, somewhat upwardly-curved ends; cell 6-8 times longer than wide . . . . . . . . . . Ralfsii, 46

i. Diameter $\frac{1}{2} \frac{1}{2}$ to $\frac{1}{55}$ in. $(35-45 \mu) ; 2$ or 3 sutures in the middle; about 20 times longer than wide. . . . . . Delpontii.*

j. Cytioderm with many distinct striæ; length 6-16 times the width; vacuole large . . . . . . . . . . striolatum, 42

j. Cytioderm with fine striæ; length $12-16$ times the width; vacuole small

decorum, 43

j. Cytioderm with 5-8 distinct striæ; length 6-8 times the width; vacuole large . . . . . . . . . . . . costatum, 42

$j$. Cytioderm smooth; cell crescent-shaped, often subsemicircular $(k)$. $j$. " " cell not conspicuously crescent-shaped $(l)$.

$k$. Ends separated $7-10$ times the diameter; width $\frac{1}{1200}$ to $\frac{1}{160} \overline{0}$ in. $($ I6-20 $\mu$ ) .

Diance, 44

*F.-w. Algæ, p. 23. 
$k$. Ends separated 7-10 times the diameter; width $\frac{1}{800}$ to $\frac{1}{1000}$ in. $(25-28 \mu)$. . . . . . . . . . . acuminatum, 44

$k$. Cell 6 to 8 times longer than wide, ends obtuse; width $\frac{1}{1785}$ in. $(14 \mu)$

k. Cell 6 to 8 times longer than wide, ends obtuse; width $\frac{T}{2000}$ in. $(12 \mu)$. . . . . . . . . . . parvulum, 45

$k$. Cell 8 to 12 times longer than wide, nearly semicircular, ends sharp; width $\frac{4_{1}}{2500}$ to $\frac{1}{3100}$ in. $(8-10 \mu)$

Venus, 44

l. Cell stout, ends broadly rounded; width $\frac{T}{800}$ to $\frac{1}{1000}$ in. $(25-30 \mu)$, cucumis, 40

$m$. Beaks slender, nearly as long as the body, ends obtuse, curved,

Kuetzingii, 47

$m$. Beaks thin, $1 / 2$ as long as the fusiform body rostratum, 46

I4. DOCIDIUM. FIG. I4.

$\S$ Suture a projecting or conspicuous rim $(a)$.

$\S$ Suture not projecting $(d)$.

a. Cytioderm hirsute; semi-cell with 3 or 4 undulations, spinosnm, $5 \mathbf{I}$

a. Cytioderm not hirsute $(b)$.

$b$. End dentate or crenate; semi-cell with I basal inflation $(c)$.

$b$. " " " semi-cell with 4 regular inflations; teeth on the margin . . . . . . . . . constrictum, 50

$b$. End dentate or crenate; semi-cell with 3 or more inflations; teeth below the margin nodulosum.*

$b$. End truncate or rounded; semi-cell with I or 2 basal inflations,

Trabecula, 48; truncatum, 48

b. semi-cell undulate to the contracted end,

crenulatum, 47

b. " " $"$ " $\quad$ a $1-2$ undulate at base only, Archerii.*

c. End with I tooth on each angle Flowtowii, 49

c. End crenulate with tubercles . . . . . . . . coronatum, 49

d. Cytioderm hirsute; base of semi-cell slightly inflated, hirsutum, 5 I

d. Cytioderm not hirsute $(e)$.

$e$. End dentate or crenate $(f)$.

$e$. End not dentate nor crenate $(j)$.

$f$. Semi-cell with 4 or more inflations $(h)$.

$f$. " with whorls of quadrangular prominences,

$f . \quad$ " with 20 or more constrictions .. . . . costatum, 53
$f$ with $\mathrm{x}$ inflation $(g)$.

$*_{F}$.-w. Algæ, p. 25. 
g. End with numerous pearly teeth or beads . . coronulatum, 49

g. End with prominent teeth, about 3 in view . . tridentulnm, $5^{2}$

$h$. End with 3-5 minute tubercles; semi-cell with 4 or more undulations

$h$. End with toothed angles $(i)$.

Floridense, 159

$i$. Semi-cell with 4 prominent nodes; 8 to ro times longer than wide, nodosum, $5 \circ$

i. " " 4 constrictions; ro-12 times longer than wide, breve, $5 \mathrm{I}$

$i$ " " 8 constrictions; 20-24 times longer than wide, sinuosum, 5 I

j. Semi-cell with I basal inflation $(k)$.

$j$. " $\quad$ " undulate to near the end $(l)$.

$j$. " with 4 larger and smaller undulations; cells $\mathbf{2} 2$ times as long as wide $(m)$.

$j$. Semi-cells not or slightly undulate; densely granulate, breve, ${ }_{15}^{8}$ $k$. Cytioderm densely, irregularly punctate . . . clavatum, 48 $k$. " smooth; ends truncately rounded, margins of ten wavy, Baculum, 49; rectum.* k. " " ends round; cell minute; diam. 7-1 $2 \mu$,

minutum, $5^{2}$ k. " " " " $\quad$ " cell, large; diam. ends $5 \circ \mu$, Woodii*

l. Diameter $\frac{1}{1000}$ in. $(25 \mu)$; about 20 times longer than wide, repandum, $5 \circ$

l. Diameter $\frac{1}{1500}$ to $\frac{1}{1900}$ in. $(13-16 \mu) ; 15-20$ times longer than wide, dilatatum, $5 \circ$

l. Diameter $\frac{1}{2500}$ to $\frac{1}{2000}$ in. $(10-12 \mu) ; 18-20$ times longer than wide, undulatum, $5^{\mathrm{I}}$

$m$. Surface punctate; suture none; ends roundly truncate,

Georgicum.*

I5. TRIPLOCERAS. FIG. I5.

(Mr. Wolle unites this with Docidium, 14.)

I. Tooth-like prominences oblong . . . . . verticillatum, 53 5 . acute gracile, 53

i6. CALOCYLINDRUS. FIG. i6.

$\S$ Chlorophyll homogeneous (I).

$\$ \quad$ divided or scattered in each semi-cell (2).

*F.-w. Algæ, p. 25 et seq. 
I. Length twice the width or less; cytioderm punctate or granulate $(a)$.

I. " " " " " " cytioderm smooth $(b)$. I. $\begin{array}{lllll}6 & 6 & 6 & 6 & 6\end{array}$

cytioderm with $5-7$ costæ,

costatus, 56

I. Length $21 / 2$ or 3 times the width; cytioderm punctate $(c)$.

I. " 4 to 6 times the width; cytioderm smooth . minutus, 54

2. Cell twice or more longer than wide; cytioderm punctate, pseudoconnatus, 55

2. " " " " " cytioderm smooth,

Thwaitsii, 56

a. Semi-cell subquadrate . . . . . . . . . . Ralfsii, 54

a. " cylindrical, rounded; constriction slight . cucurbita, 54

a. " " constriction wide, shallow . . connatus, 55

a. " sub-semicircular; constriction slight; ends rounded or somewhat truncate; end view circular . . . Cordanum, *

b. Cell somewhat fusiform, ends subconically rounded . curtus, 54

b. Cell subcylindrical, ends broadly rounded . . . diplospora, $5^{6}$

c. Cell subcylindrical, ends rounded; nuclei large, single or double,

Clevei, $5^{6}$

17. COSMARIUM. FIG. I7.

$\S$ End view without central inflations (I).

$\S$ End view with central inflations (2).

I. Cytioderm smooth or punctate $(a)$.

I. " more or less verrucose or granular $(f)$.

I. " spinous $(g)$.

2. Cytioderm smooth or punctate $(h)$.

2. " more or less verrucose or granular $(i)$.

a. Chlorophyll diffused (b).

a. Chlorophyll concentrated in $\mathbf{I}$ or more nuclei $(e)$.

b. Margins crenate, undulate, dentate or granulate $(c)$.

$b$. " not crenate, undulate, dentate nor granulate $(d)$.

c. Margin crenate $(s)$.

c. " undulate $(t)$.

c. " granulate $(u)$.

e. " dentate or notched; end truncate, smooth; sides toothed, convex . . . . . . . . . . . . . Reinschii, 68

e. Margin dentate; end 4-spined; sides smooth, convex, aculeatum, 66

$d$. Cell twice or more longer than wide $(j)$.

d. Cell $\mathrm{I} \mathrm{I} / 2$ or less than twice longer than wide $(k)$.

$d$. Cells less than $1 \frac{1}{2}$ times longer than wide $(m)$. 
$e$. Margins crenate, undulate, dentate or granulate $(v)$.

e. Margins smooth; basal angles not toothed $(w)$.

e. Margins smooth; basal angles each with $\mathbf{I}$ tooth or papilla,

Smolandicum, 69

$f$. Verrucæ or granules in patterns, or more or less restricted $(x)$.

$f$. " " " not in patterns; more or less covering the surface $(c c)$.

g. Spines on the whole surface; cell suborbicular; sinus elliptical, aculeatum, 66

g. Spines marginal, conical; centre with 7 granules, and punctate, trachypleurum, 73

$h$. Margins crenate, undulate, or dentate $(j j)$.

$h$. Margins smooth $(l l)$.

$i$. Verrucæ or granules in patterns, or more or less restricted $(n n)$.

$i$ " " " not in patterns, more or less covering the surface $(v v)$.

j. End rounded; semi-cell oblong, sides almost parallel, De Baryi, $5^{8}$ $j$. " " semi-cell spherical, . . . . moniliforme, 60 $j$. " " semi-cell elliptical or oval . cordanum, * oblongum $\dagger$ $j$. End truncate; semi-cell quadrate, sides almost parallel, anceps, 59 j. " " semi-cell pyramidal . . . . . parvulum, 59 k. Cell joined by pellucid bands into families . . . Quimbyii, 61

$k$. Cells not joined into families $(l)$.

l. Ends rounded; semi-cells oblong . . . . . . . cucumis, $5^{8}$ l. " " " semi-cells oval; diameter $\frac{1}{111}$ in. $(23 \mu)$,

Witrockiit

l. Ends truncate; semi-cells pyramidal, sides convex; diameter $\frac{1}{900}$ to $\frac{1}{1132}(22-28 \mu) \quad$. . . . . . . . . . notabile, 66

l. Ends truncate; semi-cells pyramidal, sides convex; diameter $\frac{1}{500}$ to $\frac{1}{300}\left(5^{\circ}-85 \mu\right)$. . . . . . . . . . pyramidatum, 69

l. Ends truncate; semi-cells pyramidal, sides convex; diameter $\frac{1}{1000}$ to $\frac{1}{600}(25-43 \mu)$. . . . . . . . pseudopyramidatum, 69

l. Ends truncate; semi-cells pyramidal; sides straight or slightly concave,

$m$. Cell conspicuously broader than long; semi-cells subsemicircular; side view circular, end view elliptical; diameter $32-38 \mu$,

scenedesmus, 59

m. Cell conspicuously broader than long; semi-cells subsemicircular; side view ovoid; diameter $75-85 \mu$. . . . circulare.**

* Journ. R. Micr. Soc., Dec., r885. † Journ. R. Micr. Soc., Feb., 1886.

** F. W. Algæ, p. 27 et seq. 
$m$. Cell nearly as long as broad; semi-cells rhomboid, sides all equal; șinus deep, wide . . . . . . . rhombusoides.**

$n$. Ends rounded; semi-çell subcircular, sinus a mere notch,

$\begin{array}{lll}n . & \text { " } & \text { " } \\ n . & \text { " } & \text { " } \\ n . & \text { " } & \text { " }\end{array}$

globosum, 6a

semi-cell subsemicircular $(o)$.

semi-cell oval $(r)$.

semi-cell elliptical, or hexagonal-elliptical; cell $\frac{1}{5}$

longer than wide; diam. $25-42 \mu$, sexangulare, 63

$n$. Ends rounded semi-cell elliptical; cell $1 / 2$ longer than wide; diam. $25-26 \mu$. . . . . . . . . . . . . microsphinctum.**

$n$. Ends truncate; semi-cell hexagonal; diameter $\frac{1}{1200}$ in. $(2 \mathrm{I} \mu)$ or less, . . . . . . . . . . . . . polygonum, 65

$n$. Ends truncate; semi-cell triangular; diameter $\frac{1}{500}$ in. $(5 \circ \mu)$ or less. galeritum, $7 \circ$ n. " semi-cell subsemicircular, smooth; sinus deep, narn. row . . nitidulum, 62; psendonitidulum, 62 " " punctate or granular; sinus narrow . . . . . . lobulatulum.*

$o$. Sinus deep, narrow $(p)$.

o. Sinus deep, wide, almost linear; cytioderm smooth, sejunctum, 62 $o$. " rounded or oval; semi-cells lunately curved; cytioderm punctate . . . . . . . lunatum, 65

o. Sinus deep, wide, obtuse; semi-cells widening from a narrow base, inflatum.*

o. Sinus' acute angled, enlarging outwardly, rarely linear,

p. Cell elliptical; basal angles acute perforatum.* $p$. Cell suborbicular; basal angles obtuse; diameter $\frac{1}{250}$ to $\frac{1}{420}$ in. $p$. $(60-100 \mu)$, Ralfsii, 69 66 66 6

$$
\left(30-3^{8}\right)
$$
diameter $\frac{1}{650}$ to $\frac{1}{830}$ in.

$r$. Cytioderm centrally somewhat granular; nucleus I in each semicell, . . . . . . . . . tumidum, 6r $r$ " smooth or punctate; cells small,

bioculatum, 60; tinctum, 61

s. Ends rounded; semi-cells semi-orbicular; crenæ usually 9, undulatum, 67 s. " " semi-cells subsemicircular; margins finely crenulatedentate Wolleannm.*

* Journ. R. Micr. Soc., Dec., I885. † Journ. R. Micr. Soc., Feb., I886.

** F. W. Algæ, p. 27 et seq. 
s. Ends rounded; semi-cells subsemicircular, with 8-io crenulations, Sendtnerianum.*

s. Ends truncate; semi-cells pyramidal; cells small, . . notabile, 66

s. " sides almost parallel; diameter $\frac{1}{650}$ to $\frac{1}{830} \mathrm{in.}$ $(30-38 \mu)$, . . . . . crenatum, 67 s. $\quad$ sides converging; diameter $\frac{1}{1250}$ in. $(20 \mu)$,

Nagelianum, 67

$t$. Semi-cell quadrate, smooth, angles rounded; end retuse or convex, quadratum, 59

t. “ pyramidal or subquadrate; end undulate, Holmiense, 68 t. " " end truncate; diameter $\frac{1}{700}$ to $\frac{1}{800}$ in. $(32-36 \mu)$, integrum, 68 t. " " " diameter $\frac{1}{1000}$ to $\frac{1}{1250}$ in. $(20-24 \mu)$, Hammeri, 79 t. " " end rounded, surface smooth, octogonum.* $t$. Semi-cell pyramidal, punctate, base flat, angles rounded, ansatum, 68; Nymannianum, 79

t. Semi-cell sub-semicircular, end truncate, sides with 2 emarginations; smooth . . . . . . . . . . Braunii.*

u. Ends truncate. Diameter $\frac{1}{830}$ to $\frac{1}{1250}$ in. $(20-30 \mu)$, punculatum, 74 u. Ends convex. Diameter $\frac{1}{1500}$ to $\frac{1}{1800}$ in $(14-16 \mu)$. . lave, 62 $v$. Cell twice as long as wide, rectangular; sinus linear, not widened, sinuosum, 65

v. Cell less than twice as long as wide; semi-cell pyramidal, venustum, 68 $v$. “ “ semi-cell subquadrate, small, Meneghinii, 65

$w$. Sinus narrow, not widened outwardly; cell elliptical, end convex, variolatum 63 ; exiguum, 66 $w$. Sinus widened and rounded inwardly, narrowing outwardly, cell wider than long . . . . . . . . . . obsoletum, 64

w. Sinus widened outwardly; semi-cell oval, base and end convex, contractum, 63 $w$. " " " " base and end flattend, depressum, 64 $w$. Sinus widened outwardly; semi-cell quadrate, Meneghinii, 65 $w$. " semi-cell subsemicircular, end rounded; diameter $\frac{1}{250}$ to $\frac{1}{333}$ in. $(75-100 \mu)$. pachydermum, 70 $x$. Margins crenate or granulate $(y)$.

$x$. Margins not crenate nor granulate $(b b)$. 
y. Central verrucæ none or scattered on each semi-cell (z).

$y$.

" more or less clustered on each semi-cell $(a a)$.

z. Verrucæ none central, marginal I or 2 rows; cell about twice longer than wide . . . . . . . . . ovale, 57

z. Verrucæ none central, marginal I or two rows; cell less than twice longer than wide . . . . . triplicatum, 73; Nordstedtii, * z. Verrucæ centrally scattered, marginal in series of 3 each; semicell quadrate, angles rounded . . . . . . triplicatum, 73 aa. Central verrucæ 3 , in a single row; surface smooth, Donnellii, 7 I $a a$.

3,2 above the base; punctate between,

polymorphum.*

$a a$.

5 , in 2 transverse rows, a row within the margin, quinarium.*

$a a$.

“

6 , in a triangle, apex toward the isthmus,

polymazum, 70

$a a$.

“

6 or 9 , in 2 or 3 transverse rows; marginal rows I or 2 ; semi-cell semicircular, Kitchellii, 72 ; suborbiculare 78 aa. Central verrucæ Iо; semi-cell semicircular, end truncate, anisochondrum, 72 $a a$.

66

circularly clustered; semi-cell twice longer than wide, sides emarginate, end truncate . . . . Seelyanum, 73 $b b$. Centre granularly rough and punctate; margin smooth; semi-cells oval

tumidum, 6I

bb. Centre with 3 verrucæ in a row; semi-cells semicircular,

Donnellii, $7 \mathrm{I}$

$b b$. Central verrucæ $\mathrm{I}$ at the isthmus, 8 or 9 marginal in $\mathrm{I}$ or 2 curves, taxichondrum, $7 \mathrm{I}$ $b b$. " " " 5 arched near the margin, 4 below these in the form of a cross . . . . bidentulum.* bb. " $\quad 4$ near the isthmus; semi-cells semicircular; end somewhat truncate; basal angles often pointed,

pseudotaxichondrum, 7 I

$b b$. Central verrucæ 7 , I central, 6 below in a semicircle; ends retuse, smooth . . . . . . . . . . . . oculiferum.*

bb. Central verrucæ $19 ; 7$ larger, central; 12 more or less distinct around them Americanum.*

cc. Chlorophyll diffused $(d d)$.

$c c$. " concentrated into $\mathrm{r}$ or 2 nuclei $(e e)$.

$d d$. Marginal verrucæ or granules rounded $(h h)$.

$d d$. " " conical or pointed (ii).

*F.-w. Algæ, p. 27 et seq. 
$e e$. Cells twice or more longer than wide $(f f)$.

$e e$. Cells less than twice longer than wide $(g g)$.

$f$. Cells cylindrical, sides parallel (sometimes rounded); verrucæ obtuse . . . . . . amœnum, 78 ff. " " " $\quad$ verrucæ emarginate, in lines, elegantissimum, 78

gg. Semi-cells oval or elliptical . . tumidum, 6r ; orthosticum, 78 gg. " $\quad$ semi-orbicular, tetraophthalmum, 75; intermedium, 75 $h h$. Semi-cells pyramidal, end truncate; basal angles rounded, octhodes, 76; Botrytis, 74 hh. Semi-cells oval or elliptical, approximate . . . . trigonum, * margaritiferum, 75; punctulatum, 74 hh. " " " remote, granulate, portianum, 77 hh. Semi-cells quadrangular, ends truncate; diam. $\frac{11}{500}-\frac{1}{342}(60-73 \mu)$, conspersum, 75

$\begin{array}{llll}h h . & \text { " } & \text { ends concave . . . . . retusum.* } \\ h h . & \text { diam. } \frac{1}{830}-\frac{1}{56}(30-45 \mu),\end{array}$
hh. " " diam. $\frac{1}{1920}-\frac{1}{1785}($ I $3-14 \mu)$, pseudobroomei, 86 sphalerostichum.* $h h$. Semi-cells subreniform, sinus widened and rounded inwardly, latum, 76 ; reniforme, 76 ; pardalis. * hh. Semi-cells subspherical, approximate . . . orbiculatum, 77 hh. Semi-cells hemispherical, remote; base flattened, excavatum, 77 ii. Ends and sides with teeth; sinus narrow, widened outwardly; basal angles rounded . . . . . . . Brebissonii, 75 ii. Ends without teeth, sides with ro to 20 ; sinus gaping, dentatum, 76

jj. Margins crenate; semi-cell semicircular, nuclei 2, end truncate, cruciatum, $8 \mathbf{r}$ jj " undulate; sinus widening outwardly, homalodermum, 8I jj. " " $\quad$ " sinus not widening outwardly $(k k)$.

$k k$. Cell longer than wide; diameter $\frac{1}{560}$ to $\frac{1}{650}$ in. $(38-44 \mu)$, sublobatum, 80

$k k$. Cells longer than wide, diameter $\frac{1}{1000}$ to $\frac{1}{1200}$ in. $(22-25 \mu)$, margaritum, 80

$k k$. Cell not longer than wide, end truncate . . . retusum, 80 Il. Diameter $\frac{1}{2000}$ in. ( $\left.12 \mu\right)$, end truncate; sides convex, often obtusely angled centrally . . . . Schliephanckeanum, 82 1l. Diameter greater than $(12 \mu) \frac{1}{2000}$ in. $(\mathrm{mm})$.

*F.-w. Algæ, p. 25. 
umm. Sinus acute inwardly

thithophorum, 80 $m m$. " rounded and widened inwardly . . . . .phaseolus, 8I $\mathrm{mm}$. " rounded, but not widened inwardly, pseudogranatum., I 5.8 $n n$. Margins crenate or dentate $(o o)$.

$n n$. Margins smooth; centre with one verruca; semi-cell elliptical: diameter $\frac{1}{1900}$ in. $(13 \mu)$. . . . . . . bireme, 82 .

oo. Ends truncate; diameter $\frac{1}{750}$ in. $(33 \mu)$ or larger $(p p)$.

oo. " " diameter $\frac{1}{900}$ in. $(28 \mu)$ ór smaller $(r r)$.

oo. Ends rounded, dentate . . . . . . . . Lagoense, *

$p p$. About $\mathrm{I} \frac{1}{2}$ times longer than wide; diameter $\frac{1}{500}$ to $\frac{1}{500}$ in. $(33-50 \mu)$ triplicatum 73 ; speciosum, 87

$p p$. About $\frac{1}{3}$ longer than wide; diameter $\frac{1}{400}$ to $\frac{1}{350}$ in. $(65-70 \mu)$,

supraspeciosum, 88

$p p$. About $\frac{1}{5}$ longer than wide; diameter $\frac{1}{500}$ in. $(5 \circ \mu)$,

pychnochondrum, 89

$r$. Diameter $\frac{1}{925}$ to $\frac{1}{1250}(20-26 \mu)$; ends 4 crenate, sides $4-6$ crenate, subcrenatum, 84 .

rr. " $\frac{1}{1000}$ to $\frac{1}{1250}(20-25 \mu)$; sides nearly straight,

Kjellmanii, 87

$r \%$. $\quad \frac{1}{1600}$ to $\frac{1}{1800}(14-25 \mu)$; granules not radiate; end 4 crenate, Blyttii, 87

ss. Marginal teeth numerous, long, pointed or aculeate, Eloiseanum, 85 ss. „ 17 , emarginate-truncate . . . . quadrifarium, 87 ss. Margins crenate $(t t)$.

tt. Basal inflation granulate in vertical lines (uu).

tt. " " " with scattered granules . . .pseudopectinoides, 89 tt. " " without granules, the marginal in 8 radiating lines, nasutum, 89

uи. Sinus widening outwardly; granules geminate in rows,

pectinoides, 88 uiu " not widening outwardly; cell oblong, diameter $\div \frac{1}{50}(33)$, pulcherrimum, 90 ии. " " " cell orbicular, diameter $\frac{1}{500}(50 \mu)$, radiosum, $9 \circ$

vv. End truncate $(w \%)$.

vv. End not truncate $(z z)$

wre. Diameter $\frac{1}{500}$ in. $(5 \circ \mu)$ or larger $(x x)$.

ww. Diameter smaller than $(5 \circ \mu), \frac{1}{500}$ in. $(y y)$.

*Journ. R. Micr. Soc., Dec., I885. 
$x x$. Sides granulate, concave near the ends; semi-cell twice longer than wide . . . . . . . . . . protractum, 83

$x x$. Sides granulate, end่s concave; semi-cell twice wider than long, biretum var. Floridense.* $x x$. Sides crenate-undulate, converging; cytioderm verrucose,

Quasillus, 84

$x x$. " rounded, acutely toothed, ends usually nude; cell as long as wide.

Everettense, 85

$x x$. " straight, diverging, verrucose; angles rounded, biretum, 86

yy. Cytioderm granulate; cell widest at base, sides converging,

sportella, 83

yy. " " $\quad$ " cell narrowed at base, sides straight, diverging, protuberans, 84

yy. Cytioderm verrucose; end more or less protruding and scolloped (4-crenate) . . . . . . . . . . calatum, 86

yy. Cytioderm verrucose; end more or less protruding, not scolloped, ornatum, 82 ; protractum, 82 yy. " " $\quad$ " end not protruding; semi-cell twice as long as wide, oblong-quadrangular, angles rounded; Broomei, 86

zz. Cytioderm finely granulate or punctate; semi-cells triangular, angles rounded, margins smooth . . . . Turpinii, 158

zz. Cytioderm verrucose; semi-cell subreniform, 3 times as wide as long . . . . . . commisurale, 83 zz. " " semi-cell pyramidal, angles rounded, long, tumidum, 75

zz. " " " semi-cell reniform, angles denticulate, a central inflation granulate : . . . . subcruciforme.*

i8. Tetmemorus. Fig. i8.

$\S$ Cytioderm smooth or very indistinctly punctate $(c)$.

$\S$ Cytioderm punctate $(a)$.

a. Cell 3 times as long as wide, irregularly granular; base slightly plicate.

a. Cell more than 3 times as long as wide $(b)$.

$b$. Front and lateral views fusiform; end with colorless, lip-like projection ... . . . . . . . . . granulatus, 9I

b. Front view cylindrical, not tapering; side view fusiform, tapering; end rounded Brebissonii, 9I

* F. -w. Algæ, p. 27 et seq. 
c. Three times longer than wide, smooth; diameter $\frac{T}{1250}$ to $\frac{T}{1400}$ $(\mathrm{I} 8-20 \mu)$. . . . . . . . . . . . . minutus, 9I

c. Four times longer than wide, smooth; diameter $\frac{T}{520}(48 \mu)$; linear elliptical, no lip . . . . . . . . . . . penioides. ${ }^{*}$

c. Four to six times longer than wide, smooth or indistinctly punctate; front view tapering, lateral fusiform, $\frac{1}{1250}$ to $\frac{T}{113 \Sigma}(20-22 \mu)$, lavis, 91

\section{i9. Xanthidium. Fig. ig.}

$\S$ Spines divided at the ends

$\S$ Spines subulate, ends not divided $(a)$.

a. Spines more or less scattered, numerous - armatum, 92

a. " “

4 within the margins, Columbianum**

a. Spines marginal (b).

$b$. Basal angles with 2 spines $(d)$.

b. " " " I spine $(c)$.

c. Other spiues geminate in 4 pairs

cristatum, 93 c. " " " in 2 pairs on the end, single on the sides,

c. " " not geminate, single on the ends asteptum, 93

d. Other spines 6 to ro pairs on semi-cell; protuberance beaded,

$d$. Other spines 2 to 4 pairs $(e)$.

bisenarium, 93

d. " " none

tetracentrotum, 95

e. Other spines, 4 pairs, terminal

- fasciculatum, 93

e. " " 2 pairs, basal, vertjcal . . . . rectocormutum, 94

e. " " 2 pairs, terminal; a row of granules above the central projection, a spine above the granules, Minneapoliense, 94 $e$. Other spines, 2 pairs, terminal; a row of granules above the central projection, no spine above the granules . polymazum, 94 $e$. Other spines, 2 pairs, terminal, no granules above the projection $(f)$.

f. Diameter $\frac{1}{450}$ in. $\left(55^{-6}-5\right)$ or more, Tylerianum $\downarrow$, fasciculatum, 93

$f$. " $\quad \frac{1}{500}$ in. $(5 \circ \mu)$ or less; semi-cell truncate-triangular,

f. " " " semi-cell not truncate-triangular, antilopaum, 94

*Journ. R. Micr., Soc., Feb., r886.

**F. W. Algæ, p. 34 et seq.

†Journ. R. Micr. Soc., Dec., I885. 


\section{Arthrodesmus. Fig, $20, a, b$.}

$\$$ Cytioderm smooth $(a)$.

$\$$ Cytioderm verrucose or spinous $(b)$.

a. Semi-cell with 2 spines $(c)$.

a. Semi-cell with more than 2 spines $(d)$.

b. Cytioderm with deciduous spines. . . . . . . Rauii, 95

b. " verrucose in rows, margins crenate . quadridens, 96

b. " " " ends alone crenate, notochondrus.**

c. Spines on the same side diverging $(e)$.

c. " " " parallel $(g)$.

c. " " " converging . . . convergens, 95

d. Margin of semi-cell angular, each angle with $\mathrm{I}$ or two spines,

e. End truncate; spines widely divergent octocornis, 97

$e$. End convex; spines moderately divergent $(f)$.

f. Diameter of cell $\frac{1}{625}(4 \circ \mu)$. . . . . . . . . incrassatus. f. " " " $\frac{1}{830}-\frac{1}{714}(30-35 \mu)$. . . . . . subulatus, 96

f. " " $\frac{1}{1250}(20 \mu)$. . . . . . . . ozalis, 96

g. Nuclei, 2 in each oblong-oval semi-cell . . . . . fragilis, 95

g. Nuclei none; semi-cell oval, diameter $\frac{1}{1250}$ in. $(20 \mu)$. oralis, 96

g. " semi-cell orbicular, diameter $\frac{1}{2000}($ I $2 \mu)$,

g. " semi-cell elliptical; spines often very short,

convergens var., 95

g. " $\quad$ semi-cell triangular, sinus wide, isthmus cylindrical, triangularis, $36^{* * *}$

2I. EUASTRUM. FIG. 2 I.

$\S$ End lobe evidently distinct $(a)$.

$\S$ End lobe evidently not distinct $(b)$.

a. End lobe deeply notched $(c)$.

a. End lobe more or less concave or sometimes convex $(g$.

b. End deeply notched $(e)$.

b. End more or less convex; semi-cell with 7 or 8 lateral, short, conical teeth Donnellii, 103

b. End more or less convex; sides without teeth pingue, 105

c. Margins smooth $(d$.)

c. Margins more or less spinous or beaded $(f)$.

c. Margins dentate $(h)$. 
d. Basal lobe deeply notched; basal lobule broadly marginate; central lobule obtsue . . . . . . . . . multilobatum, 98

$d$. Basal lobe undulate $(m)$.

d. " rounded or angular $(t)$.

e. Margins smooth $(k)$.

$e$. " cuspidate, spinulose or beaded $(l)$.

$f$. Basal lobe undulate $(w)$.

$f$. " rounded or angular $(x)$.

g. Margins smooth $(i)$

g. “ cuspidate, spirulose or beaded $(j)$.

h. End lobes horizontal; diam. 45-50 . . . Nordstedtianum, 105 h. " " " h. " " upright, diverging . . ... . . formosum, rо3

$i$. Basal lobes deeply notched $(y)$.

$i$. " undulate $(z)$.

j. Cytioderm rough with conic granules; semi-cells with one large central inflation, a smaller one on each side, two on end lobe, verrucosum, 100

d. Basal lobes undulate $(c c)$.

$k$. " rounded or angular $(e e)$.

l. A short spine on the angles of end and basal lobes divaricatum, r०4 l. A small projection on each side near the apex . compactum, ro7 $m$. Cytioderm more or less tuberculate $(n)$.

$m$. " $\quad$ punctate $(o)$.

$m$. " " smooth $(r)$.

n. Tubercles basal, mostly 5 . . . . . . circulare, ro n. " 5 central, 4 marginal . . . . . . elegans, ro6 $n$. " scattered; end lobe with a tooth on each side,

ornithocephalum.*

o. Semi-cell 5-lobed, basal lobe emarginate, the lateral small, entire, o. “ not 5 -lobed $(p)$.

pinnatum, $9^{8}$

$p$. Basal lobe with I lateral, subcentral tubercle, not emarginate,

ampullaceum, roo p. Basal lobe without lateral tubercle, slightly emarginate, affine, roo p. " " " " not emarginate; diam. $22-25 \mu$, didelta, 99

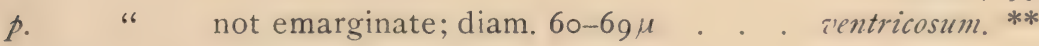
* Journ. R. Micr. Soc., Feb., r886. 
$r$. Semi-cell subrectangular, basal lobe very broad, end lobe partly included between the lateral . . . . . . crassum, 97

$r$. Semi-cell more or less pyramidal $(s)$.

s. Diameter $\frac{1}{500}$ in. or more $\left(5^{\circ}-55 \mu\right)$.

Everettense, 102

s. Diameter less then $\frac{1}{500}$ in.; apical angles acute,

Porkornyanum, ro4; erosum, ro 4

s. Diameter less than $\frac{1}{500}$ in. ; apical angles rounded . elegans, ro6

$t$. End lobe on a long slender neck; basal lobe with 6 protuberances, mammillosum, 102

t. " " " " " " " basal lobe without protuberances,

$t$. End lobe not on a long neck $(u)$.

insigne, 102

$u$. Basal lobe much wider than end lobe $(v)$.

$u$. " scarcely wider; diameter less than $\frac{1}{600}$ in. $(42 \mu)$

v. Basal sinus narrow, basal lobes approximate $(\dagger)$

v. " wide, basal lobes widely separated . intermedium, го 2

$\dagger$ Diameter $\frac{1}{250}$ in., $(1 \circ 0 \mu)$. . . . . . . . . magnificum, **

$\dagger \quad$ " less than $\frac{1}{250}$ in.; no pits on the surface,

$\dagger$ " " " " " 4 pits on semi-cell scrobiculatum, **

w. End lobe beaded: angles of basal lobes beaded. ventricosum, I6o

$w$. " dentate; angles of basal lobes dentate . simplex, го6

$w$. " " smooth, its angles spinous or cuspidate. rostratum, Io6

$x$. Angles of end lobe and margins of basal each with 3 diverging spines, cuspidatum, 105

$x$. " " with short spines, margins of basal dentate or granulate

$x$. Angles of end lobe with one cusp or spine rostratum io6

$y$. Basal and central lobules both slightly emarginate, oblongum, 98

y. Basal lobes slightly emarginate, central obtuse, multilobatum, 98

$z$. End lobe columnar, margins nearly parallel, end truncate, attenuatum, ro3

z. End lobe not columnar, partly included between the lateral lobes, 2. " " 6 not included $(a a)$. oblongum, 98

$a a$. Cell $2-3$ times longer than broad; diameter $\frac{T}{3 \frac{1}{3} 3}$ in. $(75 \mu)$,

humerosum, 99

aa. Cell about twice longer than broad, diameter $\frac{1}{1800}$ in. (14 $\mu$ ),

\begin{tabular}{|c|c|c|c|c|c|}
\hline$a a$. & " & " & " & " & $\begin{array}{c}\text { diameter } \frac{1}{2} \text { in. }(75 \mu), \\
\text { pectinatum. } * *\end{array}$ \\
\hline
\end{tabular}


$a a$. Cell $1 / 2$ or less longer than broad $(b b)$.

bb. Semi-cells urn-shaped; diameter $\frac{1}{500}$ in. $(5 \circ \mu)$. urnaforme, roo $b b$. " $\quad$ more or less quadrate; basal lobes horizontal, emarginate; protuberances minutely granulate . . . gemmatum, ror $b 6$. Semi-cells more or less pyramidal, basal lobes emarginate,

insulare, 104

cc. Angles of end lobe acute :

elegans, ro6

cc. " " rounded or obtuse $(d d)$.

dd. Diameter $\frac{1}{650}$ to $\frac{1}{850}$ in $(32-38 \mu)$. . . . . . inerme, 104

dd. " $\frac{1}{1800}$ in. ( $\left.14 \mu\right)$; length $\frac{1}{900}(28 \mu)$. . crassicolle, 105

dd. " $\frac{1}{1125}$ to $\frac{1}{1250}$ in. $(20-22 \mu)$; length $\frac{1}{900}(28 \mu)$,

ee. Angles of end lobe acute (ff).

compactum, 107

ee. " " $\quad$ obtuse or rounded $(g g)$.

ff. End notch broad, gaping, the apices upright . . binale, ro7

$f f$. " narrow, close, the apices horizontal . . simplex, ro6

$g g$. End broadly rounded, continuous with the sides; diameter $\frac{1}{1800}$ $(\mathrm{I} 4 \mu)$. . . obtusum, 107

go. " " " " " " " shaped; diam. $24-28 \mu$. . . . . . . . . . cuneatum.** gg. End elevated above the sides, a small projection near the apex on each side

compactum, 107

gg. End elevated, no lateral projections

pingue, ro5

22. MICRASTERIAS. FIG. 22. FIVE FORMS.

$\S$ Cell more or less circular (I).

$\S$ Cell oblong (2).

I. End lobe narrow, lengthened into divergent arms $(a)$.

I. " " not lengthened into arms, semi-cells 5-lobed $(b)$.

I. End lobe broad, not lengthened into arms (c).

2. Semi-cell 5-lobed, lobes horizontal; end lobe with 4 arms $(d)$.

2. " " " " " $"$ end lobe with 2 arms $(z)$.

2. " " $\quad$ lobes not horizontal, approximate; no arms $(a a)$.

2. Semi-cell 3-lobed, lobes horizontal; end lobe with 4 arms $(d)$.

2. " " " " $"$ end lobe without arms $(f)$.

a. Semi-cell 5-lobed $(k)$.

a. " 3 -lobed, lobes radiate $(l)$.

$b$. End lobe not or slightly exserted $(t)$.

b. " conspicuously exse:ted $(r)$. 
c. Semi-cells 5 -lobed $(m)$.

c. Semi-cells 3 or obscurely 5-lobed; lateral sinus shallow, obtuse; lateral angles mucronate . . . . . . decemdentata, II3 d. Basal lobes with 3 linear processes on each side. muricata, i 8 d. " without linear processes, but $(e)$.

$e$. Forked once only, margins finely serrate, Mahabuleshwarensis, 1 I 2 e. " " " margins and surface spinous . . . spinosa.** $e$. " " " margins smooth . . . . Nordstedtiana, II3 e. Forked twice (lobules forked); cytioderm spinous . . spinosa.* e. " " cytioderm smooth; margins serrate, Hermanniana, II 2 e. " " " margins not serrate, Americana, I 12 $f$. End lobe nearly as wide as the basal, apices deeply notched $(g)$.

$f$. " " " " " " apices not deeply notched $(h)$. $f$. End lobe much narrower than the basal, end convex, oscitans, 116 $f$. " " " " " end deeply emarginate, $f$. " " " " " " " " " " " " Rabenhorstii.**

g. Basal lobes furcate (with lobules), $(i)$.

g. " " not furcate $(j)$.

$h$. End lobe convex, without prominences

laticeps, 115

h. " truncate, with 2 small prominences .. . recta, 112 h. " . retuse, basal lobe furcate . . . . Baileyi, Ir8 $i$. " with 2 slender, transverse, bidentate projections,

quadrata, II 7

$i$. End lobe without projections, convex; sinuses broadly rounded, Kitchellii, I16 i. " without projections, concave; neck short; sinuses acutish . . . . Rabenhorstii, I 8 i. " " " " neck long; basal lobes curved upwards . . . . . . . . . . . . simplex.* j. Basal lobes horizontal, not curved . . . . pinnatifida, I 6 $j$. " curved upward, narrow, expansa, II7; arcuata, 117 ; simplex.* $k$. Basal and lateral lobes deeply furcate (with lobules), furcata, I I I $k$. " " " " shallowly furcate, surface smooth, (『) $k$. " " " " " surface spinous; diam.,

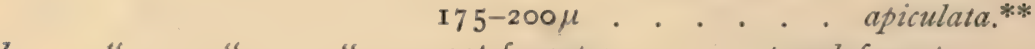
h. " " " not furcate . . . pseudofurcata, III * Journ. R. Micr. Soc., Dec. 1885.

** F.-w. Algæ, p. 36 et seq. 
Lateral and basal lobes separated by a deep acute notch,

Crux-Militensis, I I I

Lateral and basal lobes separated by a shallow rounded notch,

l. Lobules deeply furcate; borders not serrate speciosa.** l. " not furcate, borders not serrate dichotoma, I I I l. " " borders serrate ringens, $1 \mathrm{I} 2$

$m$. End lobe remote from the lateral $(n)$.

$m$. End lobe not remote from the lateral $(o)$.

$n$. End lobe triangular

triangularis, II5

$n$. " not triangular

o. Lobes closely approximate, radiating $(p)$.

$o$.

". "

not radiating, end lobe truncate, truncata, II 4

p. End lobe triangular triangularis, I 15

p. " " cuneate, end concave conferta, II 4

$p$. " $\quad$ very broad, end truncate or convex

$r$. Cytioderm papillose . . hamata, II4

$r$ " $\quad$ not papillose $(s)$.

s. Basal lobes with 4 subdivisions, lateral with 8 ; apices of end lobe furcate

$s$. " 6 rotata, fimbriata, 109

not furcate apices of end lobe apiculata, 1 го

s. Basal lobes with 2 subdivisions, lateral with $4(u)$.

s. Basal and lateral lobes with the same number of subdivision $(v)$.

$t$. End lobe with I row of pearly granules . . . . Minnesotensis. $\dagger$ $t$. " without pearly granules $(y)$.

$u$. End lobe exserted on a long neck

brachyptera, I Iо

$u$. " exserted without long neck, its apices furcate, simplex, r ro v. Margins spinous . . . . . . . . . . . brachyptera, r 10 v. " not spinous . . . . . . . . . . bispinata. $y$. Sinuses deep, inwardly widened and rounded; subdivisions of semi-cell 20-40; surface smooth . . . . . radiosa, 109 $y$. Sinuses deep, inwardly rounded, surface with rounded elevations, mamillata.**

z. Lateral lobe deeply furcate, basal part perpendicular, furcations horizontal; ends bifid .. . . . . . . . . alata.** $a a$. A row of centrally larger basal inflations across each semi-cell, verrucosa.**

$a a$. No basal inflations; minutely granulate Jenneri, II 5 ** F.-w Algæ, p. 38 et seq.

† Journ. R. Micr. Soc., Dec. 1885. 
23. STAURASTRUM. FIG. 23. FOUR FORMS.

With numerous processes, their ends more or less divided ( $\S)$

Without processes, the angles in front view produced or not $(\S)$

$\S$ Cytioderm smooth or finely punctate (I).

$\S$ Cytioderm verrucose or granulate (2).

$\S$ Cytioderm hirsute, spinulose or thorny (3).

$\S \S$ End view 2 -armed, body broadly ovate; arms serrate, apices finely toothed . . . . . . . . Minneapoliense.*

$\S \S$ End view 3 or 4 angled (B).

$\S \S$ End view 5 or 6 -angled, apices of (6) rays rounded and spinulose, Kissimmense.*

$\S \S \quad$ " 5 angled, apices spinous $(G)$.

$\S \S$ End view 6-angled, apices of cylindrical processes slightly notched, 4 processes within the margin; end view hexagonal, Wolleanum.* $\S \S \quad$ " $\S \quad$ apices of $(5-6)$ rays trifid, distended, distentum, I49

$\S \S$ End view 8 -angled; rays a whorl of 8 below, 4 above,

tetroctocerum, $\mathrm{I}_{5} \mathrm{I}$

$\S \S$ End view circular, rays a whorl of 9 below, 6 above, artiscon, 148 $\S \S$ " " $\quad$ rays marginal, very short, usually 9 , ends notched,

Eloiseanum, 149

I. Angles of semi-cell in front view not produced; rounded and smooth $(a)$.

I.

$$
\text { ous or notched }(c) \text {. }
$$

mucronate, spi-

I. Angles of semi-cell in front view produced more or less $(h)$.

2. Angles of semi-cell in front view more or less produced $(i)$.
2.
"
c.
“
" 6
not produced $(g g)$.

3. Angles of semi-cell in front view more or less produced $(o o)$.

3. " " " " " not produced $(y y)$.

a. Semi-cell oval or elliptical, ends not inflated ( 1$)$.

a. " " " ends inflated; diam. $\frac{1}{1000}$ in. $(25 \mu)$, bacillare.*

a. Semi cell semi-circular, smooth, sinus narrow, linear, orbiculare, $\mathbf{2} 20$

a. Semi-cell almost circular, sides finely dentate . . Cosmarioides.*

a. " " " sides smooth . . . . vesiculatum, ${ }^{*}$

a. Semi-cell triangular, sides concave . . . . . trihedrale, 123

a. Semi-cell cuneate; cell slightly longer than wide, 
Diameter 60-1 $12 \mu\left(\frac{1}{400}\right.$ to $\frac{1}{225}$ in.) (b).

" $32 \mu\left(\frac{1}{780}\right.$ in.); granulate-crenate .

luteolum.*

“ $13-16 \mu$ ( $\frac{1}{250}$ to $\frac{1}{1500}$ in.),

muticum, minor, Ir9; Bieneanum, 124

b. Sides slightly constricted near the angles, especially in end-view, tumidum, 120

b. Sides not constructed; diameter $\frac{1}{300}$ to $\frac{1}{333}$ in. $(75-83 \mu)$,

grande, 120

b. " " " diameter $\frac{1}{416}$ in. $(60 \mu)$. . . inerme 122

c. Angles mucronate $(d)$.

c. Angles aculeate, spinous, awned or notched (e).

$d$. Mucros double on basal angles, none on the end in front view; semi-cells truncated triangles . . . . paniculosum, 124 d. Mucros single on all angles, horizontal; diameter less than $\frac{1}{500}$ in. $(5 \circ \mu)$; semi-cells not quadrangular . . . brevispina, I I I

d. Mucros single on all angles, horizontal; semi-cells quadrangular, quadrangulare, 145

d. Mucros single on all angles, diameter larger than $\frac{1}{500}(5 \circ \mu)$,

magnum, $\mathbf{1} 20$

d. Mucros single, oblique downward and inward; diameter $\frac{1}{250}$ $(\mathbf{1 0 0 \mu )}$ or more . . . . . . . . . . majusculum, I $2 \mathrm{I}$

d. Mucros single, oblique downward and outward; diameter $5 \frac{1}{50}$ $(45 \mu)$ or less

Dickiei, 122

e. Aculei or awns I on each angle $(f)$.

$e$.

2 on each angle $(g)$.

e. " $\quad 3$ on each angle (vv).

e. " " 4 or more on each angle (ww).

$f$. Semi-cells elliptical, often angular, approximate; ends straight, concave or convex; awns horizontal, diverging, converging or upwardly oblique; diameter $\frac{1}{656}$ to $\frac{1}{1000}$ in. $(25-38 \mu)$,

dejectum, I $2 \mathrm{I}$

$f$. " " diameter $\frac{1}{455}$ to $\frac{1}{417},(55-60 \mu)$, cornutum.*

$f$. Semi-cells elliptical, separated by a long, narrow isthmus,

cuspidatum, 123

f. " triangular-fusiform; awns long; diameter $\frac{1}{500}$ to $\frac{1}{438}$. $\left(5^{\circ}-57 \mu\right)$. . . . . . . . . . megacanthum, I2I

$f$. Semi-cells triangular; sinus with a small spine on each side,

Lewisii, 122

f. " " sinus without a spine . . aristifcrum, 122

$f$. Semi-cell quadrangular, margins toothed or spinous, 
$g$. Angles in end view trifid trifidum, $\mathbf{1 2 3}$

g. " " " " simple or bifid (ss).

$h$. Arms trifid or bifid; end view $3-4$ radiate; arms smooth, brachiatum, $\mathbf{2} 4$

h. " " " end view 3-radiate; arms aculeate, rough,

h. " " " " end view 5-6 radiate . . . distentum, 149 $h$. " " " end view 7-9 radiate . . . Rotula, I35

h. Arms truncate, oblique, geniculate, short; end view 4-radiate,

inconspicuum, 125

$h$. Arms acute or aculeate, curved; end view 3 -radiate . sudeticum.*

$i$. Ends separated by a more or less elongated isthmus $(j)$.

$i$. Ends approximate $(z)$.

$j$. End view fusiform, with a central obtuse inflation, leptocladum, 136 $j$. " oval, a long arm on each side,

$j$. End view triangular or 3-radiate $(k)$.

grallatorium, ${ }_{3} 6 ;$ ungulatum, 136

$j$. " $\quad$ quadrangular or 4-radiate $(p)$.

$j . \quad$ " $\quad$-radiate $(v)$.

$j . \quad$, "6-radiate $\left(w^{\prime}\right)$.

j. " 7-8 radiate

$k$. Isthmus basally inflated; cuspidate or spinous $(l)$.

$k$. " not basally inflated; cuspidate not spinous $(m)$.

l. Isthmus basally inflated . . . . . . . . . elongatum, r 30

l. " with a I-4 cuspidate protuberance on each side; arms short . . . . . . . . . . fasciculoides, r 30

l. " with I notched spine on each side . . . spinosum, I39

$m$. Diameter $\frac{1}{500}$ in. $(50 \mu)$ or less $(n)$.

$m$. " $\frac{1}{400}$ in. $(60 \mu)$ or wider $(o)$.

$n$. End straightish, sides tapering into short, mostly obtuse processes,

tricorne, 126

n. End broadly convex; processes curved . . . cyrtocerum, 128

n. " " processes straight, slender . . gracile, 133

$o$. In end view the angles produced in long arms,

vestitum, r38; pseudosebaldi, r 39

o. In end view the angles not produced in long arms, Sebaldi, r $3^{8}$

$p$. Isthmus basally inflated or cuspidate $(r)$.

$p$. Isthmus not basally inflated nor cuspidate $(s)$.

$r$. Isthmus basally inflated, corrugated and denticulate, tetragonum, 130

$r$. " with a short spine on each side . . . odontatum, I34 *Journ. R. Micr. Soc., Dec., '85. 
s. Diameter $\frac{t}{800}$ in. $(3 I \mu)$ or smaller $(t)$.

s. $\quad$. $\frac{1}{400}$ in. $(60 \mu)$ or longer $(u)$.

t. End straight, sides tapering into short, mostly obtuse processes, tricorne, 126

t. End convex; processes short, stout crenulatum, 126

t. End concave; processes short, upwardly diverging, pusillnm, I30; Donnellii; I 32

$u$. Processes short, robust, incurved; end of semi-cell truncate,

$u$. " long, narrow, incurved; end of semi-cell convex, cerastes, I 33 ankyroides, 137

u. Processes long, horizontal tetracerum, I34

v. Processes curved, apices bifid pentacladum, I 29 v. " " apices entire incisum, $13^{2}$

v. Processes horizontally radiating; ends of cell with bifid papillæ,

v. Processes horizontally radiating; ends without papillæ, pentacerum, I34 crenulatum, $\mathrm{I} 26$ v. Processes upwardly diverging, the apices bifid . franconium, I3I $w$. Diameter $\frac{1}{625}$ in. $(40 \mu)$ or smaller $(x)$.

w. " $\frac{1}{350}$ in. $(7 \circ \mu)$ or larger $(y)$.

$x$. Isthmus centrally ribbed; rays curved downward . comptum, I 29

$x$. " not ribbed; in end view rays basally separated by an acute incision . . . . . . . . . . . . incisum, $\mathrm{I}_{32}$

$x$. Isthmus not ribbed; in end view rays separated by a rounded sinus . . . . . . . . . crenulatum, 126 y. End with prominent papillæ; diameter $\frac{1}{166}$ to $\frac{1}{180}$ in. $(140-150 \mu)$, Ophiura, $\mathbf{1} 34$

y. End with prominent papillæ; diameter $\frac{1}{294}$ to $\frac{1}{333}$ in. $(75-85 \mu)$, coronulatum, $\mathbf{I} 35$

y. End without prominent papillæ; ray margins serrate,

macrocerum, I34 y. " " " " $\quad$ ray margins granulate-crenate, hexacerum, I37

z. End view oval, ends produced in a long, thin arm, ungulatum, 136 z. " fusiform ............ . . fusiforme, 137

z. End view triangular or 3-radiate $(a a)$.

z. " 4-radiate or angular (ee).

z. " 5-radiate $(f f)$ 
aa. Apices of rays obtuse; diameter $\frac{1}{500}$ to $\frac{1}{650}$ in. $(40-50 \mu)$,

aa. " " " diameter $\frac{1}{1250}$ to $\frac{1}{1562}$ in. $(15-20 \mu)$,

$a a$. Apices of rays not obtuse $(b b)$.

$b b$. End of cell in front view papillose or verrucose $(c c)$.

$b b$. " " " " not papillose nor verrucose $(d d)$.

cc. Diameter $\frac{1}{700}$ in. $(36 \mu)$ or smaller, arcuatum, $130 ;$ subarcuatum, 140

cc. " $\frac{1}{300}$ to $\frac{1}{400}$ in. $(60-80 \mu)$; arms diverging, anatinum, 139

$d d$. End view, sides straight, angles $3-4$ spinous, polymorphum, I 26 $d d$. " sides concave; arms long, straight, in front view diverging . . . . . . . . . . . . . paradoxum, 129 dd. End view, sides concave; arms short, Haaboliense, I3 I ; nanum, I 38 dd. " " sides convex; arms short, tumid at base, Heleanum, I33 $e e$. Apices of arms inconspicuosly bifid or trifid,

Haaboliense, I3I; paradoxum, 129 ee. Apices of arms prominently and deeply trifid . . . Osceolense.* ff. Apices of arms obtuse; the arms mere lobes, very short,

silatatum, 128

ff. " " " arms long, narrow . . . . arachne, 129

ff. Apices of arms bifid; front view end with a crown of papillæ,

Floridense, 135

f. Apices of arms bifid; front view end without papillæ, pentacladum, 136

$g g$. End view 4, 5, 6, or 7 -angular or radiate $(h h)$.

gg. End view triangular (ii).

$h h$. Cytioderm rough with pearly granules; rays $4-7$, short, obtuse, margaritaceum, $\mathbf{1} 25$

$h$. " granulate; end view 4-6 angled, sides straight, Meriani, $\mathbf{1}^{32}$ hh. " " . . end view 4 angled, angles with 2 spines, Nova Casarea, 145 hh. " " $"$ end view 4-5 angled, sides concave, angles without spines . . . . . . . . . dilatatum, 128

ii. Angles in front view notched or otherwise divided $(j j)$.

ii. Angles entire $(k k)$.

*Bulletin Torrey Botanical Club, Dec. 1885 . 
jj. Surface granules emarginate or divided; semi-cells broadly elliptical, asperum, 127 jj. $\quad$ not emarginate; semi-cells elliptic, truncata, I 28 $j j$. " not emarginate; semi-cells subsemiorbicular, angles truncate . . . . . . . . . . . muricatum, 127 jj. Surface scabrous, semi-cells elliptic . . . . . . scabrum, 130 jj. Surface tuberculate; sides at base convex, spinous; a central, spherical, spinous projection conspicuous . . . bullosum.* jj. Surface tuberculate; sides at base concave; no central protuberance..... tuberculatum.* jj. " " " " " not concave, pseudocrenatum.** $k k$. End view sides concave (ll).

$k k$. " " sides nearly straight, very slightly convex $(n n)$.

$k k$. " " sides convex; semi-cells subsemiorbicular,

muricatum, 127

Il. Semi-cells twisted; $2-3$ times longer than wide, elliptic or oblong, alternans, $\mathbf{I}_{2} 8$

Il. Semi-cells not twisted $(\mathrm{mm})$.

$m m$. Front view ends concave; end view angles rounded, striolatum, 126 $m m$. " " $\quad$ end view angles acute, Pringlei, 132 $m m$. Front view ends convex; end view angles crenate, sides smooth, crenatum, $\mathbf{2} 26$ $m m$. " " $\quad$ end view angles not crenate, somewhat truncate . . . . . . . . . . . dilatatum, 128 $m m$. " " $\quad$ end view angles granulate, rounded, erasum.** $n n$. Diameter $\frac{1}{1000}$ in. $(25 \mu)$ or less pygmaum, 128 $n n$. " greater than $\frac{1}{1000}$ in. $(25 \mu)$; end broadly truncate, sides slightly convex or nearly straight, converging,

botrophilum, $\mathbf{1} 31$

$n n$. Diameter greater than $\frac{1}{1000}$ in. $(25 \mu)$; end rounded, sides convex; semi-cell elliptic . . . . rugulosum, I27; punctulatum, 127

oo. End view 3-radiate or angular, sides nearly straight $(p p)$.

oo. " " " sides concave $(r r)$.

oo. End view 4-radiate or angular $(x x)$.

$p p$. Cells spinulose on the whole surface

aculeatum, 140

$p p$.

on the margins only setigerum, I4 I

*Journ. R. Micr. Soc., Feb. I886.

**F.-w. Algæ, p. 42 et seq. 
$r r$. Cells spinulose, a short, irregular process on each side,

controversum, $\mathbf{I} 43$

$r r$. Cells spinulose on the margins of the long, colorless, diverging arms

ss End view triangular or 3-radiate (uu).

ss. $\quad 4$ or 5 -angular or radiate $(t t)$.

ss. End view circular, with usually 9 short, marginal, notched processes . . . . . . . . . . . . . Eloiseanum, 149

tt. End view margins smooth; spines short; semi-cells in front view twice as wide as long .. . . . . . . . avicula, 123

tt. End view margins smooth; spines short; semi-cells in front view 3 . or 4 times as wide as long . . . . . commutatum, I 24

$t t$. End view margins smooth; spines on the angles only, very long, longispinum, $\mathbf{1} 45$ tt. " spines on the margins and surface as well as on the angles .. . . . . . . . Minnesotense.**

$t t$. End view margins verrucose, the verrucæ emarginate or not,

$t$.

“ denate, angles usually 3

forficulatum, 144

uu. End view margins smooth, concave; angles notched,

quadrangulare, 145 .

uu. " " $\quad$ crenate; spines long, divergent,

$u$.

4

66

spinous; angles produced, furcate,

Nova Casarea, 145

forficulatnm, $\mathbf{1 4 4}$

vv. End view triangular; aculei short, Hystrix, 142; tridentiferum, $\mathbf{I}_{42}$ vข.

“ spines long, colorless,

tricornutum, 145 ; triquetrum.**

vv. End view 4-angled, angles broadly rounded, spines scattered; sides concave . . . . . . . . . . Hystrix, 142 vv. End view 5-angled, sides concave . . . . Brasiliense, 146 wr. Angles with numerous setæ as long as the lobes; cells in front view cruciform ......... c . cruciatum, $\mathrm{I}_{42}$

zu. Angles with 4 teeth, 2 projecting upward, 2 downward, cerberus, 142

ww. ". .2 spines; margins concave, spinous

quaternium, I44

$x x$. Sides unequally produced, spinulose or spinous, controversum, $\mathbf{1} 43$ $x x$. Sides equally produced, spineless; angles spinous aculeatum, I 40 **F.-w Algre, p. 4I et seq. 
$y y$. Diameter $\frac{1}{650}$ in. $(38 \mu)$ or less $(z z)$.

$y y$. Diameter greater than $(38 \mu) \frac{1}{650}$ inch $(A)$.

1 zz. Cytioderm aculeated, aculei larger and denser at the angles,

teliferum, I 40

zz. Cytioderm aculeated except at the centre, echinatum, I 4 I ; pecten, I 4 I zz. " " spinous; margins dentate . . . . convexum.* zz. " " margins crenate ... . Ravenellii, I43

4. Cytioderm aculeated, aculei geminate . . . . sociatum, 142 A. " " aculei not geminate, densest at the angles, Brebissonnii, I4I A. " " " aculei evenly covering the surface,

Saxonicum, I4I; hirsutum, I4I A. Cytioderm spinous, spines not notched . . . echinatum, I4I A. " " " spines or short processes notched,

spongiosum, 148

$B$. End view 3 -angled; processes within the margin, 6 in number $(C)$. $B$. " " " " " " 3 in number $(D)$. $B$. " " " " " $\quad$ " $B$. " " " " processes at the angles only $(E)$.

$B$. End view 3 -angled, angles broadly truncate, each with 3 prominences . xiphidiophorum.*** B. " " " " " " each with 2 prominences . . . . . . . . . . simplex.**

$B$. End view 4-angled, body quadrangular, ends of arms trifid, Osceolense.**

$B$. End view 3 or 4 -lobed, emarginate or bifid; cell very irregular or quadrate

enorme, I5 I

$C$. Front view lateral margins crenate; basal margins crenate,

C. " lateral margins smooth . . . pseudofurcigerum, I 47

C. " lateral margins with $3^{-6}$ sharp teeth; basal margin smooth

cuneatum, 148

D. Cytioderm granular . . . . . . . . furcigerum, 146

$D$. Cytioderm smooth; end view angles produced into 2 processes, a third above and between them . . . . . Pottsii, I5 I

$D$. Cytioderm smooth or flnely punctate; end view angles notched, Kitchellii, 150

E. Processes 9, nearly as long as semi-cell diameter, ends furcate, Tohopekaligense.**

*Jour. R. Micr. Soc, Feb., r 886.

**F. W. Algæ, p. 4 I et seq. 
E. Processes shorter than semi-cell diameter, ends furcate,

furcatum, $\mathbf{x}_{50}$

$E$. Processes 6, short, notched; semi-cell rectangular, twice wider than long . . . . . . . . . . . duplex, 149

$F$. End view central radiating processes 6; marginal, including angles, 9, . . . . . . . . . senariam, 147

F. " central and marginal spines short, numerous, notched, spongiosum, 148

$G$. Semi-cells saucer-shaped, margin with 5 divergent spines,

calyxoides.* *F. 一w. Algæ, p. 46. 


\section{GLOSSARY.}

Aculeate: having one or more sharp points or prickles.

Acuminate: ending in a sharp point.

Antheridium, plural Antheridia: certain reproductive organs supposed

to have the function of the anthers of higher plants.

Annulate: ringed, marked with rings.

Articulate: jointed, formed of joints.

$B i .:$ in compound woods, meaning two or twice.

Bidentate: with two teeth or tooth-like projections.

Bifurcate: forked, separating into two branches or parts.

Bullate: blistered or puckered.

Cenobium: a community of individual cells united in one body or cluster.

Connate: united at base, as two opposite branches around the stem.

Costa, plural Costa: a rib.

Costate: ribbed.

Crenate: scolloped.

Crenulate: with small scollops.

Crescentic: crescent-shaped, like the new moon.

Cruciform: cross-shaped.

Cuneate: wedge-shaped.

Cuspidate: with a short, stiff, sharp point.

Cytioderm: the membrane of the cell.

Decussate: in pairs alternately crossing.

Dentate: toothed.

Dichotomous: with the divisions in pairs; two forked.

Diacious: having the male and female flowers on separate plants.

Dissepiment: a partition or division.

Dorsum: the back, here the back or curved portion of Closterium. 
Filiform: thread shaped, or thread-like.

Flexuose: bending in opposite directions.

Fusiform: spindle shaped, large in the middle and tapering to both ends.

Geminate: twin, in pairs.

Geniculate: bent like a knee.

Gonidia: propagative bodies, not produced by any act of fertilization. Granulate: with small or fine granules.

Hirsute: hairy.

Hyaline: transparent as glass.

Impacted: matted, the whorls indistinct.

Lamellate, lamellose: formed of superposed layers or plates.

Lunate: crescent-shaped.

Mikron $(\mu)$ : the $\frac{1}{25000}$ of an inch.

Monacious: having the male and female organs separate but on the same plant.

Moniliform: like a string of beads, or necklace-like.

Mucronate: tipped with a short, stiff point.

Nucleus, plural Nuclei: in this case, one or more collections of chlorophyll in the cell.

Obovate: egg-shaped, but with the broader end upward.

Oögonium, plural Oögonia: the sac bearing the oöspores.

Oöspore: spores formed in the ovarian sac or oögonium.

Orbicular: circular, or nearly so, in outline.

Pellucid: transparent.

Piliferous: bearing short hairs.

Plicate: folded.

Polymorphus: having several or many forms.

Pubescent: bearing fine, soft hairs.

Punctate: dotted with minute elevations or depressions.

Pyriform: pear-shaped.

Ramulus, plural Ramuli: a small or secondary branch.

Reniform: kidney-shaped. 
Saccate: sac-like, baggy.

Scabrous: rough.

Septate: with a partition.

Serrate: with saw-teeth, or teeth pointing forward.

Setiform: bristle-like.

Setigerous: bearing bristles or setæ.

Sigmoid: s-shaped.

Sinus: the depression between two parts of a cell.

Spermatozoa: active, thread-like bodies in certain cells.

Spermogonia: cells which give rise to the spermatozoa.

Spinulose: bearing short spines or prickles.

Stipe: the stem or stalk.

Stipitate: with a short stem or stalk.

Stratum: a layer, anything spread out in a layer.

$S u b .:$ in compound words, meaning less than.

Subulate: awl-shaped.

Thallus: a mass of cells, consisting of one or more layers, often a flat expansion.

Tortuous: irregularly curved, winding, twisted.

Truncate: as if cut off square at the end.

Tnberculose: with small rounded projections or tubercles.

Umbellate: the branches or parts beginning at the same point, like the ribs of an umbrella.

Ventrum: in this case, the concave region of Closterium. Verruca, plural Verruce: rounded, wart-like elevations.

Whorl: in a circle round the stem.

Zoöspores: spores with active movements. 



\section{INDEX.}

Page.

Anabæna

Anacystis

Aphanizomenon

Aphanocapsa

Aphanochæte

Aphanothece

Apiocystis

Arthrodesmus

Asterothrix

Bambusina

Bangia

Batrachospermum

Beggiotoa

Botrycoccus

Botrydium

Botrydina

Bulbochæte

Calocylindrus

Calothrix

Chætomorpha

Chætophora

Chamæsiphon

A.

B.

C

um

Chantransia

Characium

Chlamydococcus

Chlamydomonas

Chroococcus

Chroolepus

Chytridium

Cladophora

Clathrocystis

Closterium

Cœlastrum

Cœlosphærium

80

Coleochæte

Campsopogon

Conferva

37

7 I

Cosmarium

54 Craterospermum

49 Crenothrix

54 Cylindrocapsa

$4 \mathrm{I}$ Cylindrospermum

D.

Desmidium

62 Dictyosphærium

47 Dimorphococcus

44 Docidium

68 Draparnaldia
Page. 
E.

Enteromorpha

Eremosphæra

Euastrum

Eudorina

Euglena

G.

Genicularia

Glœocapsa

Glœeocystis

Glœothece

Glœotrichia

Gomphosphæria

Gonatonema

Gonatozygon

Gongrosira

Gonium

H.

Hapalosiphon

Hildebrantia

Hyalotheca

Hydrodictyon

Hydrurus

I.

Introduction

Isactis

I.

Lemanea

Leptothrix

Leptozosma

Lyngbya

M.

Mastigonema

Merismopedia

Mesocarpus

Mesotænium
Page.

Micrasterias

Microcystis

Microcoleus

55

96

49

50

Microthamnion

Mischococcus

Mougeotia

N.

8o Nephrocytium

54

73

54

Nodularia

Nostoc

72

63

72

62

80

44

50

CEdogonium

Olpidium

Onychonema

Ophiocytium

Oscillaria

O.

P.

Palmella

Phymatodocis

Pleurocarpus

37 Porphrydium

7 I Polycystis 72

8I Polyedrium 53

68 Prasiola 43

Protococcus

R.

63

72 Raphidium

62 Rhizoclonium

8I Rivularia 
INDEX.

S.

Page.

Scenedesmus

Schizogonium

Schizochlamys

Schizomeris

Sciadium

Scytonema

Sirogonium

Sirosiphon

Sorastrum

Sphæroplea

Sphærozosma

Sphærozyga

Spirogyra

Spirotænia

Spirillum

Spirulina

Staurastrum

Staurogenia

Staurospermum

Stephanosphæra

Stigeoclonium

Symphyosiphon

Symploca

Synechoccocus

62

50

43
T.

Page.

94

54

37

65

86

37

U.

Ulothrix

Urococcus

45

V.

56,58 Vaucheria

82 Volvox

48,49

49

X.

Xanthidium

Zygnema

6I

Zygogonium

6I 


